\title{
sposta e Avaliação de um Conjunto de Requisitos para Sistemas de Autoria Hipermídia Educacional
}

\author{
Débora Maria Barroso Paiva
}

Orientadora: Profa. Dra. Maria das Graças Volpe Nunes

Dissertação apresentada ao Instituto de Ciências Matemáticas e de Computação - ICMC-USP, como parte dos requisitos para obtenção do título de Mestre em Ciências de Computação e Matemática Computacional. 
A Comissão Julgadora:

Profa. Dra. Maria das Graças Volpe Nunes

Profa. Dra. Fernanda Cláudia Alves Campos

Profa. Dra. Maria da Graça Campos Pimentel

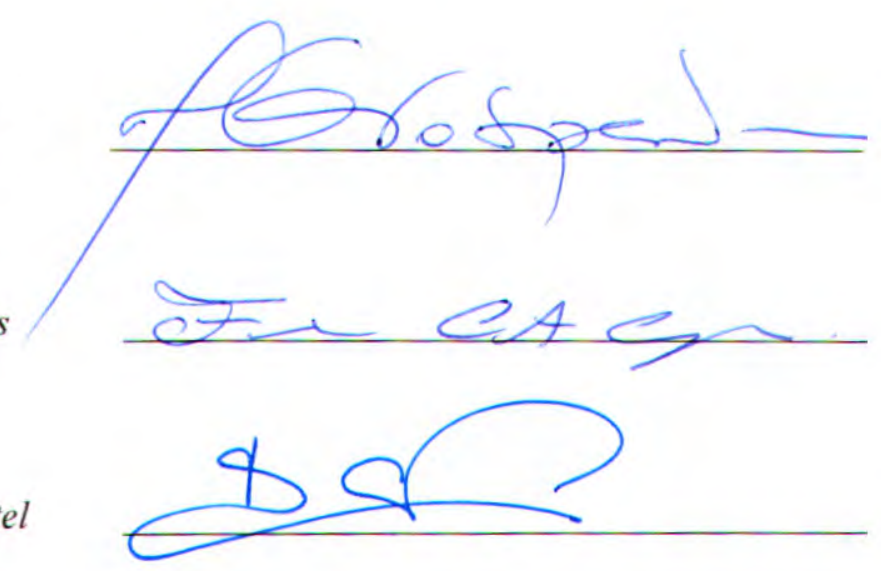


À minha querida mäe, Maria das Graças, pelos esforços dedicados à minha formaçāo.

À memória de meu pai. 


\section{Agradecimentos}

A Deus, por mais uma etapa vencida. Obrigada por ter concedido-me forças nos momentos difíceis, por ter iluminado meus caminhos e por ter proporcionado-me a oportunidade de conhecer pessoas tão especiais neste período.

À minha irmã Wanderléia, pelo carinho, amizade e incentivo.

Ao Wanderley, pelo apoib e amizade.

À minha orientadora Małia das Graças Volpe Nunes, pelo exemplo de profissionalismo, pela amizade, pelos conselhos e pela confiança em mim.

Aos professores José Carlos Maldonado, Maria da Graça Campos Pimentel e Renata Pontin de Mattos Fortes, pelas colaboraç̃̃es durante o desenvolvimento do projeto.

A todos do Labes, pelo carinho e companheirismo. Em especial a Aline, Adenilso e Auri. E também ao Enzo, Cláudia, Walter, Iris, Valéria, Elaine e Lea pela amizade e por tantos momentos alegres.

Ao Renato Haber e Luciano Pansanato pelos esclarecimentos prestados.

Ao professor Carlos Alberto Marques Pietrobon, pelo incentivo para que eu fizesse o mestrado.

Àqueles que colaboraram com este projeto disponibilizando-se a participar dos experimentos. Obrigada pelas valiosas qontribuições!

À Capes, pelo apoio finahceiro. 


\section{Sumário}

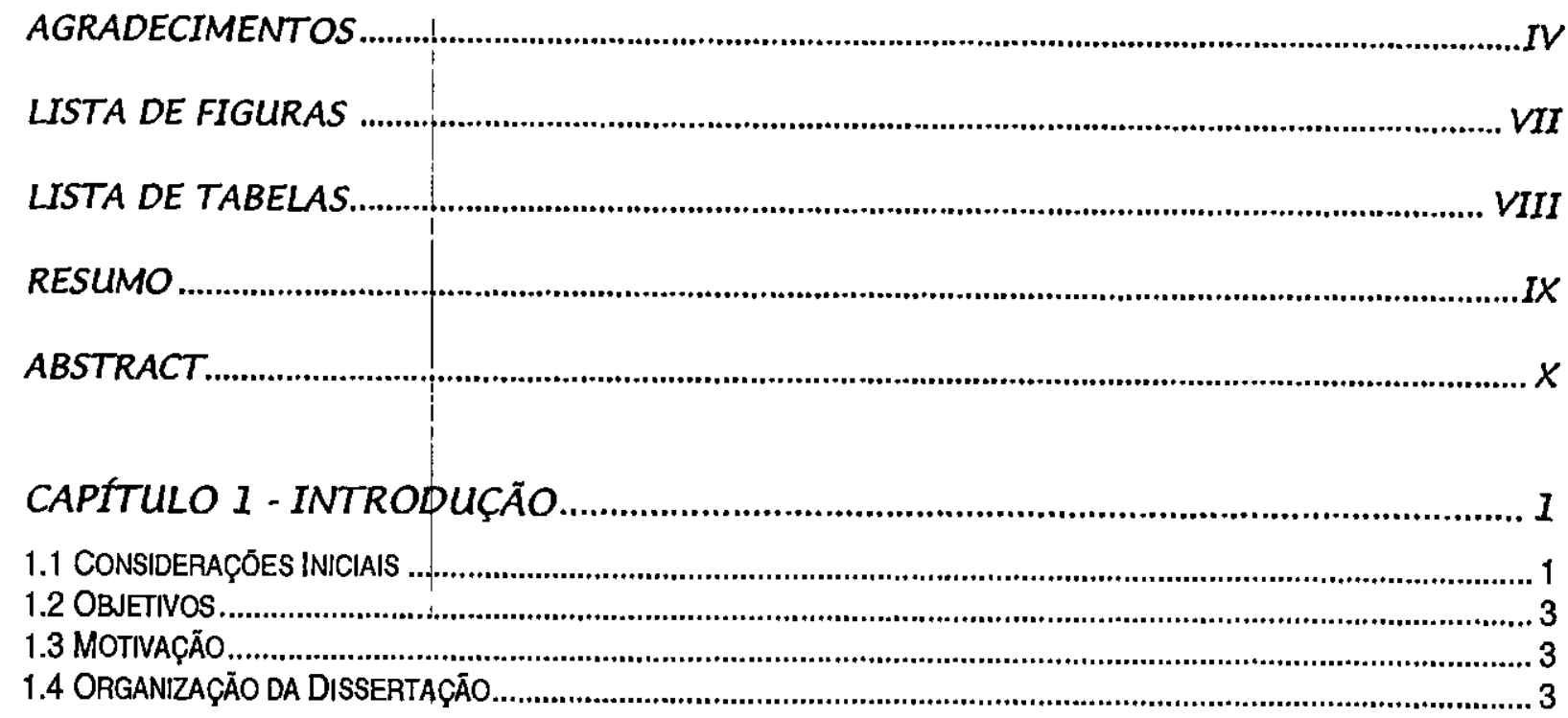

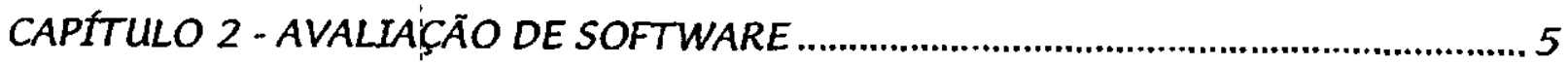

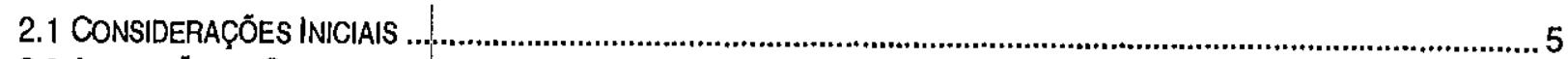

2.2 AVALIAÇĂO DE SOFTWARE .

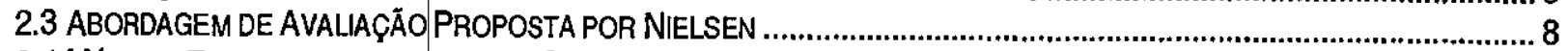

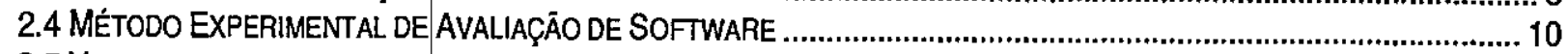

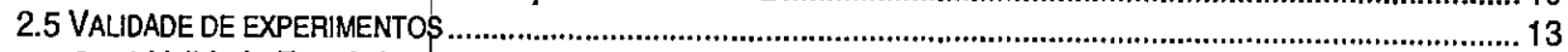

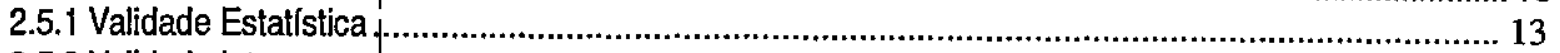

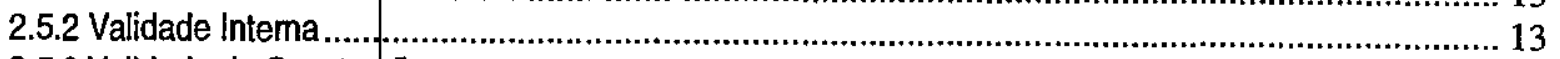

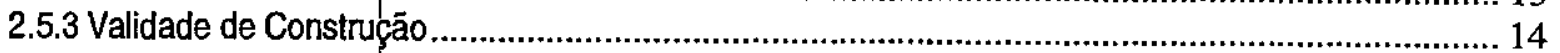

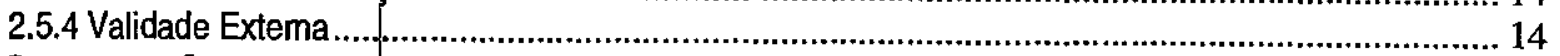

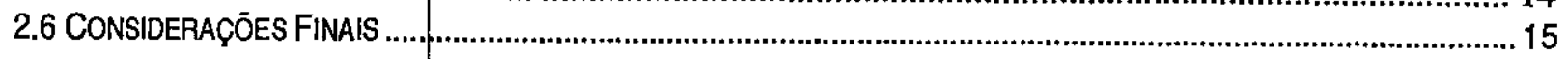

CAPITULO 3 - SISTEMAS E MODELOS HIPERMÍDIA .................................................. 16

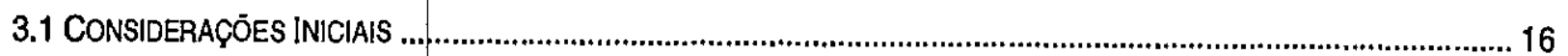

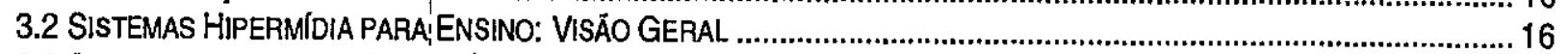

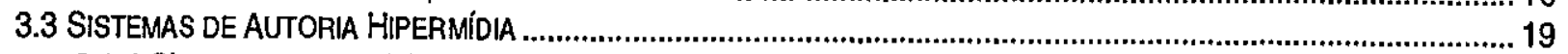

3.3.1 Sistemas comerciais para autoria hipermídia educacional ............................................................... 19





3.3.2 Sistemas disponíveis na Intemet para autoria hipermidia educacional ...............................................20

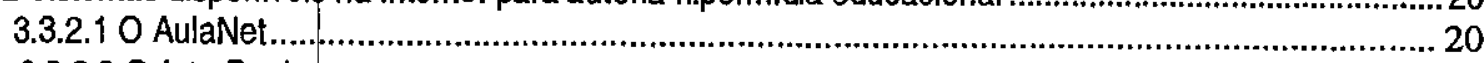

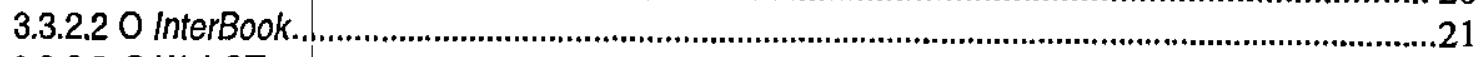

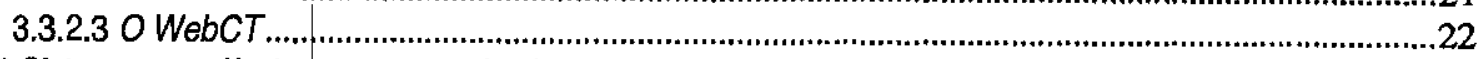

3.3.3 Sistemas acadêmicgs para autoria hipermídia educacional ..............................................................2

3.3.3.1 As ferramentas HyperBuilder, QuestBuilder e TaskBuilder ....................................................2. 23

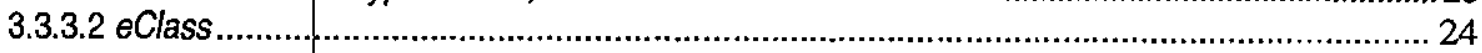

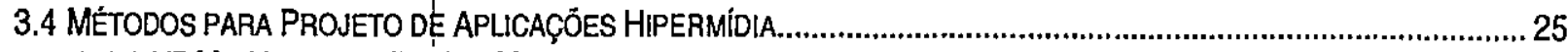

3.4.1 HDM - Hypertext Design Model (Garzotto et al., 1993).......................................................................26

3.4.2 RMM - Relationship Management Methodology (lsakowitz et al., 1995) ..............................................22

3.4.3 OOHDM - Object-Oriented Hypermedia Design Method (Shwabe \& Rossi, 1995) ...............................2 28

3.4.4 EORM - Enhanced Object-Relationship Model (Lange, 1994)...........................................................28 
3.4.5 HMBS/M - Hypertex Model Based on Statecharts/Method (Carvalho, 1998)......................................2.29

3.5 MÉTODOS PARA PROJETO DE APLICAÇóES HIPERMIDIA EdUCACIONAIS ........................................................ 30

3.5.1 MAPHE - Metodologla de Apoio a Projetos de Hipertextos Educacionais ............................................30

3.5.2 Daphne - Definição de Aplicaçōes Hipermídia na Educação ...............................................................31

3.6 SASHE (SISTEMA DE AUTORIA E SUPORTE HIPERMIDIA PARA ENSINO) E EHDM (EDUCATIONAL HYPERDOCUMENTS

DESIGN METHOD)

3.6.1 O sistema SASHE.

3.6.1.1 Arquitetura do SASHE

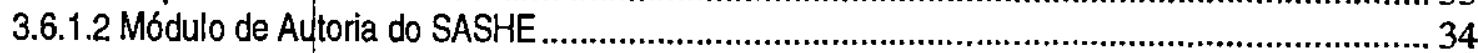

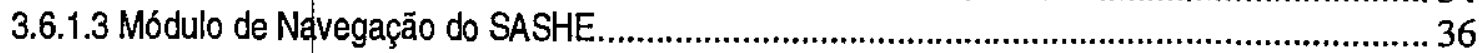

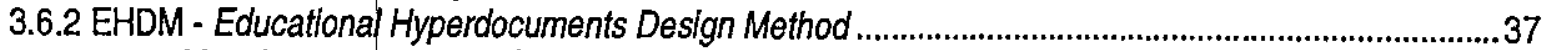

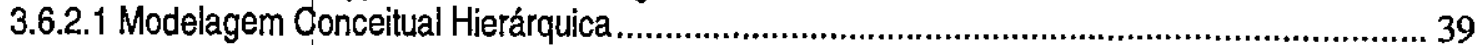

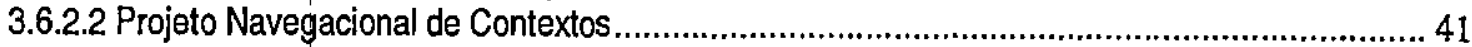



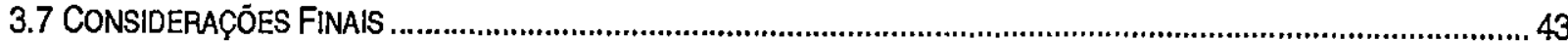

\section{CAPITULO 4 - REQUISITOS PARA SISTEMAS DE AUTORIA HIPERMFDIA}

EDUCACIONAL: REVISÃO BIBLIOGRAFICA …………................................................ 44

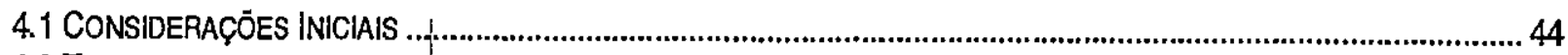

4.2 TRABALHO DESENVOLVIDO POR CAMPOS (CAMPOS, 1994; CAMPOS ET AL., 1999) ..............................................44

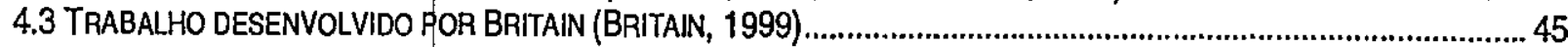

4.4 TRABALHO REALIZADO NO AMMBITO DO PROJETO WEBCT (COMPARISON OF ONLINE COURSE DELIVERY SOFTWARE

PRODUCTS, 2000)

4.5 TRABALHO DESENVOLVIDO ROR PAPATHEOdOROU ET AL. (PAPATHEODOROU ET AL., 1998) ................................. 47

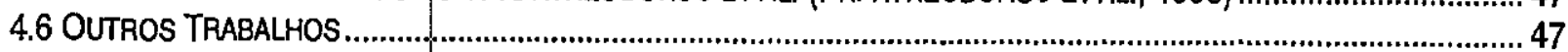

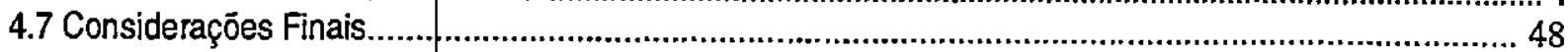

CAPITULO 5 - PROPOSTA DE UM CONJUNTO DE REQUISITOS PARA SISTEMAS DE AUTORIA HIPERM IDIA EDUCACIONAL ..................................................................49

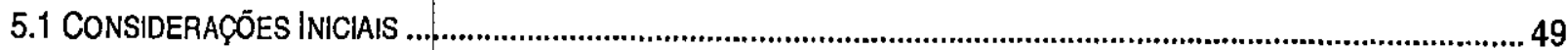

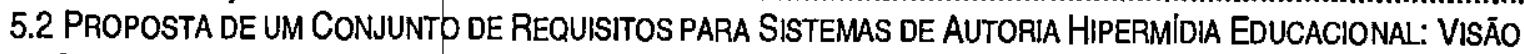

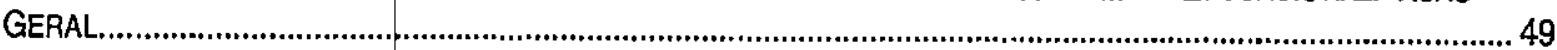

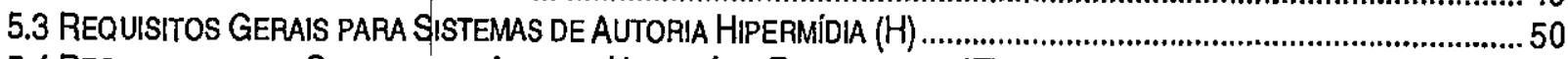

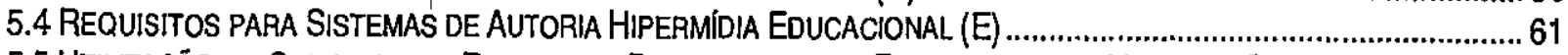

5.5 UTILIZAÇÄO dO CONJUNTO DE REQUISITOS PROPOSTO EM UM EXPERIMENTO DE VERIFICAÇĀO COM USUÁRIOS-

AUTORES.

65



CAPÍTULO 6 -ESTUDO DE CASO: AVALIAÇÃO DE UM SISTEMA DE AUTORIA HIPERMIDIA EDUCACIONAL SEGUNDO OS REQUISITOS PROPOSTOS.....................69

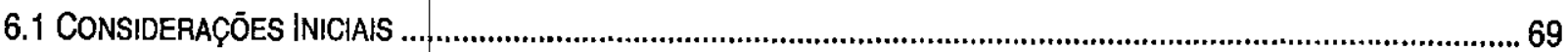

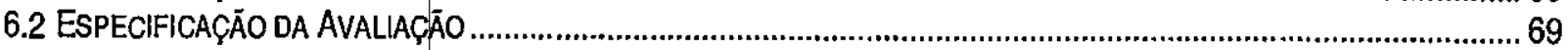

6.2.1 Escopo da avalią̧äo.......................................................................................................... 70

6.2.2 Objetivos da avaliaçăo...................................................................................................70

6.2.3 Funçöes atribuidas aos participantes ............................................................................................ 70

6.2.4 Descrị̧ão do produtb submetido à avaliação ...............................................................................71



6.3.1 Treinamento oferecido aos avaliadores............................................................................................71

6.3.2 Método de avaliaçåa.............................................................................................................72

6.3.3 Avaliaçäo piloto......................................................................................................................

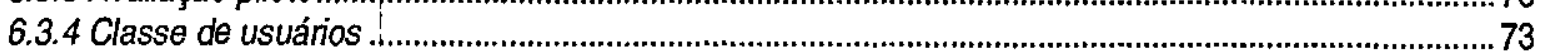




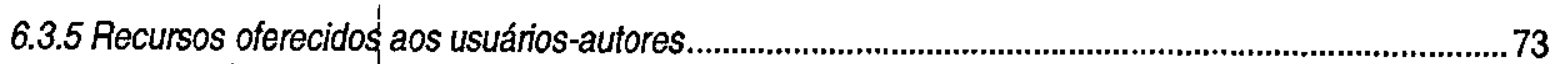

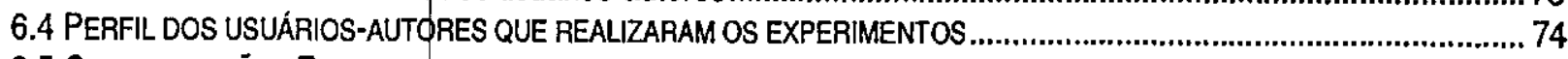

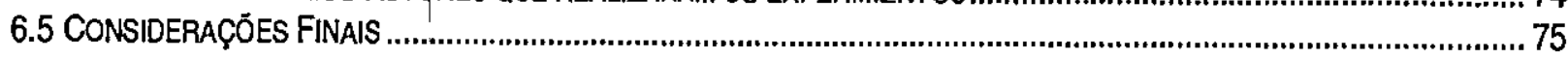

CAPÍTULO 7 - RESULTADOS OBTIDOS A PARTIR DO ESTUDO DE CASO...............76

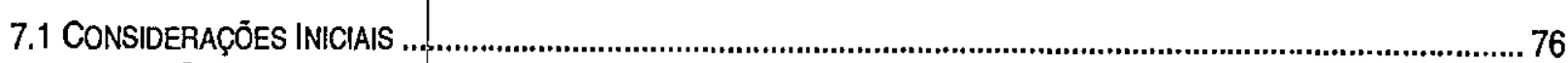

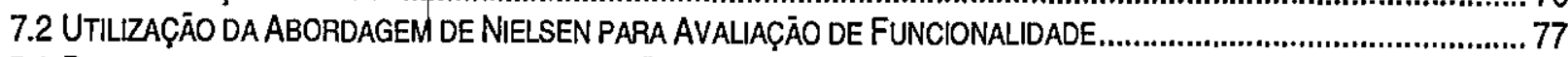

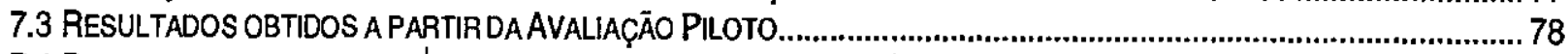

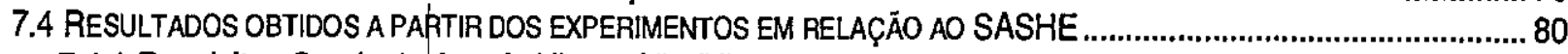

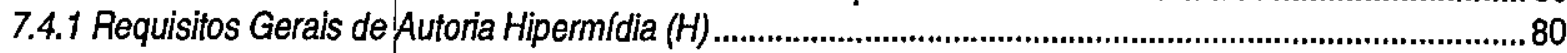

7.4.2 Requisitos para Sistemas de Autoria Hipermidia Educacional (E) ....................................................92

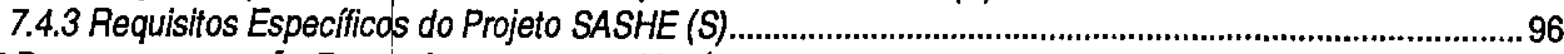

7.5 REQUISITOS QUE NĀO FORAM AVALIADOS POR USUÁRIOS.AUTORES ............................................................ 98

7.6 RESULTADOS OBTIDOS A PARTIR DOS EXPERIMENTOS EM RELAÇÄO AO CONUUNTO DE REQUISITOS PROPOSTO... 99

7.7 CONSIDERAÇŌES FINAIS.

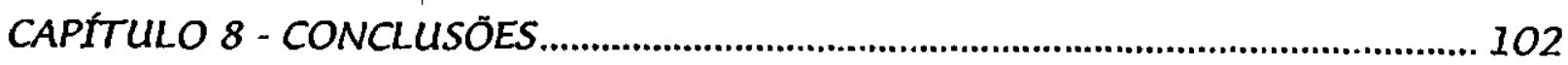

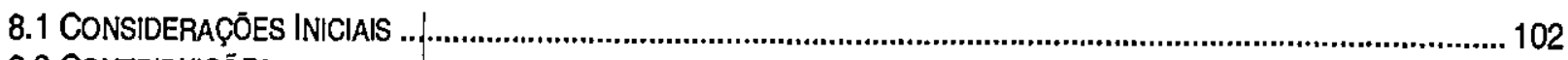

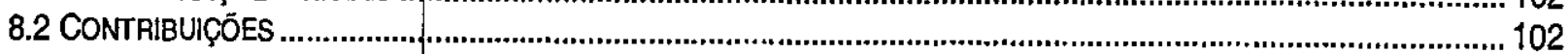

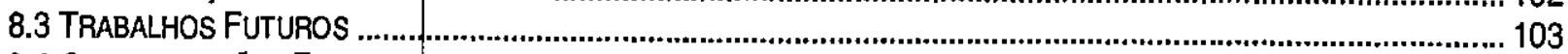

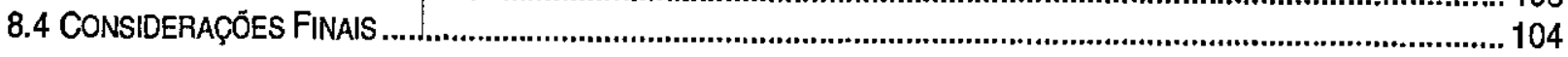

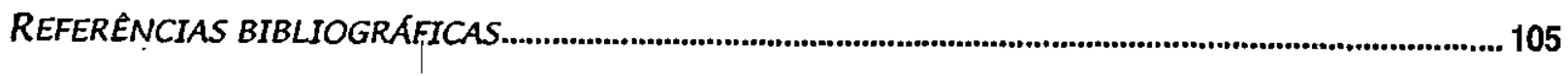




\section{Lista de Figuras}

FIGURA 2.1 - RELAÇÃo ENTRE O NÚMERO DE USUÁRIOS E OS PROBLEMAS ENCONTRADOS (NIELSEN, 2000) ............9

FIGURA 3.1 - ARQUITETURA GERAL Do SASHE VERSÃo 2.0 (HABBER, 1999; PANSANATO, 1999) .........................34

FIGURA 3.2 - TELA PRINCIPAL DO MÓDULO DE AUTORIA DO SASHE .............................................................36

FIGURA 3.3 - TELA PRINCIPAL DO MÓDULO DE NAVEGAÇĀO DO SASHE ….....................................................2

FIGURA 3.4 - FASES DO MÉTODO EHDM (PANSANATO, 1999) ………........................................................... 38

FIGURA 3.5 - PRIMITIVAS GRAFICAS PARA A CATEGORIA CONCEITO E SEUS RELACIONAMENTOS DE ORDEM ........... 39

FIGURA 3.6 - PRIMITIVAS GRÁFICAS PARA A CATEGORIA RESULTADO E SEU RELACIONAMENTO DE ORDEM .............40

FIGURA 3.7 - PRIMITVAS GRÁliCAS PARA A CATEGORIA EXEMPLO E SEU RELACIONAMENTO DE ORDEM..................40

FIGURA 3.8 - PRIMITIVAS GRÁFICAS PARA OS RELACIONAMENTOS ENTRE AS CATEGORIAS DE CONHECIMENTO....... 41

FIGURA 3.9 - PRIMITTVAS GRÁFICAS PARA MODELAGEM NAVEGACIONAL ...........................................................4 42

FIGURA 5.1 - CLASSIFICAÇÃO PARA O CONJUNTO DE REQUISTTOS PROPOSTO ......................................................50

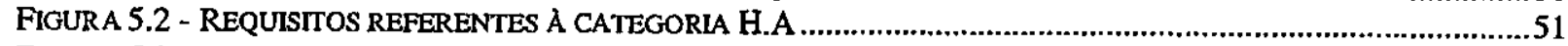

FIGURA 5.3 - REQUISTTOS REFERENTES A CATEGORIA H.B …...................................................................53

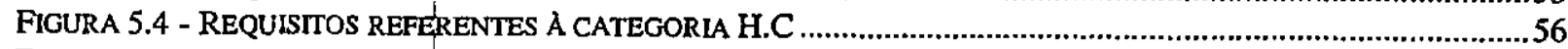

FIGURA 5.5 - REQUISITOS REFERENTES A CATEGORIA H.D .........................................................................5

FIGURA 5.6 - REQUISITOS REFERENTES A CATEGORIA H.E ............................................................................58

FIGURA 5.7 - REQUISTTOS REFERENTES A CATEGORIA H.F ….......................................................................6

FIGURA 5.8 - REQUISTTOS REFERENTES A CATEGORIA E.A …........................................................................61

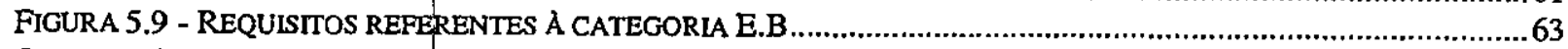

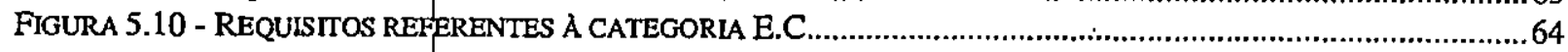

FIGURA 7.1 - GANHO DE INFORMAÇĀO A PARTIR DOS EXPERIMENTOS DE CADA USUÁRIO ......................................78 


\section{Lista de Tabelas}

TABELA 2.1 - CARACTERÍSTICAS DE QUALIDADE DE SOFTWARE (ISO/IEC 9126, 1991).

TABELA 2.2 - TÉCNICAS EXPERIMENTAIS PARA O DOMINIO DE ENGENHARIA DE SOFTWARE (WALLACE \&

ZELKOWITZ, 1998)

TABELA 5.1 - REQUISITOS ESPECIFICADOS NA ETAPA DE ENGENHARIA DE REQUSITOS DO SASHE ......................66 11

TABELA 6.1 - RECURSOS DDÁTICOS UTLIZADOS PELOS PARTICIPANTES DOS EXPERIMENTOS 74

TABELA 6.2 - EXPERIENCIA EM DOCÊNCIA DOS PARTICIPANTES DOS EXPERIMENTOS

TABELA 6.3 - GRAU DE INSTRUÇĀO E ÁREA DE PESQUISA DOS PARTICIPANTES DOS EXPERIMENTOS. 


\section{Resumo}

A partir da análise de diversos trabalhos publicados sobre requisitos para sistemas de autoria hipermídia educacional, foi proposto um novo conjunto de requisitos que tem por objetivo auxiliar as etapas de engenharia de requisitos e de avaliação no processo de desenvolvimento de um sistema pertencente a este domínio. De forma geral, foi proposto um conjunto de requisitos que privilegia tanto as necessidades do contex to educacional quanto as necessidades relacionadas aos ambientes de autoria hipermídia. Esses requisitos foram utilizados na avaliação do sistema SASHE, tendo sido obtidos resultados que indicaram a eficácia desta proposta e, simultaneamente, a qualidade da implementação do sistema. 


\section{Abstract}

This study proposes a new set of requirements which aims to support both the requirements engineering and the eyaluation stages in the development process of an educational hypermedia authoring system. These requirements distinguishe both the characteristics of educational context and of hypermedia authoring environments. These requirements were utilized in the evaluation of SASHE, an hypermedia authoring system. The effectiveness of the proposal and the quality of the implementation of SASHE have been analysed through data obtained in this evaluation. 


\section{Capítulo 1}

\section{Introdução}

\subsection{Considerações Iniciais}

A aplicação da informática em ambientes de ensino-aprendizado tem sido alvo de intensas pesquisas. A maioria desses trabalhos aponta para a necessidade de se romper as fronteiras da sala de aula convencional, oferecendo aos professores a oportunidade de tornar seus conteúdos mais dinâmicớs e proporcionando aos estudantes uma nova forma de construção do conhecimento.

Valente (Valente, 1999) defende a relevância do uso de tecnologias de informática em ambientes de ensino-aprendizado ao relatar que o computador deve ser visto como nova mídia educacional, que possui o papel de ser uma ferramenta de complementação, de aperfeiçoamento e de possível mudança na qualidade do ensino. Ao invés de memorizar informação, os estudantes devem ser ensinados a buscar e a usar a informação, e a presença dos computadores pode auxiliar essas mudanças ao propiciar condições para que os estudantes exercitem a cappacidade de procurá-las e selecioná-las.

Outros autores (Campos et al., 1994; Geller \& Enricone, 1999) justificam a utilização da informática no contexto|educacional ao mencionarem que os alunos adquirem habilidades para resolver problemas, gerenciar informação e investigar. Além disso, eles acreditam que esse paradigma traz a perspectiva de aproximar a educação ao novo perfil do aluno através da valorização não só da aquisição do conhecimento mas, principalmente, das habilidades do pensamento. 
Nesse contexto, pode-se observar o surgimento e aprimoramento de diversas tecnologias e ferramentas computacionais como mecanismos de apoio ao processo de ensino-aprendizagem. Dentre elas podem-se citar (a) os sistemas de autoria e navegação de aplicações hipermídia educacionais, (b) os ambientes que integram lousa eletrônica, câmeras de vídeo, projetores e outros recursos e (c) a disponibilização de cursos pela internet (ensino a distância).

Em relação a essas tecnologias, pode-se observar uma ênfase no desenvolvimento de sistemas de autoria e apresentação de material didático, podendo ser encontrados diversos exemplos de sistemas destinados a este fim. Observa-se, portanto, a existência de ambientes comerciais, como o LearningSpace (LeamingSapce, 2000) e o TopClass (TopClass, 2000), de ambientes disponíveis na Internet, como o Aulanet (Aulanet, 2000; Lucena et al., 1997) e o Web Course Tool (WebCT) (Goldberg et al., 1996), e de ambientes acadêmicos, como as ferramentas HyperBuilder, QuestBuilder e TaskBuilder (Pimentel et al., 1998) e o eClass (Abowd, 2000).

Em relação aos sistemas de autoria e navegação hipermúdia, foram desenvolvidos vários trabalhos que indicaram fequisitos para esses sistemas (Campos, 1994; Campos et al., 1999; Britain, 1999; Papatheodorou et al., 1998) que tiveram por objetivo estabelecer as principais necessidades relacionadas à funcionalidade destes sistemas. No entanto, diferentes perspectivas foram consideradas nestas propostas e, além disso, algumas restrições foram observadas nestes trabalhos, conforme é explicitado no Capítulo 4.

Dessa forma, considerando-se a concentração de trabalhos relacionados ao desenvolvimento de sistemas hipermídia e as limitações observadas nos trabalhos revisados relacionados à definição de requisitos para o desenvolvimento desses sistemas, este trabalho propõe um conjunto único de requisitos, que possui as propriedades de ser abrangente e suficientemente completo para auxiliar a etapa de engenharia de requisitos de um novo sistema ou para permitir a avaliação de um sistema já existente. Esse conjunto de requisitos considera tanto as necessidades do contexto educacional quanto as necessidades relacionadas aos ambientes de autoria hipermídia, suprindo, portanto, as limitações observadas naqueles trabalhos.

Para permitir a verifiçação das propriedades mencionadas acima, foram realizados experimentos utilizando os requisitos propostos neste trabalho. O sistema SASHE (que é um sistema de autoria e navegação de aplicações para ensino) (Nunes et al., 1997; Santos et al., 1997) foi avaliado com o objetivo de verificar a eficácia desta proposta. A utilização do SASHE foi motivada pella constatação da necessidade de se obter informações sobre as 
condições atuais de sua implementação, de forma que os resultados obtidos pudessem contribuir para a evoluçä̉o do projeto.

Os benefícios advindos a partir da realização deste trabalho estāo relacionados principalmente à proposta de um conjunto de requisitos para sistemas de autoria hipermídia educacional e à obtenção de informações referentes à qualidade da implementação do SASHE.

Este trabalho contextualiza-se na área de Engenharia de Software, por fornecer um conjunto de requisitos que auxiliạ o processo de desenvolvimento de sistemas de uma área específica, e também na área de Informática na Educação, pela necessidade de se considerar as características inerentes a este domínio, visto que esta proposta se refere a ambientes educacionais.

\subsection{Objetivos}

Este trabalho tem por pbjetivo propor um conjunto de requisitos cuja implementação é considerada desejável em sistemas de autoria hipermídia educacional e verificar a abrangência e completude desta proposta através da realização de um estudo de caso. Para isso, foram revisadas diversas publicações relacionadas a este tema, de forma a indicar os requisitos considerados importantes nesses estudos para a implementação de tais sistemas. Esta proposta é justificada pela necessidade de se obter um conjunto único de requisitos, que possa suprir as deficiências observadas em trabalhos realizados anteriormente e auxiliar satisfatoriamente as etapas de engenharia de requisitos de novos sistemas e a avaliação de sistemas já existentes.

\subsection{Motivação}

Com a crescente utilização da informática no contexto educacional, tornou-se incontestável a necessidade de desenvolvimento e aprimoramento de tecnologias que pudessem suportar este novo paradigma. Em relação ao desenvolvimento de sistemas de autoria hipermídia, a primeira etapa a ser realizada é o estabelecimento dos requisitos segundos os quais o sistema será implementado. Além disso, a relevância da etapa de avaliação durante o desenvolvimento de um sistema exige que o conjunto de requisitos segundo o qual ela será realizada esteja bem definido, uma vez que nem sempre a etapa de análise de requisitos é documentada formalmente. Logo, este trabalho foi proposto de forma a colaborar na execução dessas 
atividades, fornecendo um conjunto de requisitos que possua as características mencionadas anteriormente.

\subsection{Organização da Dissertação}

O Capítulo 2 aborda os aspectos relacionados à avaliação de software que foram importantes para o desenvolvimento deste trabalho. O Capítulo 3 faz uma revisão sobre sistemas hipermídia e métodos para projeto de aplicações hipermídia, citando as principais características de alguns sistemas e métodos disponíveis na literatura. O Capítulo 4 apresenta a revisão bibliográfica rẹalizada neste trabalho que forneceu subsídios para a proposta de um novo conjunto de requisitos para sistemas de autoria hipermídia educacional. O Capítulo 5 apresenta o conjunto de requisitos proposto neste trabalho. O Capítulo 6 corresponde às etapas de especificação e planejamento da avaliação realizada com o SASHE, que permitiu a verificação, em relação à eficácia, do conjunto de requisitos. O Capítulo 7 apresenta os resultados obtidos a partir da avaliação. O Capítulo 8 corresponde às conclusões deste trabalho. 
Capítulo 2

\section{Avaliação de Software}

\subsection{Considerações Iniciais}

A explosão do mercado de software ocorrida nos últimos anos trouxe à tona a necessidade de criação de técnicas e metodologias que favoreçam a atividade de avaliação de software. Tendo em vista as diverśas perspectivas segundo as quais uma avaliação pode ser realizada, sob o ponto de vista de usuários ou desenvolvedores; em relação à qualidade, funcionalidade, entre outros, observa-se o surgimento de abordagens que privilegiam diferentes aspectos. Pode-se citar como exemplo a abordagem de avaliação de usabilidade proposta por Nielsen (Nielsen, 2000), que privilegia a avaliação e projetos iterativos, de forma a favorecer não só a obtenção de informações sobre o sistema, mas também a implementação imediata das melhorias necessárias.

Este capítulo faz uma revisão sobre alguns aspectos relacionados à avaliação de software, enfatizando aqueles que foram relevantes para o desenvolvimento deste trabalho.

\subsection{Avaliação de Software}

A avaliação de um software consiste no exame de um produto final resultante de um processo de desenvolvimento, ou de produtos resultantes de atividades de fases intermediárias desse processo. Deve-se avaliaf a qualidade de um produto por diversas razões (Bache \& Bazzana, 1994): (1) identificação e compreensão das razões técnicas para as deficiências e limitações do produto, que podem manifestar-se através de problemas operacionais ou problemas de manutenção; (2) comparáção de produtos e (3) formulação de um plano de ação para fazer o produto de software evoluir. 
De acordo com Dix et all (Dix et al., 1998) um processo de avaliação de um sistema possui três objetivos básicos: (1) avaliar sua funcionalidade; (2) avaliar sua interface e (3) identificar seus problemas específicos. A avaliação da funcionalidade é importante porque permite averiguar se o sistema está de acordo com os requisitos do usuário, ou seja, se ele possibilita que o usuário execute as tarefas requeridas de forma fácil. Isso inclui não somente tornar a funcionalidade do sistema disponível, mas torná-la claramente alcançável ao usuário em termos das ações que elę deverá executar para atingir seus objetivos. Avaliações em nível de funcionalidade podem incluir medições da performance do usuário com o sistema e a avaliação de sua efetividade em suportar as tarefas. Em relação à avaliação da interface, é importante medir o impacto do projeto sobre o usuário. Isso inclui considerar aspectos tais como facilidade de aprendizado e usabilidade do sistema. Segundo o autor, é importante identificar também áreas do projeto que causam alguma forma de sobrecarga ao usuário, talvez por requerer excessiva quantidade de informação a ser lembrada. O objetivo final da avaliação é identificar problemas específicos do projeto e que causam resultados inesperados.

A esses três objetivos đe avaliação citados por Dix, pode-se acrescentar a avaliação de qualidade do software, enfatizada por diversos autores (Jorgensen, 1999; Pressman, 1997; Tsukumo et al., 1997; Welzel \& Hausen, 1997). De forma geral, a avaliação de qualidade tem por objetivo verificar se determinado software atende aos requisitos funcionais especificados na etapa de análise de requisitos do processo de seu desenvolvimento e aos requisitos não funcionais, que devem ser implementados em todo software.

Avaliação e qualidade de software são temas da série de normas ISO/IEC 14598-5 (ISO/IEC 14598-5, 1996) e ISO/IEC 9126 (ISO/IEC 9126, 1991), dentre outras. Essas normas são brevemente descritas a seguir.

A ISO/IEC 14598-5 proyê um conjunto de recomendações que orientam o planejamento e a execução de um processo de avaliação de um produto de software, definindo as atividades que devem ser executadas. $Q$ processo de avaliação proposto pode ser utilizado (1) para avaliar produtos já existentes ou produtos em desenvolvimento ou (2) por avaliadores em laboratório, fornecedores ou compradores de software, usuários e entidades certificadoras, cada qual com seu objetivo.

A norma sugere que cinco etapas sejam executadas durante o processo de avaliação. A primeira delas refere-se|à Análise de Requisitos, em que são descritos os objetivos da 
avaliação, fazendo-se um levantamento dos requisitos a serem avaliados. Vários pontos de vista podem ser considerados, dependendo dos diferentes usuários do produto. A etapa de Especificação da Avalíação tem por objetivo a definição do escopo da avaliação e as medidas a serem executadas no produto submetido à avaliação nos seus vários componentes. São definidas também as restrições, os métodos a serem utilizados e as responsabilidades de todos os envolvidos no processo de avaliação. Na etapa de Planejamento da Avaliação são documentados os procedimentos a serem usados pelo avaliador para executar as medidas especificadas na fase anterior. $O$ avaliador deve produzir um plano que descreva os recursos necessários para executar a avaliação especificada, a distribuição desses recursos nas várias ações a serem executadas bem como os prazos, a equipe de avaliação, os riscos associados e todas as atividades envolvidas. Na etapa de Execução da Avaliação são obtidos resultados da execução de açбes para medir e verificar o produto de software de acordo com os requisitos, com a especificação e com o projeto da avaliação. Ao executar essas ações obtém-se o rascunho do relatório e dos registros da avaliação. Na etapa de Conclusão da Avaliação deve-se revisar o relatório da avaliação e disponibilizar os dados resultantes da mesma.

Esta norma registra, ainda, alguns benefícios em se realizar uma avaliação de software:

- O desenvolvedor pode usar os resultados da avaliação de seu produto para identificar ações corretivas, com o objetivo de melhorá-lo ou tomar decisões com relação à evolução do mesmo;

- A avaliação pode ser usada para fins comerciais;

- A avaliação fornece resultados qualitativos do produto de software.

A norma ISO/IEC 9126 stabelece um conjunto de seis características de qualidade para um produto de software, apresentado na Tabela 2.1. As características foram posteriormente refinadas em sub características, que podem ser adotadas como referência básica para realização de uma avaliação de qualidade. Essas sub características de qualidade de software não permitem uma medição direta, havendo necessidade da definição de métricas para correlacioná-las ao software propriamente dito. A importância de cada característica de qualidade varia dependendo da classe do software e do ponto de vista considerado: visão do usuário, visão da equipe de desenvolvimento ou visão do gerente. 
Tabela 2.1 - Características de qualidade de software (ISO/IEC 9126, 1991)

\begin{tabular}{|c|l|}
\hline Característica & Definição \\
\hline Funcionalidade & $\begin{array}{l}\text { Refere-se à existência de um conjunto de funções que atende às necessidades } \\
\text { explícitas e implícitas para a finalidade a que se destina o produto. }\end{array}$ \\
\hline Confiabilidade & $\begin{array}{l}\text { Refere-se à capacidade de o software manter seu nível de desempenho sob } \\
\text { condições estabelecidas ao longo do tempo. }\end{array}$ \\
\hline Usabilidade & Refere-se ao esforço necessário para se utilizar o software. \\
\hline Eficiência & $\begin{array}{l}\text { Refere-se ao relacionamento entre o nível de desempenho do software e a } \\
\text { quantidade de recursos utilizados sob condições estabelecidas. }\end{array}$ \\
\hline Manutenibilidade & $\begin{array}{l}\text { Refere-se ao esforço necessário para fazer modificações específicas no } \\
\text { software. }\end{array}$ \\
\hline Portabilidade & $\begin{array}{l}\text { Refere-se à habilidade de o software ser transferido de um ambiente para } \\
\text { outro. }\end{array}$ \\
\hline
\end{tabular}

A seção seguinte discute alguns resultados obtidos por Nielsen sobre avaliação de usabilidade. Conforme explicitado posteriormente (seção 7.2), observou-se neste trabalho que a proposta de avaliação de Nielsen é extensível à avaliação de funcionalidade.

\subsection{Abordagem de Avaliação Proposta por Nielsen}

De forma geral, os estudos de Nielsen em relação à avaliação de usabilidade indicam que os melhores resultados são obtidos executando-se três etapas de testes com cinco usuários participando de cada etapa (Bias \& Mayhew, 1994; Nielsen, 2000). Considerando-se os diversos estudos de caso realizados pelo autor, observou-se que a maior parte do aprendizado em relação a um sistema está vinculada aos testes dos primeiros usuários. Recomenda-se utilizar entre três e cinco usuários por etapa de testes, como uma forma de simplificar esta atividade e obter quase os mesmos benefícios que seriam obtidos em testes mais elaborados e com maior número de usuários.

Landauer e Nielsen (Landauer \& Nielsen, 1993) mostraram em um modelo matemático que o número de problemas de usabilidade encontrado em um teste com $i$ usuários é:

Problemas Encontrados $(i)=N\left(1-(1-L)^{i}\right)$

onde Problemas Encontrados (i) indica a quantidade total de diferentes problemas de usabilidade encontrados considerando-se os relatórios de $i$ avaliadores; $N$ é o número total de problemas de usabilidade do projeto e $L$ é a proporção de problemas de usabilidade encontrados no teste com um usuário. O valor típico de $L$ é $31 \%$ e o valor de $N$ é, em média, 33. Esses valores foram dbtidos pelos autores a partir do estudo de vários projetos. $O$ gráfico a 
seguir (Figura 2.1) mostra a relação existente entre o número de usuários e os problemas encontrados, de acordo com a fórmula dada. É importante observar que a curva pode variar de acordo com os parâmetros $N$ e $L$, que variam de acordo com as características de cada projeto.

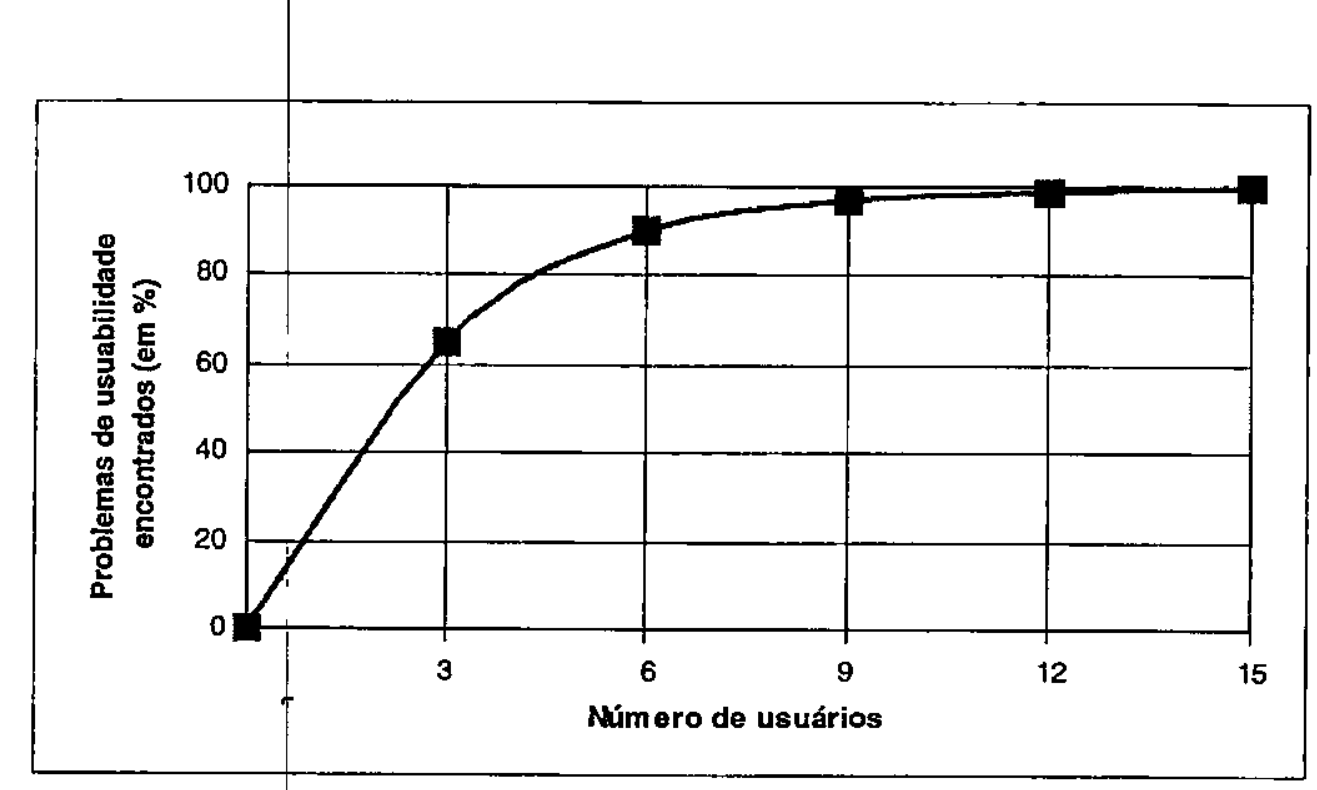

Figura 2.1 - Relação entre o número de usuários e os problemas encontrados (Nielsen, 2000)

De acordo com este gráfico, observa-se que o teste com o primeiro usuário fornece quase um terço de tudo o que há para aprender (conhecer) sobre a usabilidade de um projeto. O segundo usuário faz algumas das mesmas coisas que o primeiro usuário fez, mas ainda há um ganho de aprendizado. Assim, o segundo usuário acrescenta alguma informação, mas não tanto quanto o primeiro. O terceiro usuário faz muitas das coisas que o primeiro e o segundo fizeram, mas também gera uma pequena quantidade de novos dados, mesmo que não seja tanto quanto o primeiro e o segundo. Dessa forma, quanto mais usuários são acrescentados, menos informação nova é obtida, porque as mesmas informações serão obtidas várias vezes e, segundo o autor, não há necessidade de continuar observando as mesmas coisas múltiplas vezes. Após o quinto usuário, há muito pouco aprendizado em relação ao sistema.

A curva apresentada na Figura 2.1 mostra que é necessário realizar testes com quinze usuários para descobrir todos os problemas do projeto. No entanto, Nielsen recomenda distribuir esses usuários em três etapas de testes, com cinco usuários em cada uma, ao invés de todos os usuários participarem de uma única etapa. Conforme pode ser observado no gráfico, após o primeiro estudo com cinco usuários, obtém-se $85 \%$ dos problemas de usabilidade. Recomenda-se, então, reprojetar o sistema considerando-se os resultados obtidos nesta primeira etapa de testes. 
Após o reprojeto do sistema que está sendo avaliado é necessário testá-lo novamente, basicamente por dois motivos: porque os problemas que foram observados podem estar escondendo outros problemas, e porque há o risco de que novos problemas tenham sido inseridos no projeto. Aléton disso, a segunda etapa de testes com cinco usuários descobriria a maior parte dos $15 \%$ de problemas remanescentes do projeto original (ainda permaneceriam cerca de $2 \%$ dos problemas do projeto original, que seriam identificados somente na terceira etapa).

Dessa forma, a segunda etapa de testes servirá como forma de garantir a qualidade dos resultados obtidos na primeira etapa e fornecerá novos dados em relação ao sistema. Esta etapa sempre fornecerá uma nova, porém menor, lista de problemas encontrados.

A próxima seção refere-se à avaliação experimental de software, descrevendo uma taxonomia de doze técnicas experimentais e abordando a validade de experimentos.

\subsection{Método Experimental de Avaliação de Software}

Diversos autores (Basili, 1992; Dix et al., 1998; Papaspyrou et al., 1999; Pfleeger et al., 1994; Tichy et al., 1995) concordam que um dos mais poderosos métodos de avaliação de um projeto é a execução de experimentos. Os resultados obtidos fornecem evidência empírica para suportar uma determinada hipótese. De forma geral, os experimentos podem ser usados para estudar diversas questões em diferentes níveis de detalhes.

Basili expressa a importância de se aplicar uma avaliação analítica ou experimental em um projeto ao afirmar que esses paradigmas servem como base para distinguir atividades de pesquisa de atividades de desenvolvimento. Para ele, se algum desses paradigmas não estiver sendo usado de alguma forma em um projeto, este provavelmente não será um projeto de pesquisa. Dessa forma, simplesmente construir um sistema ou ferramenta constitui desenvolvimento e não pesquisa. Pesquisa envolve compreender como e por que uma ferramenta é útil, e certificar-se de que uma ferramenta possui certas propriedades ou efeitos, projetando-se cuidadosamente um experimento para medir essas propriedades ou compará-las com outros sistemas (Basili, 1992). Portanto, a proposta básica da experimentação é 
determinar se os métodos utilizados durante o desenvolvimento de um produto produzem um software efetivo ${ }^{1}$ (Wallace \& Zelkowitz, 1997).

Há diferentes abordagens de experimentação no domínio de Engenharia de Software. Wallace e Zelkowitz (Wallace \& Zelkowitz, 1998) propõem uma taxonomia que consiste de doze técnicas que podem ser utilizadas para mostrar que uma tecnologia de fato alcança seus objetivos. Essas técnicas,estão resumidas na Tabela 2.2. Outras características dessas técnicas, bem como suas vantagens e desvantagens, podem ser encontradas em (Wallace \& Zelkowitz, 1996; 1997).

Tabela 2.2 - Técnicas experimentais para o domínio de Engenharia de Software (Wallace \& Zelkowitz, 1998)

\begin{tabular}{|c|c|}
\hline Técnica Experimental & Definição \\
\hline $\begin{array}{c}\text { Projeto } \\
\text { Monitorado }\end{array}$ & $\begin{array}{l}\text { Consiste na coleta e armazenamento de dados durante o desenvolvimento } \\
\text { do projeto. Os dados obtidos não influenciam ou redirecionam o processo } \\
\text { de desenvolvimento. Supõe-se que eles serão utilizados para algum tipo } \\
\text { de análise do processo de desenvolvimento. }\end{array}$ \\
\hline Estudo de Caso & $\begin{array}{l}\text { Consiste no estabelecimento de um objetivo específico e subsequente } \\
\text { coleta de dados. Alguns atributos são definidos (por exemplo, } \\
\text { confiabilidade, custo) e os dados são coletados para medir esses atributos. }\end{array}$ \\
\hline Afirmação & $\begin{array}{l}\text { Consiste na execução de um experimento simples (geralmente executado } \\
\text { pelo próprio desenvolvedor) para justificar uma nova tecnologia. } \\
\text { Frequentemente o experimento favorece a tecnologia proposta em relação } \\
\text { a outras alternativas. }\end{array}$ \\
\hline Estudo de Campo & $\begin{array}{l}\text { Consiste na comparação de projetos, ferramentas ou técnicas. Os dados } \\
\text { de cada elemento envolvido na comparação são coletados para determinar } \\
\text { a efetividade de cada um. }\end{array}$ \\
\hline $\begin{array}{l}\text { Pesquisa } \\
\text { Literária }\end{array}$ & $\begin{array}{l}\text { Consiste na investigação e análise de artigos e outros documentos } \\
\text { disponíveis. Isso pode ser útil para confirmar uma hipótese existente ou } \\
\text { comparar os dados coletados em um projeto com dados previamente } \\
\text { publicados em projetos similares. }\end{array}$ \\
\hline $\begin{array}{c}\text { Legalidade de } \\
\text { Dados }\end{array}$ & $\begin{array}{l}\text { Consiste em compreender determinado projeto para aplicar as } \\
\text { informações obtidas em um projeto em desenvolvimento. Considera-se a } \\
\text { disponibilidade para análise de código fonte, especificação, projeto, } \\
\text { documentação de testes e dados coletados durante o desenvolvimento. }\end{array}$ \\
\hline $\begin{array}{c}\text { Liçōes } \\
\text { Aprendidas }\end{array}$ & $\begin{array}{l}\text { Consiste em analisar os documentos gerados após o término de um } \\
\text { projeto. Um estudo desses documentos pode revelar aspectos qualitativos } \\
\text { que podem ser utilizados para melhorar desenvolvimentos futuros. } \\
\text { Entrevistas com os desenvolvedores são frequentemente realizadas. }\end{array}$ \\
\hline $\begin{array}{l}\text { Análise } \\
\text { Estática }\end{array}$ & $\begin{array}{l}\text { Consiste em compreender um produto para obter informações } \\
\text { importantes sobre ele. É um caso especial da técnica legalidade de dados, } \\
\text { com a diferença de que esta inclui o estudo do processo de } \\
\text { desenvolvimento e o método de análise estática está centrado no produto } \\
\text { que foi desenvolvido, analisando-se a estrutura do produto para } \\
\text { determinar suas características. }\end{array}$ \\
\hline
\end{tabular}

\footnotetext{
${ }^{1}$ Segundo os autores, o termo efetivo pode assumir diferentes significados dependendo do problema em questão: software efetivo pode significar software de baixo custo, confiável, desenvolvido rapidamente, seguro, ou com algum outro atributo relevante.
} 
Tabela 2.2 (cont.) - Técnicas experimentais para o domínio de Engenharia de Software

(Wallace \& Zelkowitz, 1998)

\begin{tabular}{|c|l|}
\hline $\begin{array}{c}\text { Experimentos } \\
\text { Replicados }\end{array}$ & $\begin{array}{l}\text { Consiste na execução de uma tarefa de múltiplas formas (por exemplo, } \\
\text { substituindo-se um código em uma linguagem por um código em outra) e } \\
\text { ha comparação dos resultados obtidos nas diversas abordagens. Esta } \\
\text { técnica representa a experimentação científica clássica. }\end{array}$ \\
\hline $\begin{array}{c}\text { Experimentos em } \\
\text { Ambiente Artificial }\end{array}$ & $\begin{array}{l}\text { Consiste em executar experimentos replicados em um ambiente diferente } \\
\text { daquele no qual o software será executado (que é apenas uma } \\
\text { aproximação do ambiente real) com o objetivo de reduzir os custos } \\
\text { envolvidos na atividade experimental. }\end{array}$ \\
\hline Análise Dinâmica & $\begin{array}{l}\text { Consiste em demonstrar e avaliar características do produto quando ele é } \\
\text { executado. Além disso, o produto pode ser modificado ou executado sob } \\
\text { situações controladas para extrair informações sobre seu uso. }\end{array}$ \\
\hline Simulação & $\begin{array}{l}\text { Consiste na execução do produto utilizando-se um modelo do ambiente } \\
\text { teal. Nesse caso, são obtidas hipóteses sobre como o ambiente real } \\
\text { feagirá à nova tecnologia. Pode-se usar a simulação como alternativa à } \\
\text { execução do produto completo para facilitar e diminuir os custos dos } \\
\text { experimentos. }\end{array}$ \\
\hline
\end{tabular}

Outras classificaçōes também foram propostas. Basili (Basili, 1996) classifica um experimento em in vivo (executado em ambiente real e sob condições normais) ou in vitro (executado em um laboratório, sob condições controladas). Além disso, um projeto pode envolver um grupo de desenvolvedores ou vários grupos, e um experimento pode envolver um projeto ou múltiplos projetos, o que gera oito diferentes classificações de tipos de experimentos. Kitchenham (Kitchenham, 1996) considera outra classificação para experimentos: (1) experimentos quantitativos, que identificam os benefícios mensuráveis advindos da utilização de um método ou ferramenta. Nesse caso, os dados mensuráveis obtidos estão usualmente relacionados à redução de custos e tempo de trabalho. Kitchenham refere-se a esse tipo de avaliação como sendo quantitativa ou objetiva; (2) experimentos qualitativos, que avaliam a adequação das características fornecidas por um método ou ferramenta, considerando-se as características fornecidas pelo software e em termos de seus requisitos iniciais. As avaliações são realizadas, usualmente, baseando-se nas opiniōes dos avaliadores a respeito do fornecimento das características requeridas. Um avaliador investiga, portanto, quão bem as características consideradas importantes são fornecidas por um ou por vários métodos ou ferramentas. Kitchenham refere-se a esse tipo de avaliação como análise de características e identifica-a como uma avaliação qualitativa ou subjetiva, porque requer uma avaliação subjetiva da importância relativa de diferentes características e como essas características foram implementadas; e (3) benchmarking, em que testes padrões são executados em algumas tecnologias para avaliar a performance de cada uma. 
Independentemente da técnica experimental escolhida, espera-se que os resultados obtidos sejam válidos e confiáveis. A seção seguinte apresenta um estudo de Gray e Salzman (Gray \& Salzman, 1998) sobre possíveis ameaças à validade de um experimento. Para eles, alguns aspectos devem ser considerados durante o planejamento dos experimentos de forma a garantir a validade dos resultados que serão obtidos.

\subsection{Validade de Experimentos}

Segundo (Gray \& Salzman, 1998) para que os resultados obtidos sejam válidos e significativos, os experimentos devem possuir validade estatística, validade intema, validade de construção e validade externa.

\subsubsection{Validade Estatística}

Um experimento é estațisticamente válido quando evita o baixo poder estatístico (poucos participantes no processo de experimentação) e a heterogeneidade randômica dos participantes (os resultados dos experimentos podem não refletir as condições reais do sistema ou da ferramenta alvo do experimento quando a amostra de usuários é composta por indivíduos que são significativamente melhores ou piores que a média).

Baixo poder estatístico e heterogeneidade randômica dos participantes devem ser considerados de forma conjunta. Baixo poder estatístico pode fazer com que problemas verdadeiros não sejam notados. Heterogeneidade randômica dos participantes pode fazer com que problemas notados não sejam verdadeiros. As soluções para esses problemas seriam aumentar o número de participantes por grupo e considerar grupos diferentes de acordo com as diferenças dos indivíduos que participam dos experimentos, o que faz com que estes se tornem complexos, demorados e, algumas vezes, caros e inviáveis.

\subsubsection{Validade Interna}

Três fatores precisam ser considerados no contexto da validade interna: instrumentação, seleção e cenário. 
A instrumentação refere-se às tendências segundo as quais os observadores identificam ou avaliam a intensidade dos problemas. Por exemplo, se durante um experimento, os avaliadores modificam a forma como eles identificam, classificam e qualificam problemas, então um problema de instrumentação existe. Fatores que podem ter levado a tais mudanças são o aumento de sensibilidade aos problemas e o aumento de experiência com o sistema.

O fator seleção torna-se uma ameaça à validade interna de um experimento quando um resultado está relacionado às diferenças entre as pessoas em um grupo experimental. Uma ameaça de seleção exiște quando os participantes possuem características diferentes em relação ao experimento, por exemplo, conhecimento e experiência na utilização do sistema.

O fator cenário está relacionado às possíveis alterações nos resultados devido ao fato de se executar os experimentos em diferentes cenários: em casa, em um laboratório ou em um escritório. Nesse caso, as diferenças de cenário tomam-se ameaças à validade intema do experimento pois não se consegue determinar se os efeitos observados são resultados do experimento, são influenciados pelo cenário ou por uma combinação experimento-cenário.

\subsubsection{Validade de Construção}

A validade de construção está relacionada à garantia de que os experimentos estão manipulando o que eles alegam estar manipulando e que estão medindo o que eles alegam estar medindo.

Um dos fatores que devem ser considerados para garantir a validade de construção é a explicitação do significado dos principais termos do contexto da atividade experimental. Isso evita que conceitos sejam mal interpretados por leitores que poderiam tirar falsas conclusões a partir dos resultados obtidos na experimentação.

\subsubsection{Validade Externa}

A validade externa está relacionada à forma como os resultados dos experimentos são registrados. As informações obtidas devem estar direcionadas a grupos particulares de pessoas, cenários e épocas e não devem, portanto, exceder esses grupos. 
Generalizações que excedam o escopo dos cenários e dos avaliadores proporcionam falta de validade externa ao experimento. A diferença entre os cenários e as pessoas que participaram do experimento e o alcance de cenários e pessoas para os quais os experimentos parecem generalizar são problemas constantes em relatórios de resultados experimentais. Ao registrar os resultados, os pesquisadores devem tentar balancear as alegações em relação a limitações específicas.

É fundamental que os experimentos sejam válidos com relação aos fatores citados anteriormente, no sentido de evitar que falhas na administração e execução desses experimentos comprometam os resultados obtidos. Gray e Salzman alertam para o fato de que possíveis atividades experimentais que não considerem esses critérios podem ser invalidadas devido aos resultados errốneos que poderão ser apresentados.

Outras informações sobre validade de experimentos podem ser encontradas em (Dunsmore et al., 1986), (Ransdell, 1993) e (Yin, 1984).

\subsection{Considerações Finais}

A importância e os benefícios advindos da avaliação de um software foram tratados neste capítulo. Observou-se que algumas etapas devem ser cumpridas antes da execuçăo efetiva da avaliação do software. Em particular, o planejamento da avaliação deve ser cuidadosamente especificado, de forma a definir as estratégias que irão orientar a execução da avaliação.

Comentou-se também a proposta de avaliação obtida a partir de estudos de Nielsen, que sugere a realização de quinze experimentos divididos em três etapas de testes. É importante, contudo, que estes experimentos possuam validade estatística, interna, de construção e externa. 


\section{Capítulo 3}

\section{Sistemas e Modelos Hipermídia}

\subsection{Considerações Iniciais}

O uso dos computadores nas escolas, apesar de questionado, motiva a utilizaçāo de abordagens que possam enriquecer a prática educacional. Dentre essas abordagens, destaca-se o surgimento dos cursos virtuais, que corresponde a um novo paradigma que contribui para a construção do conhecimento. De forma a permitir a elaboração desses cursos, os sistemas de autoria fornecem subsídios através dos quais os autores podem rapidamente estruturar e disponibilizar o material didático.

Este capítulo faz uma revisão sobre alguns sistemas de autoria hipermídia disponíveis na literatura, descrevendo tảmbém os principais métodos para projeto de aplicações hipermídia que aprimoram o processo de autoria. Em particular, o sistema SASHE e o método EHDM (desenvolvido para permitir o projeto de aplicações hipermídia educacionais no contexto do SASHE) (Pansanato, 1999; Nunes \& Pansanato, 1999c) foram descritos, devido ao fato de terem sido detalhadamente estudados durante o desenvolvimento deste trabalho.

\subsection{Sistemas Hipermídia para Ensino: Visão Geral}

As constantes mudanças e evoluções ocorridas na área de informática, provenientes dos aprimoramentos aos níveis de software e hardware, têm contribuído para a consolidação dos sistemas hipermídia. Além disso, a disseminação da Internet faz com que a busca de informações em documethtos hipermídia seja uma atividade diária para seus usuários. Fatores 
como esses incentivam um grande número de pesquisas na área, que procuram desenvolver novas técnicas e características a serem incorporadas aos sistemas hipermídia, buscando também atender às novas exigências das aplicações.

Nesse contexto, a possibilidade de livre exploração de páginas com informações representadas por diferentes mídias (texto, áudio, vídeos, imagens) e a utilização de links na estruturação dessas páginas estimulam a utilização dessa tecnologia no processo de ensinoaprendizagem. Para Hall e Mendes (Hall \& Mendes, 1999) a característica pedagógica mais significativa de uma apliçação hipermídia é sua maleabilidade, ou seja, ela é capaz de oferecer múltiplas perspectivas de um domínio particular. Além disso, é possível apresentar e representar idéias de formas que são difíceis, ou até mesmo impossíveis, de se alcançar quando se utiliza material impresso. Outros fatores, como a facilidade de disponibilização de material e o baixo custo dos recursos tecnológicos necessários, incentivam a utilização de aplicações hipermídia no contexto educacional.

Algumas características possíveis de serem obtidas em aplicaçðes hipermídia, que podem contribuir para o processọ de ensino-aprendizado são (Nunes et al., 1997):

- A fácil exibição e navjegação de/por documentos extensos;

- A individualização do ensino com relação ao aluno, onde a forma de acesso à informação segue interesses também do usuário;

- A criação de um ambiente onde o estudante não se sinta intimidado ao cometer erros, aumentando sua interação com o meio que transmite a informação;

- A capacidade de o usuário aprender e (re)definir relacionamentos entre os conceitos apresentados, através da percepção da estrutura lógica que define o documento;

- Os estudantes podem obter respostas às suas perguntas no momento em que elas são geradas, através da possibilidade e facilidade de exploração do documento a ser estudado.

Premkumar et al. (Premkumar et al., 1998) citam como vantagens de utilização de sistemas hipermídia no domínio de ensino a possibilidade de os aprendizes estudarem de acordo com horários e locais mais convenientes e a utilização de simulações e softwares de realidade virtual que permitem práticas de habilidades es pecíficas.

Por outro lado, podem-se encontrar também problemas na utilização de sistemas hipermídia nesse domínio (Nunes et a1., 1997; Premkumar et al., 1998):

- Superexposição de informações ao usuário; 
- Passagem do controle sobre a apresentação do material do autor para o estudante;

- Impossibilidade de se antecipar e programar as necessidades de cada estudante;

- Poucas semelhanças entre simulaçōes e realidade.

Em particular, os sistemas de autoria hipermídia são ambientes que facilitam a criação de uma aplicação hipermídia apoiando atividades tais como o planejamento, o projeto e a implementação das aplịcações. Diversos exemplos de sistemas de autoria hipermídia educacional podem ser encontrados na literatura, podendo-se citar, como sistemas comerciais - LearningSpace (LearningSpace, 2000) e o TopClass (TopClass, 2000); como sistemas disponíveis na Internet, o Aulanet (Lucena et al., 1997), o InterBook (Brusilovsky et al., 1996) e o WebCT (Goldberg et al., 1996) e como sistemas acadêmicos, o HyperBuilder, o QuestBuilder e o TaskBuilder (Pimentel et al., 1998) e o eClass (Abowd et al., 1999). Essas ferramentas têm em comum o fato de se concentrarem na criação da estrutura, armazenamento do conteúdo e controle de acesso ao material didático, delegando a tarefa de modelagem do conhecimento para o autor.

A etapa de autoria que envolve planejamento e estruturação do domínio de conhecimento de uma aplicação educacional é reconhecidamente complexa, volumosa e determinante para o sucesso da aplicação. A utilização de um modelo de representação para o domínio da aplicação pode auxiliar o autor na atividade de autoria porque permite que ele trabalhe em um nível de abstração mais próximo a este domínio (Garzotto et al., 1993). Geralmente esse modelo está inserido no contexto de um método, que pode oferecer uma abordagem mais sistemática e estruturada para realizar essa atividade.

Atualmente existem vários métodos para projeto de aplicaçōes hipermídia, destacando-se: HDM (Hypertext Design Model) (Garzotto et al., 1993), RMM (Relationship Management Methodology) (Isakowitz et al., 1995), OOHDM (Object-Oriented Hypermedia Design Method) (Shwabe \& Rossi, 1995), EORM (Enhanced Object-Relationship Model) (Lange, 1994) e HMBS (Hypertext Model Based on Statecharts/Method) (Carvalho, 1998). Entretanto, esses métodos privilegiạm a generalização de domínio, perdendo informações importantes sobre as características de um domínio mais específico, que, para o caso do ensino, é de fundamental importância. Além disso, ao aceitar qualquer domínio, esses métodos tendem a utilizar modelos de representação que são estranhos aos autores, fazendo com que estes tenham dificuldade em modelar o material instrucional (Nunes \& Pansanato, 1999b). 
São apresentadas a seguir as principais características dos sistemas de autoria hipermídia mencionados anteriormente.

\subsection{Sistemas de Autoria Hipermídia}

De forma geral, os ambientes de autoria citados têm por objetivo facilitar o desenvolvimento de aplicações hipermídia com finalidades educacionais. No entanto, diversas particularidades os diferenciam entre si. As subseções seguintes apresentam as principais características de tais ambientes.

\subsubsection{Sistemas comerciais para autoria hipermídia educacional \\ No contexto de sistemas comerciais destacam-se o LearningSpace (LearningSpace, 2000) e o TopClass (TopClass, 2000). As principais características desses sistemas são apresentadas a seguir.}

\subsubsection{0 LearningSapace}

O Learning Space é um ambiente educacional que tem por objetivo oferecer soluçōes para o aprendizado online. A arquitetura básica do ambiente é formada por cinco componentes principais, utilizados para gerenciar diferentes aspectos de desenvolvimento e apresentação de um curso.

O componente Schedule possibilita a navegação pelo material de um curso. O componente MediaCenter atua como um repositório de materiais de um curso. O CourseRoom permite que os alunos participem de discussões entre si e com o professor, além de apoiar atividades em grupo. As informações sobre os alunos estão contidas em Profile Manager. O componente Assessment Manager apóia o processo de avaliação dos alunos.

\subsubsection{O TopClass}

O TopClass foi um dos primeiros ambientes educacionais baseados em Web. Os cursos elaborados no TopClass são baseados em unidades de estudo - Units of Learning Material (ULMs). Cada $U L M$ consiste em páginas, exercícios ou mesmo em outras $U L M s$, que podem ser livremente importadas ou exportadas de um curso para outro. O TopClass também oferece ferramentas para administração do curso, bem como para acompanhamento do aluno. 
As ferramentas de ensino presentes no TopClass incluem um web browser e links embutidos nos documentos. Comunicação assíncrona e compartilhamento são apoiados por e-mail, grupos de discussão e troca de arquivos BBS. Ferramentas para comunicação síncrona não estão disponíveis. $O$ aluno pode realizar testes para auto-avaliação e o progresso em um curso pode ser monitorado tanto pelo professor quanto pelo aluno. Também é possível elaborar planos de trabalho individualizados para os alunos.

As ferramentas de tutor são projetadas de forma a facilitar a elaboração e adaptação de cursos. As ULMs são aninhadas hierarquicamente; os alunos são divididos em grupos e o acesso a fóruns de discussão pode ser restrito aos grupos. Além disso, as ULMs podem ser facilmente criadas e associadas a um grupo particular de alunos.

\subsubsection{Sistemas disponíveis na Internet para autoria hipermídia educacional \\ No contexto de sistemas disponíveis na Internet destacam-se o Aulanet (Aulanet, 2000), o Interbook (Brusilovsky et al., 1996) e o WebCT (Goldberg et al., 1996). As principais características desses sistemas são apresentadas a seguir.}

\subsubsection{O AulaNet}

O AulaNet é um ambiente para a administração, criação, manutenção e assistência de cursos WWW, desenvolvido no Laboratório de Engenharia de Software do Departamento de Informática da PUC-Rio.

Esse ambiente visa adotar a web como ambiente educacional, criando uma transição da sala de aula convencional para a sala de aula virtual, oferecendo a oportunidade de se reutilizar o material educacional existente. Além disso, a proposta do ambiente AulaNet é permitir um elevado grau de interatiyidade e intensa participação do estudante, sem que o autor tenha conhecimento profundo sobre o ambiente WWW (Aulanet, 1997). Outras características desse ambiente são: (1) os cursos criados devem possuir grande capacidade de interatividade, de forma a atrair a participação intensa do aprendiz no processo de aprendizado; (2) o autor do curso não precisa ter conhecimentos prévios sobre as tecnologias empregadas no desenvolvimento de hipetdocumentos web; (3) os recursos oferecidos para a criação de cursos devem corresponder aos de uma sala de aula convencional, acrescidos de outros normalmente disponíveis no ambiente web. 
Basicamente, o processo de criação de um curso através do ambiente AulaNet inclui a identificação do ator (que pode ser o autor, estudante ou o administrador); a descrição das informações gerais do cưrso (nome, descrição sumária e ementa) e a seleção de recursos (que podem ser didáticos, de avaliação, administrativos e fixos). $\mathrm{O}$ administrador é caracterizado como sendo a pessoa que cuida das tarefas de gerenciamento, tais como inscrição do estudante e divulgação dẹ datas.

O ambiente oferece ao aluno um menu de serviços, configurado pela seleção dos mecanismos de comunicação, coordenação e cooperação, realizada previamente pelo professor. Ao contrário de links de baixo nível, a utilização de um menu de serviços proporciona facilidades de navegação de alto nf́vel, que ajudam a minimizar o problema de desorientação. Ressalta-se, ainda, que os cursos oferecidos usando o ambiente são estruturalmente parecidos, aumentando o sentido de orientação do aluno.

Os serviços oferecidos no ambiente AulaNet estão divididos em três categorias: serviços de comunicação, cooperação e coordenação. Os serviços de comunicação compreendem os contatos com o docente, grupos de discussão, grupos de interesse, debates e contatos com os participantes do curso. Os serviços de coordenação envolvem as agendas, os planos de aulas, as avaliações por tarefas e o acompanhamento da participação do estudante. Por fim, os serviços de coordenação focalizam o uso de bibliografias, documentações, co-autoria de docentes e de estudantes e downloads.

\subsubsection{0 interBook}

O sistema InterBook consiste de um ambiente de autoria que oferece ferramentas para a publicação de livros-texto na World Wide Web (WWW), aos quais podem ser associados índices, glossários e uma|interface de busca.

O sistema suporta navegação seqửencial e hierárquica entre as unidades. Utilizando-se de bullets coloridos, os links têm seu status marcado com base no histórico da navegação, da etapa de conhecimento e dos pré-requisitos. Além disso, cada unidade possui uma ligação para um glossário dos donceitos envolvidos e ligações (f́ndices) para outras unidades que também estão relacionadas a estes conceitos. 
Durante o processo de autoria de um livro-texto, o autor fornece os títulos das unidades (capítulos, seções e subseções) de forma hierárquica (como um livro) sendo que, para cada unidade, pode ser inserida uma anotação que fornece o conjunto de conceitos relacionados com a unidade e o papel do conceito na unidade (pré-requisito ou resultado). A partir das anotações, o sistema reconhece quais conceitos são apresentados em cada página e quais conceitos têm que ser aprendidos antes de exibir/apresentar cada página, proporcionando a utilização de diversas técnicas de adaptação.

\subsubsection{3 $\mathrm{WebCT}$}

$\mathrm{O}$ ambiente WebCT é baseado em documentos HTML, tanto para a autoria quanto para a navegação.

O desenvolvedor do cursq (autor) é responsável por prover o seu conteúdo. A interatividade, a estrutura navegacional e as ferramentas educacionais são fornecidas pelo ambiente, que também permite a incorporação de funcionalidades adicionais (tais como ferramentas para verificação do progresso ido aprendiz, elaboração de testes, etc) e a alteração do layout do curso.

Atualmente o WebCT é visto como um dos mais completos ambientes para desenvolvimento de cursos para o ambiente WWW, por fornecer aos professores e estudantes os recursos necessários para a elaboração e realização do curso, incluindo as ferramentas de gerenciamento.

Neste ambiente existem quatro grupos de usuários que possuem diferentes direitos de acesso sobre as ferramentas que fazem parte do ambiente (WebCT, 2000). O administrador é o usuário responsável pelo servidor WebCT (em que ficam armazenadas todas as informações sobre os cursos disponíveis); é quem autoriza a criação de novos cursos e cria permissão para os usuários designers. Oidesigner, na maioria dos casos, é o professor responsável por um curso. É ele quem cria é organiza as páginas do curso, publica-o na Internet enviando o material para o servidor WebCT, cadastra os usuários alunos e lhes atribui notas, além de poder criar o usuário monitor. O monitor é o usuário que auxilia os professores a administrar os usuários alunos e suas notas. Eles podem criar, alterar ou excluir usuários alunos do curso. O aluno é o usuário que fealiza o curso criado. Cada curso tem um grupo de usuários alunos que foi cadastrado por um designer ou por um monitor. 
O WebCT oferece ferramentas para autoria do material didático e para o gerenciamento da maioria das atividades, tais como o fornecimento de dados estatísticos do curso, progresso individual do estudante, controle de acesso pelos estudantes, testes on-line com tempo prédeterminado e correção automática dos testes, dentre outros.

A principal vantagem associada a ele está na possibilidade de se estabelecer um ambiente de ensino e aprendizado integrado, contendo uma série de ferramentas educacionais tais como sistema de conferência, chat, correio eletrônico, suporte para projetos colaborativos, autoavaliação, questionários, distribuição e controle de notas, glossário, controle de acesso, calendário do curso, geração automática de índices e pesquisa, entre outras (Goldberg et al., 1996).

Toda a interação com o| WebCT é baseada na WWW, não sendo necessário criar versões especiais do software para diferentes plataformas. Além disso, o software é executado a partir de um servidor central, podendo ser acessado de qualquer local onde um computador conectado à internet esteja disponível.

No entanto, observa-se que, apesar dos muitos recursos oferecidos pela ferramenta, o emprego de uma estrutura proprietária para os documentos gerados dificulta os processos de reuso e intercâmbio com outros ambientes de autoria e apresentação.

\subsubsection{Sistemas acadêmicos para autoria hipermídia educacional}

No contexto de sistemas disponíveis na Internet destacam-se as ferramentas HyperBuilder, QuestBuilder e TaskBuilder (Pimentel et al., 1998) e o eClass (Abowd et al., 1999). Suas principais características são apresentadas a seguir.

\subsubsection{As ferramentas HyperBuilder, QuestBuilder e TaskBuilder}

Este projeto correspond̦e à implementação de ferramentas que permitem a autoria de hiperdocumentos com finalidades. educacionais, a autoria de questionários de avaliação do aprendizado, a autoria de testes de múltipla escolha baseados em textos e imagens e a publicação desse material no ambiente WWW. 
Uma característica fundamental desse pacote de ferramentas é que, durante o processo de criação do material didático, o autor não precisa ter conhecimentos prévios sobre detalhes técnicos das linguagens de desenvolvimento para a WWW (tais como HTML, Java e JavaScript), pois essas ferramentas atuam como uma camada que separa os usuários dessas tecnologias.

A ferramenta HyperBuilder promove a orientação ao professor (autor) na inserção de tópicos no texto didático, obedecendo-se uma estruturação pré-definida por Pimentel et al. (Pimentel et al., 1998). Para gerar o conteúdo correspondente aos itens e subitens, o professor deve carregar o arquivo gerado pela ferramenta em um editor de documentos HTML convencional.

Na ferramenta QuestBuilder, o autor encontra suporte à criação de questões dissertativas, de múltipla escolha, de verdádeiro e falso e questões que envolvem o relacionamento de colunas.

Além de questionários d'e avaliação, foi especificado um item denominado "exercício" que permite a inserção de um teste de múltipla escolha na estrutura do texto didático. Para isso, o autor tem a sua disposição a ferramenta denominada TaskBuilder.

Finalmente, o processo de disponibilização de material utiliza-se dos recursos da classe FTP (File Transfer Protocol) presente na linguagem Java. Dessa forma, quando o autor seleciona a opção de publicação do material é estabelecida uma conexão com o webserver desejado e, então, realizado o processo de transferência de arquivos para uma área pública do referido servidor.

\subsubsection{2 eClass}

O eClass, ou Classroom 2000, desenvolvido no Georgia Institute of Technology (GATECH), é um projeto que tem gomo principal objetivo a criação de um modo automatizado para transformar o conteúdo rico de uma sala de aula tradicional em mídias digitais extensíveis, de forma que possam ser reutilizadas a curto e longo prazo (Abowd et al., 1999).

A filosofia do eClass difere-se dos ambientes apresentados por focalizar o uso do material produzido (gerado) nas salas de aula para a formação do conhecimento que, posteriormente, é disponibilizado sob a forma de hiperdocumentos aos estudantes. Segundo Pimentel (Pimentel et al., 2000), a sala de aula é um ambiente rico em recursos áudio-visuais que combinam os 
materiais apresentados pelo professor, as discussões em tomo do tema abordado e as anotações e experiências de estudantes e professores que, na maioria das vezes, são perdidas por não se ter mecanismos adequados de captura e armazenamento dessas informações.

Do ponto de vista de hardware, o ambiente eClass necessita de uma sala equipada com tecnologias de computação ubíqua -lousa eletrônica, projetor, microfone, câmera de vídeo e computador em rede. Do ponto de vista de software, apóia-se em um conjunto de aplicaçōes cliente-servidor - módulos para captura, sincronização, armazenamento e geração automática de hiperdocumentos bas£ados na infra-estrutura do ambiente WWW. Sob a visão de sistemas hipertexto, o eClass produz automaticamente, como resultado da captura de cada aula, um conjunto de hiperdocumentos multimídia (Pimentel et al., 2000).

Mark Guzdial, professor e pesquisador do GATECH, projetou um ambiente hipermídia de edição colaborativa denominado CoWeb (Guzdial, 1999). Através deste ambiente, estudantes e professores podem fazer a autoria de páginas web sem conhecimento prévio de quaisquer tecnologias relacionadas, como comunicação cliente-servidor, linguagens de marcação e de scripts. Sua principal całacterística é a autoria aberta: qualquer usuário no ambiente CoWeb pode criar e editar as páginas, o que permite a edição colaborativa de documentos.

Observando que o ambiente CoWeb dá suporte às atividades ocorridas fora de sala de aula, enquanto que o eClass registra as atividades ocorridas dentro de sala de aula, pesquisadores do GATECH e do ICMC-USP trabalharam colaborativamente na integração desses ambientes, permitindo, assim, conectar as informações produzidas nos dois ambientes (Abowd et al., 1999), de modo que estudantes possam acrescentar suas anotações, enriquecendo ainda mais o material didático.

Os principais métodos propostos para auxiliar o processo de desenvolvimento de uma aplicação hipermídia são apresentados resumidamente a seguir.

\subsection{Métodos para Projeto de Aplicações Hipermídia}

Conforme mencionado na seção 3.2, existem atualmente diversos métodos para projeto de aplicações hipermídia, domo o HDM (Hypertext Design Model), o RMM (Relationship Management Methodology), o OOHDM (Object-Oriented Hypermedia Design Method), o EORM (Enhanced Object-Relationship Model) e o HMBS/M (Hypertext Model Based on 
Statecharts/Method). Esses métodos possuem em comum: (1) a definição de modelos para a descrição dos dados do domínio; (2) a consideração da associação semântica que existe entre os relacionamentos do domínio e os elos hipermídia e (3) a utilização de estruturas de acesso para modelar os aspectos navegacionais. Entretanto, estes métodos também apresentam diversas diferenças, conforme apontado a seguir.

\subsubsection{HDM - Hypertext Design Model (Garzotto et al., 1993)}

Este modelo é bastante utilizado para o desenvolvimento de aplicações, tendo sido considerado o primeiro modelo para o domínio de hipermídia. Dessa forma, o HDM foi utilizado como base para o desenvolvimento de outros sistemas, como o RMM e o OOHDM.

O HDM se concentra na modelagem dos dados do domínio de conhecimento, possuindo abstrações simples. Para a modelagem da navegação, utiliza estruturas de acesso (índices e roteiros). Um índice age como uma tabela de conteúdos para uma lista de itens de informação, fornecendo acesso direto a cada item da lista. Os roteiros são sequiências de nós ou páginas que compõem o hiperdocumento.

Uma aplicação (hiperdocumento) no HDM consiste de estruturas de informação chamadas entidades, que denotam um objeto físico ou conceitual do domínio, e são agrupadas em tipos de entidades (entity types).

Apesar de o HDM ser utilizado principalmente para a modelagem de aplicações, ele fornece uma semântica de navegação padrão, derivada diretamente da especificação e compatf́vel com a navegação comum de nós e elos encontrada em muitos sistemas. Entretanto, é possível definir semânticas de navegação especfficas para um determinado sistema alvo da aplicação.

O HDM não possui suporte à modelagem da interface do usuário e à geração de protótipos das aplicações (não fornece regras para de tradução automática da especificação do modelo para uma especificação executável). 


\subsubsection{RMM - Relationship Management Methodology (Isakowitz et al., 1995)}

O RMM é um método dé desenvolvimento de aplicações hipermídia indicado principalmente para aplicações que apresentam uma estrutura regular do domínio e que necessitam de frequentes atualizações (um catálogo de produtos, por exemplo).

Este método consiste na execução de sete passos, alguns dos quais podendo ser conduzidos em paralelo: projeto de entidade-relacionamento, projeto de entidade, projeto de navegação, projeto de protocolo de conversão, projeto de tela de interface de usuário, projeto de comportamento de tempq de execução e construção.

O desenvolvimento da metodologia RMM foi baseado nos Modelos de EntidadeRelacionamentos (Elmassi \& Navate, 1990) e no HDM. Cada passo da metodologia trata objetos de projeto (entidades, relacionamentos, atributos, slices e estruturas de acesso) de formas particulares, sendo que os objetos de projeto não são exclusivos de um estágio de desenvolvimento específico.

Para a modelagem da navegação, o RMM utiliza as estruturas de acesso índices, roteiros e agrupamentos, sendo que esta última serve como ponto de acesso a outras partes do documento hipermídia. Por exemplo, a tela inicial de muitas aplicações contém um menu ou conjunto de botőes que fọmecem acesso a diferentes funções ou classes de informação.

A metodologia RMM difere do HDM (e de outros modelos) em muitos pontos, incluindo a recomendação de uma sequiência de passos, formalismos para estruturas de acesso, ênfase em um projeto incremental e representações gráficas e um maior detalhamento dos procedimentos para o projeto e desenyolvimento de aplicações hipermídia. Destaca-se que o HDM se concentra somente na modelagem do domínio de conhecimento.

A ferramenta RMCase (Díaz \& Isakowitz, 1995) foi desenvolvida de forma a suportar a geração de protótipos de aplicaçőes desenvolvidas segundo a abordagem RMM. 


\subsubsection{OOHDM - Object-Oriented Hypermedia Design Method (Shwabe \& Rossi, 1995)}

O OOHDM é um método para construção de aplicações hipermídia que utiliza abstrações orientadas a objetos. Este método compreende quatro atividades: modelagem conceitual, projeto navegacional, projeto da interface abstrata e implementação. Esse processo suporta os estilos de desenvolvimento incremental, iterativo e baseado em protótipo. Cada atividade produz ou enriquece um modelo orientado a objetos focalizando um determinado interesse de projeto.

Para se obter uma aplicação utilizando o OOHDM, é necessário definir um modelo navegacional para o modelo conceitual. Esse modelo navegacional é uma visão do modelo conceitual e diferentes modelos navegacionais podem ser construídos para expressar diferentes visões do mesmo domínio. Essa visão é construída durante o projeto navegacional observando-se os tipos de usuários e as tarefas que serão realizadas por eles. Além da utilização de índices e roteiros como estruturas de acesso, o OOHDM utiliza também primitivas de alto nível chamadas de contextos navegacionais.

Observa-se que o OOHDM oferece abstrações orientadas a objetos, enquanto o HDM e RMM são baseados no modelo de dados entidade-relacionamento. Além disso, em relação à modelagem de navegaçăo, o OOHDM oferece as estruturas de acesso comuns ao HDM e RMM (índices e roteiros) e utiliza também primitivas de alto nível chamadas de contextos navegacionais. O OOHDM é o único, dentre os métodos revisados, que fornece um método formal para descrever a interface do usuário.

A ferramenta OOHDM-CASE (Rossi, 1996) foi desenvolvida de forma a suportar a geração de protótipos de aplicaçổes desenvolvidas segundo a abordagem OOHDM.

\subsubsection{EORM - Enhanced Object-Relationship Model (Lange, 1994)}

O EORM é uma abordàgem orientada a objetos para o projeto de aplicações hipermídia. A abordagem utiliza como base uma metodologia de análise orientada a objetos, a Object Modeling Technique (OMT) (Rumbaugh et al., 1991) e estende esta metodologia com construções para capturạr a semântica das interações entre objetos. 
A idéia central da metodologia é representar, explicitamente, os relacionamentos semanticamente ricos nó modelo orientado a objetos. Esses relacionamentos são definidos como classes que têm estrutura e comportamento próprios. Dessa forma, os relacionamentos são capazes de capturar não apenas as restrições estruturais básicas dos relacionamentos OMT, mas também as propriedades complexas desses relacionamentos, por exemplo, a semântica de ligações hipermídia. A semântica hipermídia de um relacionamento é modelada em uma aplicação definindo-se classes e hierarquias de ligações e associando as semânticas dessas ligações aos relacionamentos.

Em relação aos demais métodos revisados, o EORM possui uma metodologia para desenvolvimento orientada a objetos estendida, além de utilizar composiçōes para a modelagem da navegaçāo.

O EORM não possui suporte à modelagem de interface (apenas reserva uma fase específica para esta tarefa) e à geração de protótipos das aplicações.

\subsubsection{HMBS/M - Hypertext Model Based on Statecharts/Method (Carvalho, 1998)}

O HMBS/M é um método para apoiar o projeto e o desenvolvimento estruturado de aplicações hipermídia. É composto por quatro fases, sendo que o produto de cada fase é incrementado ou melhorado na fase posterior. As melhorias introduzidas no(s) modelo(s) de uma das fases devem ser especificadas no(s) modelo(s) da(s) fase(s) anterior(es), permitindo assim um desenvolvimento interativo. As fases do método são: Modelagem Conceitual, Modelagem Navegacional, Modelagem da Interface e Implementação e Teste.

Este método adota o Hyperdocument Model Based on Statecharts (HMBS) (Turine, 1998) para especificar precisamente o comportamento navegacional do hiperdocumento. O HMBS utiliza a estrutura semântica operacional de Statecharts (Harel, 1987) para especificar a estrutura organizacional e semântica de navegação de hiperdocumentos. As instâncias das classes e dos relacionamentos do modelo navegacional de tipos são modeladas em termos de estados e transições.

Em relação aos demais métodos revisados, o HMBS/M destaca-se por fornecer uma tradução efetiva do modelo navegacional de tipos para uma especificação segundo o modelo HMBS. O 
ambiente HySCharts (Turine et al., 1998) permite criar, interpretar e executar especificações segundo o HMBS.

A seção seguinte apresenta alguns métodos desenvolvidos para permitir a modelagem de aplicações hipermídia pertencentes ao domínio específico de ensino.

\subsection{Métodos para Projeto de Aplicações Hipermídia Educacionais}

A organização e estruturação de material didático são atividades que envolvem, principalmente, a organiząção das informações sobre o domínio que se deseja ensinar. Dessa forma, a utilização de ferramentas que apóiem a modelagem da aplicação hipermídia educacional permite ao autor capturar e organizar a estrutura de um domínio complexo e tomá-la clara e acessível aos aprendizes. Esta seção discute algumas abordagens propostas para o projeto de aplicaçổes hipermídia educacionais.

\subsubsection{MAPHE - Metodologia de Apoio a Projetos de Hipertextos Educacionais}

A metodologia MAPHE (Pimentel, 1997) propōe o desenvolvimento de hipertextos educacionais por meio de quatro etapas: Planejamento, Modelagem, Implementação e Testes.

A etapa de Planejamento estipula as estratégias a serem utilizadas no desenvolvimento do hiperdocumento. A etapa de Modelagem visa investigar a natureza do hipertexto a ser construído. Os modelos definidos nesta etapa permitem implementar o hipertexto em uma plataforma específica, que é o objetivo da etapa de implementação. A etapa de Testes tem por objetivo identificar os ęrros ocorridos na etapa de implementação e verificar a validade educacional do hipertexto.

A etapa de Modelagem, que é o foco desta metodologia, objetiva estruturar um hipertexto antes de sua implementação. Esta etapa enfatiza a automação do processo de implementação e, sobretudo, o desenvolvimento de um projeto adequado, para que se possa gerar um hipertexto educacionalmẹnte válido.

A Modelagem consiste no desenvolvimento de quatro modelos: Modelo Orientado a Conceitos (MOC), Modelo de Páginas, Ferramentas Navegacionais e Modelo de Padrōes. 
O Modelo Orientado a Conceitos tem como finalidade elaborar uma estrutura coerente do conteúdo programático contido no hiperdocumento. No Modelo de Páginas, o conteúdo é mapeado para as páginas do hiperdocumento. A navegação entre páginas também é definida neste modelo. A interface gráfica com o usuário e os aspectos envolvidos na apresentação das páginas são definidos no Modelo de Padrões. As Ferramentas Navegacionais acrescentam outras formas de navegação, como índices e roteiros.

\subsubsection{Daphne - Definição de Aplicações Hipermídia na Educação}

O DAPHNE (Kawasaki \& Fernandes, 1996) é um modelo criado para desenvolver cursos hipermídia com base no HDM, Mapas Conceituais (Moreira \& Buchweitz, 1987; Faria, 1995) e na técnica de Mapeamento de Informação (Horn apud Santibañez \& Fernandes, $1998^{1}$ ).

Mapeamento conceitual é uma técnica de análise que pode ser utilizada para ilustrar a estrutura conceitual de uma fonte de conhecimento. Essa ilustração é chamada de mapa conceitual. De forma gerál, os mapas conceituais são diagramas hierárquicos que indicam os conceitos que serão apresentados e as relaçōes entre esses conceitos.

A técnica de Mapeamento de Informação consiste em dividir a informação em pedaços mais detalhados (blocos) para obter uma compreensão global do assunto (mapas). Os blocos de informação representam a menor porção de informação que pode ser recuperada individualmente. Quando esses blocos são organizados em estruturas maiores, denominam-se mapas de informação.

O modelo DAPHNE é composto por três camadas: Estrutura de Acesso Programado (EAP), Hiperbase e Estrutura de Acesso Direto (EAD).

A camada EAP contém mecanismos que permitem selecionar e ordenar os tópicos que o aluno terá acesso, conforme os objetivos do curso. Esta sequiência é previamente definida pelo autor do curso. Na camada Hiperbase encontram-se as informações do curso, organizadas segundo a combinação de Mapas Conceituais, HDM e Mapas de Informação. A camada EAD permite localizar um determinado bloco de informação de forma direta.

\footnotetext{
${ }^{1}$ Horn, R, E. Mapping Hypertext. Lexington: Lexington Institute, 1989. Apud Santibañez, M.R.F., Fernandes, C.T. SICH: Uma ferramenta para a Construção de Cursos Hipermídia na WWW. In: Simpósio Brasileiro de Informática na Educação (SBIE'98), Fortaleza. Anais, 1998.
} 
Conforme citado anteriormente, os ambientes educacionais descritos na seção 3.3 concentram-se na criaçãol da estrutura, armazenamento do conteúdo e controle de acesso ao material didático, delegando a tarefa de modelagem do conhecimento para o autor. Em relação aos métodos para projeto de aplicações hipermídia, descritos na seção 3.4, observa-se que eles fornecem primitivas para modelar o domínio da aplicação baseadas em diagramas Entidade-Relacionamentos ou em uma abordagem orientada a objetos. Portanto, esses métodos procuram abranger domínios genéricos e não cobrem todos os aspectos de um domínio mais específico, como o domínio de ensino. Além disso, os autores de hiperdocumentos educacionais encontram dificuldades para utilizar esses métodos porque seus modelos de representação não proporcionam uma linguagem adequada para essas aplicações. Sobre as metodologias para projeto de aplicações hipermídia educacionais abordadas na seção 3.5, pode-se dizer que elas possuem como restrição a necessidade de que o autor da aplicação domine técnicas como Mapas Conceituais e Mapeamento de Informações, o que pode trazer dificuldades para a descrição do domínio de conhecimento. Estas restrições, dentre outros fatores, motivaram o desenvolvimento do SASHE e do EHDM. Apresenta-se, a seguir, suas principais características.

\subsection{SASHE (Sistema de Autoria e Suporte Hipermídia para Ensino) e EHDM (Educational Hyperdocuments Design Method)}

O sistema SASHE foi desenvolvido com o objetivo de permitir que um autor de hiperdocumentos possa qualificar e organizar os elementos do documento, de modo que a aplicação final contenha funções adicionais à navegação tradicional. Para apoiar a modelagem de aplicações hipermídia para ensino, foi desenvolvido o EHDM, que propõe uma série de etapas de projeto e fornece modelos de representação adequados para modelar o domínio de conhecimento e os aspectos navegacionais dessas aplicações.

\subsubsection{O sistema SASHE}

SASHE é um ambiente de autoria e navegação de hiperdocumentos para aplicaçōes educacionais desenvolviłdo no Instituto de Ciências Matemáticas e de Computação da Universidade de São Paulo. O modelo de dados utilizado em sua implementação foi o Modelo de Contextos Aninhados (MCA) (Casanova et al., 1991). 
O MCA é um modelo conceitual para definição, apresentação e navegação de hiperdocumentos. A defínição de hiperdocumentos é baseada nos conceitos usuais de nós e elos. O modelo distingue duas classes básicas de nós: os nós terminais e os nós de composição, sendo esses últimos o ponto central do modelo.

Um nó terminal é um nó cujo conteúdo e conjunto de âncoras é dependente da aplicação. $O$ modelo permite a especialização da classe de nós terminais em outras classes (texto, gráfico, áudio, vídeo, etc). Um no de composição agrupa entidades, chamadas de componentes, incluindo outros nós de composição. A classe de nós de composição pode ser especializada em duas outras classes: nós de contexto e nós do tipo trilha.

O MCA básico trata um hiperdocumento como estruturas de dados essencialmente passivas. O modelo de apresentação do MCA trata dos aspectos de edição, apresentação e navegação através da estrutura dos hiperdocumentos.

Os mecanismos de navegação oferecidos pelo modelo são: navegação por elos, idéia essencial de hipermídia; navegaçã̉o por consulta, que permite ao usuário atingir um nó específico descrevendo propriedades que o nó satisfaz; navegação em profundidade (perspectiva), que é a ação de seguir o aninhamento de nós de composição, movendo-se para cima e para baixo na hierarquia de composiçōès; navegação através de browsers, que possibilita uma visão gráfica do hiperdocumento (ou parte dele); e navegação através de trilhas, que permite ao usuário seguir trilhas preestabelecidas ou definidas como default no hiperdocumento.

\subsubsection{Arquitetura do SASHE}

A Figura 3.1 apresenta a arquitetura do SASHE versão 2.0, com os módulos desenvolvidos para auxiliar a autoria (Modelagem e Importação). Esses dois módulos, juntamente com o módulo de Edição, que engloba os recursos de autoria existentes na versão 1.0 , compõem a camada de Autoria.

As camadas de Autoria e: Navegação utilizam-se das funções da camada Hip/Windows, que é uma extensão do ambiente HIP/Windows (Nunes et al., 1996) e que faz o mapeamento da estrutura gerada no móculo de autoria para uma hiperbase MCA. As setas da Figura 3.1 indicam que os módulos (Modelagem, Importação e Edição) utilizam diretamente as funções da camada Hip/Windows, não existindo módulo (ou interface) intermediário. Essa camada é 
composta por funções que manipulam uma hiperbase MCA, que consiste de um hiperdocumento estruturado segundo o MCA.



Figura 3.1 - Arquitetura geral do SASHE versão 2.0 (Haber, 1999; Pansanato, 1999)

\subsubsection{Módulo de Autoria do SASHE}

No módulo de Autoria o autor pode criar hiperdocumentos com vários níveis de aninhamento, sendo que a qualidade da navegação encontrada pelo aprendiz está diretamente relacionada a essa estruturação organizacional proposta pelo autor.

O módulo de Edição permite a construção de hiperdocumentos estruturados de acordo com as definições do MCA, utilizando apenas os conceitos de nó terminal (texto, gráfico, áudio e vídeo), nó de composição (trilha, contexto de usuário e hiperbase pública), âncora e elo.

A interface de edição utiliza o termo "Informação" para referir-se a um nó terminal devido a sua associação com um conteúdo (fragmento de informação) armazenado segundo uma mídia de representação. As informações (nós terminais) são classificadas quanto a função didática (motivação, introdução, definição, exemplo, exercícios, resumo, bibliografia e ajuda), dificuldade (baixa, regular e alta) e palavras-chave relacionadas ao conteúdo. Esses atributos são utilizados por estratégias tutoriais durante a navegação.

Após a autoria da estrutura, o autor pode definir um ou mais roteiros de navegação através do hiperdocumento. Um róteiro (nó composição do tipo trilha do MCA) é definido pela sequência de informações e contextos que serão apresentados durante a navegação. Para cada elemento da sequência do roteiro, o autor deve definir o grau de liberdade associado através da seleção de um dos contextos que contém o elemento. Essa característica distingue as aplicações criadas no SASHE daquelas criadas em outros sistemas. O objetivo desse comportamento é estabelecer um equilíbrio entre o controle do aprendiz e do sistema, de 
modo a oferecer um certo grau de orientação para que o aprendiz possa atingir seu objetivo sem perder a flexibilidade da leitura (Nunes \& Fortes, 1997).

O módulo de Importação do SASHE implementa o protótipo da ferramenta Html2Hip (Haber, 1999), que tem por objetivo permitir a importação e adaptação de documentos HTML para a representação interna do SASHE, que se baseia na estruturação de objetos multimídia segundo a hierarquia de classes propostas pelo MCA.

A relevância da ferramenta $\mathrm{Html} 2 \mathrm{Hip}$ está no fato de que ela permite que o autor possa importar hiperdocumentos HTML (do ambiente WWW, por exemplo), introduzir estratégias tutoriais/pedagógicas e agrupar os elementos de informação em contextos que tratam de um mesmo assunto (domínio de conhecimento), utilizando-se as funcionalidades do SASHE.

A inclusão do módulo de Modelagem foi motivada pelas dificuldades advindas da utilização do MCA. Com o objetivo de fornecer uma base para o desenvolvimento da ferramenta de modelagem, foi definido o Educational Hyperdocuments Design Method (EHDM) (Pansanato, 1999), que fornece uma série de etapas para o desenvolvimento de aplicações hipermídia para ensino, além de oferecer modelos de representação adequados para descrever o domínio de conhecimento e os aspectos navegacionais dessas aplicações. Este método é discutido na seção 3.6.2.

A Figura 3.2 apresenta a tela principal do módulo de autoria do SASHE, em que estão representadas, do lado esquerdo, a estrutura de uma aplicação hipermídia e, do lado direito, o conteúdo de dois nós da aplicação (a visualização do conteúdo dos nós permite ao autor navegar por protótipos dạ aplicação durante o desenvolvimento). 


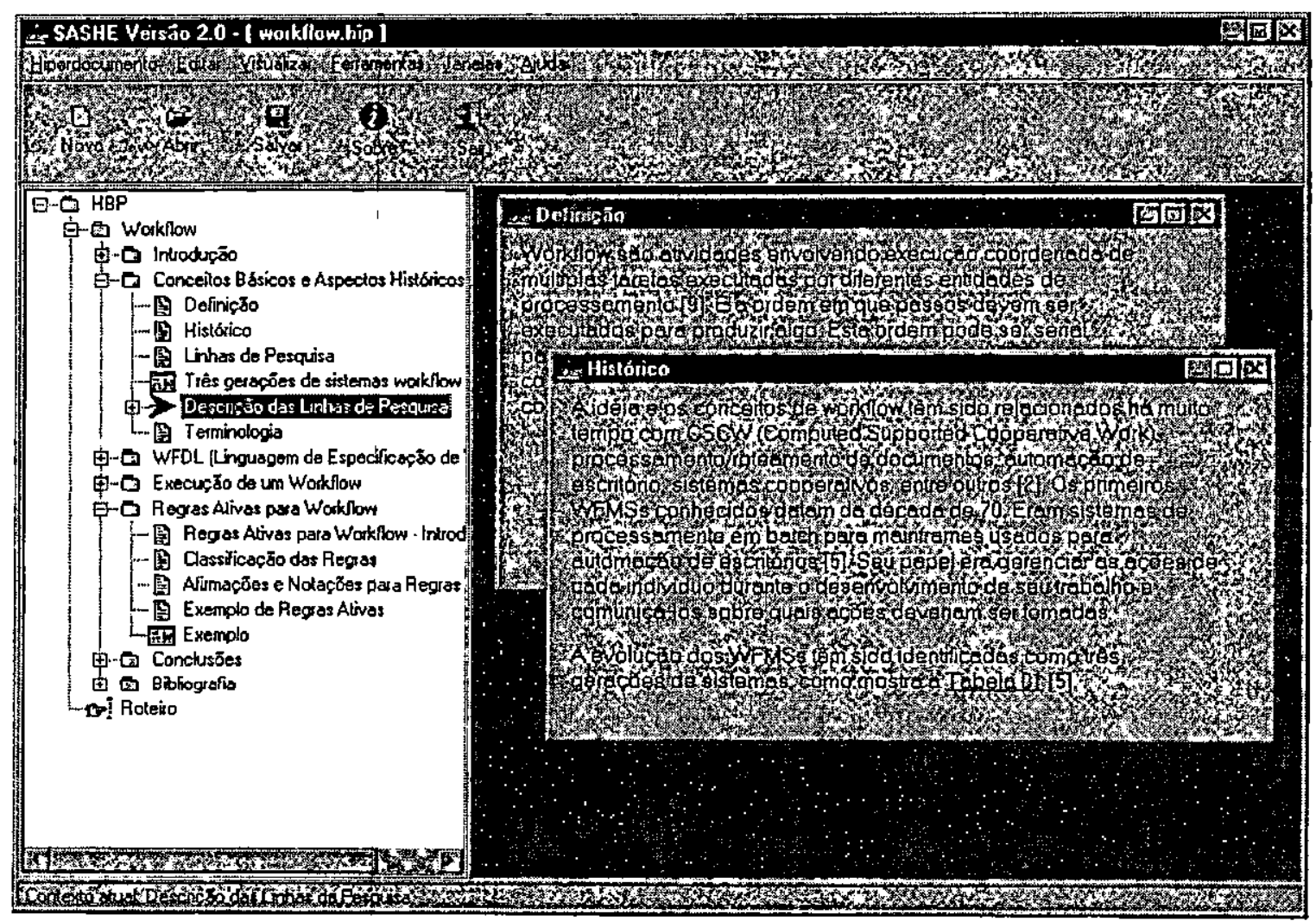

Figura 3.2 - Tela principal do módulo de Autoria do SASHE

\subsubsection{Módulo de Navegação do SASHE}

No módulo de navegação, o aprendiz encontra os recursos ilustrados pela Figura 3.3. Aos botões de navegação estão associadas funções que utilizam, em sua maioria, informações provenientes dos atributos e da contextualização dos nós de informação.

Os botões "Está Fácil" e "Está Difícil" remetem a estratégias que visam apresentar informações relacionadas ao tópico em questão (do mesmo contexto), porém julgadas de maior ou menor grau de dificuldade, respectivamente. Se o autor criou explicitamente um nó de informação correspondente e de grau de dificuldade diferente, então este será selecionado nessa busca. Caso contrário, uma segunda estratégia considera o atributo "função didática" para a seleção do próximo nó.

Essas buscas ocorrem primeiramente no próprio contexto. Se, após aplicar a primeira estratégia, o sistema não encontrar um nó de informação alternativo, aplica-se a segunda estratégia. No caso de sucessivas escolhas do mesmo botão ("Está Fácil" ou "Está Difícil"), aplica-se sempre a sequência "primeira estratégia/segunda estratégia", ou seja, sempre se 
procura por um nó de informação classificado pelo autor como mais fácil ou mais difícil do que o atual e apenas se nạ̃o for encontrado é que as correspondências entre atributos (segunda estratégia) são utilizadas.

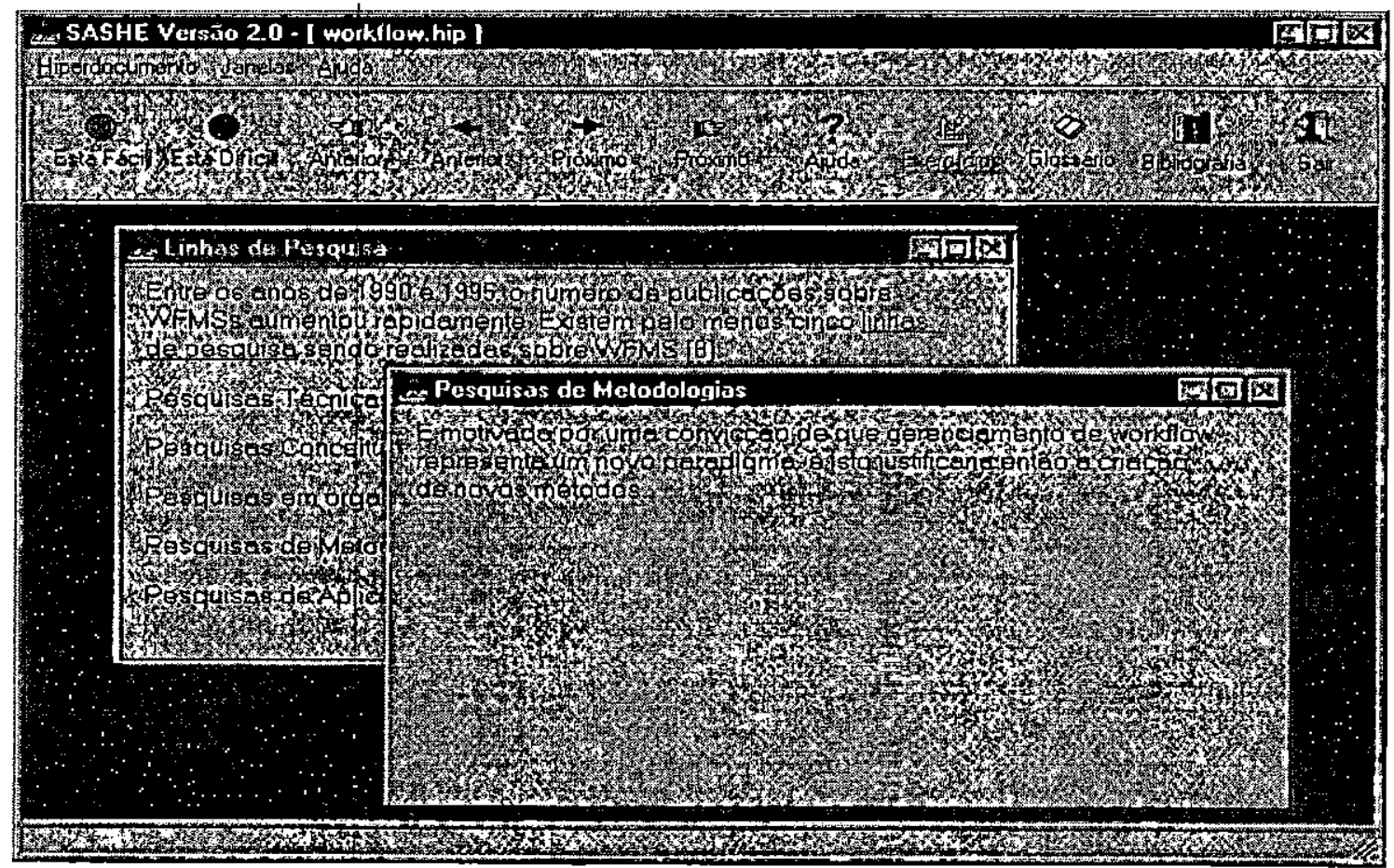

Figura 3.3 - Tela principal do módulo de Navegação do SASHE

Os botōes "Bibliografia" e "Glossário" fornecem informações úteis relativas ao domínio. A busca, nesse caso, ocorre no menor contexto que contém o nó de informação sendo visualizado/apresentado e a existência desses nós é dependente do processo de autoria.

O primeiro botão "Anterior" e o segundo botão "Próximo" servem para avançar e retroceder no roteiro criado pelo autor na autoria da aplicação. Os demais botões "Anterior" e "Próximo" servem para avançar e retroceder no caminho percorrido pelo aprendiz.

\subsubsection{EHDM - Educational Hyperdocuments Design Method}

A técnica de Mapas Conceituais (Faria, 1995; Moreira \& Buchweitz, 1987) e o modelo proposto por Michener (Michener, 1978) para representar o conhecimento matemático constituem a base teórica utilizada na definição do modelo conceitual para descrever o domínio de conhecimento de uma aplicação hipermídia para ensino, que constitui a primeira etapa de desenvolvimento de aplicações no EHDM. 
Conforme mencionado anteriormente, Mapas Conceituais são diagramas hierárquicos que indicam os conceitos que serão apresentados e as relações entre esses conceitos. O modelo de Michener indica três categorias de informação (conceitos, resultados e exemplos) para representar o conhecimento matemático. A categoria de Conceitos refere-se às definições e aos princípios matemáticos. A categoria de Resultados refere-se aos aspectos lógicos tradicionais da Matemática, isto é, aos teoremas e suas provas. Finalmente, a categoria de Exemplos, contém o material ilustrativo.

Com base nas teorias citadas anteriormente e nos principais métodos para projeto de aplicações hipermídia citados na seção 3.4, foi desenvolvido o EHDM, que tem como principal objetivo auxiliar o projeto de hiperdocumentos educacionais. A característica principal do EHDM é a utilização de primitivas de categorias de conhecimento e relacionamentos para modelar o domínio de conhecimento do hiperdocumento.

O EHDM é composto por três fases distintas: (1) modelagem conceitual hierárquica, (2) projeto navegacional de contextos, (3) construção e teste. Essas fases podem ser visualizadas na Figura 3.4. As setas de linhas cheias indicam a seqüência do processo e as setas com linhas pontilhadas os possíveis laços de realimentaçāo ("feedback loops").

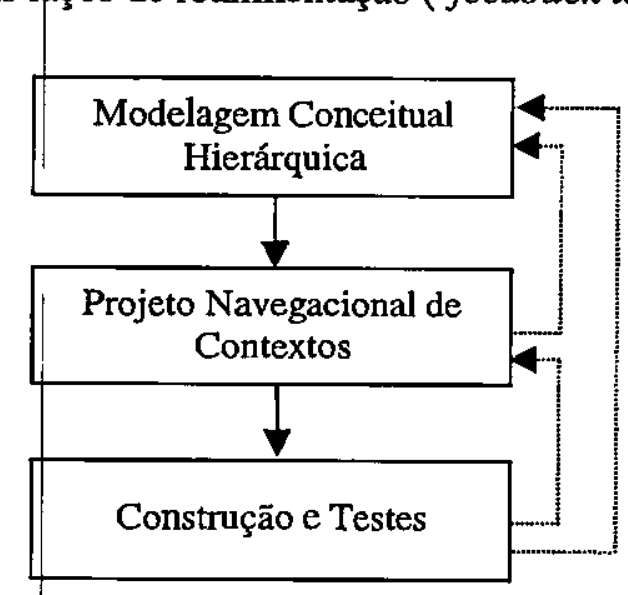

Figura 3.4 - Fases do método EHDM (Pansanato, 1999)

A fase de modelagem conceitual hierárquica consiste em estruturar o domínio de conhecimento, através da classificação de partes da teoria em categorias de conhecimento prédefinidas, e do estabelecimento de relações entre estas partes. O projeto navegacional de contextos deriva um modelo navegacional de contextos do modelo conceitual hierárquico criado na fase anterior. Contextos navegacionais, nós, elos e estruturas de acesso são

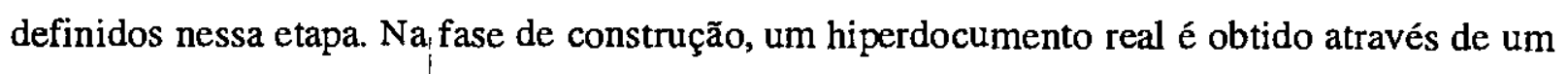
processo de tradução do modelo navegacional de contextos para uma plataforma hipermídia. 
Nessa fase também ocorrem os testes, que procuram identificar os erros ocorridos na construção do hiperdocumento.

\subsubsection{Modelagem Conceitual Hierárquica}

A fase de modelagem conceitual hierárquica tem como objetivo descrever o domínio de conhecimento escolhido para o hiperdocumento. Durante essa fase, um modelo conceitual hierárquico é construído para representar as partes relevantes do domínio de conhecimento e suas relações.

O EHDM fornece primitivas gráficas para representar as categorias e os relacionamentos de modo a facilitar a visualização do domínio de conhecimento modelado. É importante ressaltar que essas definições procuram extrapolar o domínio matemático com o objetivo de estender a modelagem para outros domínios.

O modelo conceitual hierárquico permite a classificação de partes de uma teoria em três categorias de conhecimento: Conceito, Resultado e Exemplo.

A categoria Conceito abrange as características, propriedades, atributos, regularidades e/ou observações de um objeto, fenômeno ou evento relativo a um domínio de conhecimento. De um modo geral, as descrições, definições, princípios e procedimentos podem ser considerados como conceitos.

Os conceitos podem ser estruturados através de relacionamentos indicando que um conceito A deve ser apresentado antes de um conceito B, refletindo uma relação de ordem pedagógica. Essa relação pode representar simplesmente uma preferência na seqüência de apresentação dos conceitos ou ainda que a seqüência é pedagogicamente necessária para o aprendizado (relação de pré-requisito). As primitivas gráficas para a categoria Conceito e para os relacionamentos "precedência preferencial" e "precedência necessária" são apresentadas na Figura 3.5.

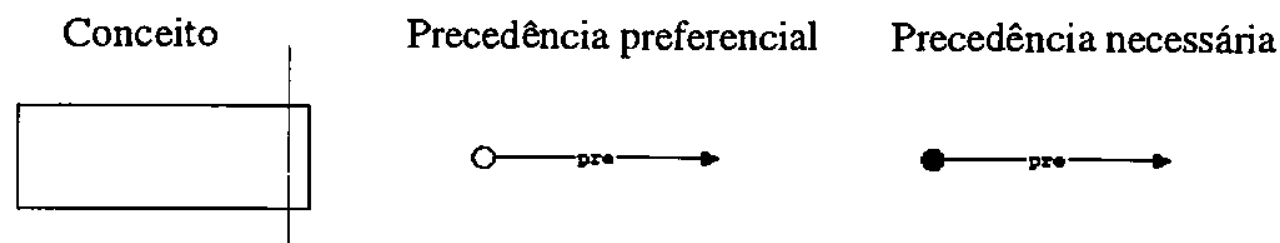

Figura 3.5 - Primitivas gráficas para a categoria Conceito e seus relacionamentos de ordem 
A categoria Resultado abrange as consequiências lógicas obtidas a partir de conceitos do domínio e de outros resiltados previamente estabelecidos. Essa categoria inclui teoremas, deduções, generalizações, consequiências e soluções.

Os resultados podem ser estruturados através de uma relação de dedução, indicando que um resultado A deduz (ou dẹriva/causa) um resultado B. As primitivas gráficas para a categoria Resultado e para o relacionamento "dedução" são apresentadas na Figura 3.6.
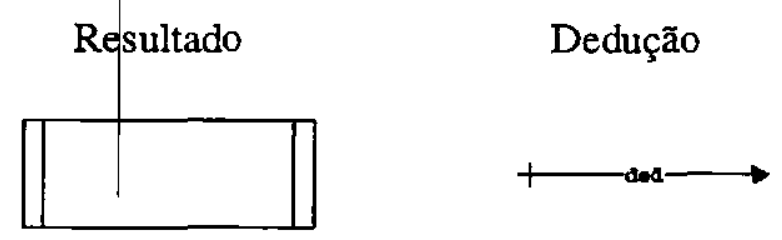

Figura 3.6 - Primitivas gráficas para a categoria Resultado e seu relacionamento de ordem

A categoria Exemplo abłange as instâncias individuais relativas a um conceito ou resultado identificado no domínio. As ilustrações e instanciações de conceitos e resultados são classificadas como exemplos.

Os exemplos podem ser estruturados por relacionamentos que refletem uma ordem de complexidade. Essa relação indica que um exemplo A é menos complexo (ou mais simples) que um exemplo B. As primitivas gráficas para a categoria Exemplo e para o relacionamento "complexidade" são apresentadas na Figura 3.7.



Figura 3.7 - Primitivas gráficas para a categoria Exemplo e seu relacionamento de ordem

O EHDM também fornece primitivas gráficas para relacionamentos que podem ser estabelecidos entre as categorias de conhecimento. $O$ conjunto de todos os relacionamentos definidos no modelo contribui para que o resultado de uma modelagem possa ser visto como um grafo orientado. Isso permite a automação de processos que explorem essas características.

O relacionamento "motivação / ilustração" relaciona a categoria Exemplo com as outras duas categorias (Conceito e Resultado). Quando o relacionamento parte de um exemplo, considerase que este exemplo é utilizado para motivar um conceito ou resultado. Por outro lado, quando 
um exemplo é destino ido relacionamento, ele é utilizado para ilustrar um conceito ou resultado. Os relacionamentos "necessidade" e "utilização" podem relacionar as três categorias de conhecimento. O relacionamento "necessidade" indica que um determinado item de uma categoria é necessário para discutir, descrever ou apresentar outro. O relacionamento "utilização" indica que um item de uma categoria utiliza outro como base para sua construção ou definição. As primitivas para esses relacionamentos são apresentadas na Figura 3.8.

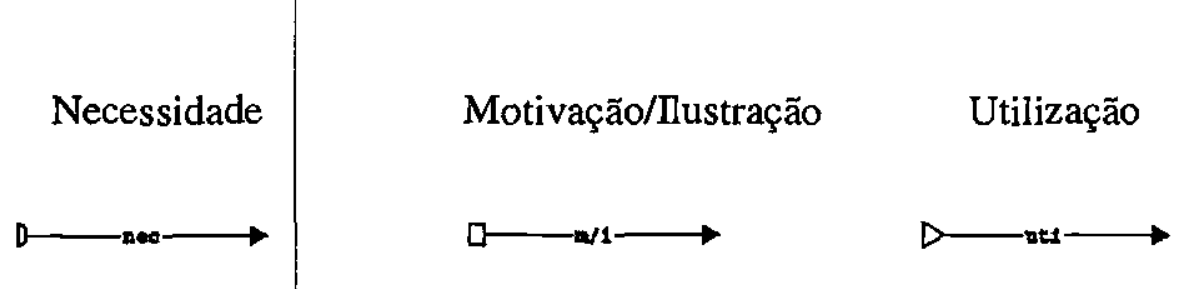

Figura 3.8 - Primitivas gráficas para os relacionamentos entre as categorias de conhecimento

O EHDM fornece um mecanismo para estruturar hierarquicamente o domínio de conhecimento. Partes do domínio que correspondem a elementos mais gerais, mais inclusivos, podem ser decompostas em elementos mais específicos em termos de detalhe e especificidade, criando uma hierarquia de elementos conceituais. Esse mecanismo de decomposição hierárquicá é baseado no princípio da diferenciação progressiva utilizado pelos Mapas Conceituais.

\subsubsection{Projeto Navegacional de Contextos}

As aplicações hipermídia são projetadas para efetuar navegação através de um espaço de informações. No EHDM, os aspectos navegacionais de um hiperdocumento são modelados durante a fase de projeto navegacional de contextos. O resultado dessa fase é um modelo navegacional de contextoș que representa um hiperdocumento.

$\mathrm{Na}$ fase de projeto navegacional de contextos, diferentes modelos navegacionais de contextos podem ser construídos, baseados no mesmo modelo conceitual hierárquico criado na fase anterior (modelagem conceitual hierárquica), e de acordo com propósitos educacionais diferentes. A motivação é permitir que usuários (aprendizes) diferentes vejam o mesmo conteúdo através de perspectivas diferentes.

No EHDM, vários modelos navegacionais de contexto podem ser derivados de um mesmo modelo conceitual hierárquico, enfatizando determinadas partes do domínio de conhecimento, e de acordo com o perfil do usuário a quem se destina o hiperdocumento. Essa abordagem é 
semelhante à proposta pelo OOHDM (Schwabe \& Rossi, 1995), que utiliza visões navegacionais do modelo conceitual, cada uma delas constituindo um tipo distinto de hiperdocumento. No OOHDM é utilizada uma linguagem de definição de visões orientadas a objetos, enquanto que no EHDM é especificado um mapeamento de elementos conceituais em navegacionais.

Um modelo navegacional de contextos define um conjunto de contextos e entidades navegacionais. Os contextos navegacionais determinam a estrutura (organização hierárquica) do hiperdocumento, enquanto as entidades navegacionais, nó e elo, especificam os elementos que são apresentados ao usuário. As estruturas de acesso (índices e roteiros) são utilizadas para proporcionar uma navegação adicional à realizada através dos elos. A Figura 3.9 mostra as primitivas gráficas para representar contexto navegacional, nó e elo.

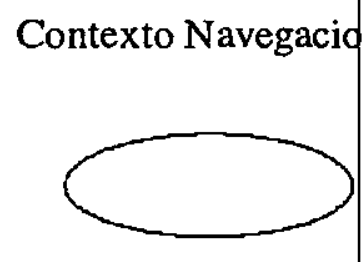

Nó

Elo

Figura 3.9 - Primitivas gráficas para modelagem navegacional

As estruturas de acesso índice e roteiro são utilizadas para proporcionar uma navegação adicional à realizada através dos elos. Nesse sentido, as estruturas de acesso permitem que um elemento do hiperdocumento seja visitado, mesmo quando não existem elos associando este a outros elementos.

Um índice é um conjunto de nós e contextos navegacionais que permite a navegação direta a um elemento do hiperdocumento especificado neste conjunto. Um índice pode ser definido através da especificação das entradas relativas aos nós e contextos que podem ser atingidos a partir do índice. Um roteiro é um conjunto de nós e contextos navegacionais que estabelece um caminho de navegação pelo hiperdocumento. Um roteiro pode ser definido através da especificação da sequiência dos nós e contextos selecionados para compor o roteiro.

\subsubsection{Construção e Testes}

Durante a fase de Constr ção e Testes, o modelo navegacional de contextos é convertido em objetos disponíveis no ambiente de implementação escolhido. O resultado, a aplicação hipermídia final, pode sef obtido através de três possíveis tipos de implementação (Carvalho, 
1998): interpretada, traduzida e de tradução livre.

A implementação interpretada requer um sistema capaz de interpretar e executar as especificações da aplicaçăo desenvolvida. A implementação traduzida consiste em traduzir as especificações em artefatos de algum sistema de autoria de aplicações hipermídia como HyperCard, ToolBook, HTML e apresentar a aplicação final utilizando um viewer ou um browser. A implementação com tradução livre não utiliza sistemas intermediários para interpretação, autoria ou apresentação.

O EHDM forneceu a base metodológica para o desenvolvimento do EHDT (Educational Hyperdocuments Development Tool) (Pansanato, 1999), desenvolvido como uma ferramenta de suporte automatizado integrada ao SASHE que proporciona um ambiente de modelagem para auxiliar a autoria de hiperdocumentos para ensino neste sistema.

Um exemplo de modelagem utilizando-se o EHDT pode ser visto no Apêndice A.

\subsection{Considerações Finais}

Neste capítulo foram apresentadas as principais características de alguns sistemas de autoria hipermídia para ensino que oferecem a possibilidade de enriquecimento dos ambientes de ensino-aprendizado, proporcionando uma nova forma de disseminação do conhecimento.

Além disso, foram abordados os principais métodos para projeto de aplicações hipermídia disponíveis na literatura. Em particular, o SASHE e o EHDM foram descritos mais detalhadamente, devido ao fato de terem servido como objeto de estudo para o desenvolvimento deste trabalho.

O capítulo seguinte refere-se à revisão bibliográfica realizada no contexto de requisitos para sistemas de autoria hipermídia educacional. 


\section{Capítulo 4}

\section{Requisitos para Sistemas de Autoria Hipermídia Educacional: Revisão Bibliográfica}

\subsection{Considerações Iniciais}

O estado da arte em termos de requisitos para ambientes de autoria hipermídia educacional revela que muitos trabalhos relacionados a este tema estão sendo desenvolvidos atualmente. Dessa forma, este capítulo descreve brevemente alguns trabalhos relacionados à definição de requisitos para sistemas de autoria hipermídia educacional revisados durante o desenvolvimento deste projeto.

\subsection{Trabalho desenvolvido por Campos (Campos, 1994; Campos et al.,} 1999)

Esse trabalho tem por objetivo propor requisitos para avaliação de qualidade para sistemas hipertexto/hipermídia, sob o ponto de vista de usuários-autores, de usuários selecionadores/avaliadores, de usuários leitores e de usuários co-autores (aqueles que farão a manutenção dos hiperdocumentos). Para isso, os autores fizeram uma extensa revisão bibliográfica sobre características gerais cujas implementaçōes são importantes para esses sistemas. Além disso, fọi realizado um estudo a respeito da utilização da hipermídia na educação, com o intuito de enfatizar as características relevantes para um ambiente educacional que proponha situaçōes de aprendizagem adequadas a uma prática pedagógica 
que estimule a construção do conhecimento.

Sob a perspectiva de usuários-autores, esse trabalho propõe requisitos de avaliação relacionados (1) à operacionalidade, (2) à portabilidade, (3) à eficiência, (4) à rentabilidade do sistema de autoria, (5) ao suporte à reutilização e (6) à manutenibilidade das aplicações desenvolvidas. Para isso, foram criadas listas de verificação (checklists) com o objetivo de facilitar o processo de avaliação dos sistemas hipermídia/hipertexto e hiperdocumentos educacionais a serem adquiridos ou desenvolvidos.

Como aspectos positivos desse trabalho, podem-se citar (1) a revisão bibliográfica realizada, que indicou diversos requisitos relacionadas ao contexto educacional, bem como registrou a opinião de vários autores sobre esse tema, e (2) o processo de validação ao qual os requisitos propostos nesse trabalho foram submetidos (Campos et al., 1999).

No entanto, alguns aspectos específicos do domínio de ensino, por exemplo, os recursos relacionados ao projeto da navegação das aplicações não foram explorados. Observa-se, ainda, que os autores não registraram possíveis utilizações do conjunto de requisitos proposto em avaliações de sistemas de autoria hipermídia.

\subsection{Trabalho desenvolvido por Britain (Britain, 1999)}

Britain apresenta requisitos para avaliação e comparação de ambientes educacionais sob a perspectiva de usuários-autores e usuários-leitores. Seu trabalho teve por objetivo propor uma metodologia de avaliação pedagógica para ambientes de aprendizado virtual, que permitisse determinar se uma nova tecnologia auxilia o processo de ensino e aprendizagem no contexto de uma determinada instituição.

O autor ressalta que um dos problemas associados aos ambientes educacionais é a falta de um método de avaliação coerente dentro do qual seja possível avaliar tanto os benefícios pedagógicos quanto as mudanças organizacionais requeridas para a sua efetiva utilização.

Considerando-se o fato de que geralmente as ferramentas de software são avaliadas em relação às características que elas fornecem, suas especificações técnicas e custo, o autor propõe um conjunto de requisitos para avaliação que considera as características inerentes ao 
domínio ao qual o software pertence, considerando, portanto, características pedagógicas para avaliação de ambientes de aprendizado virtual.

Esse trabalho aborda requisitos para ferramentas do professor, para ferramentas do aluno e requisitos para ferramentas de interação. No primeiro e segundo casos, são considerados o gerenciamento de recursos, de alunos e de cursos.

Apesar de o conjunto de requisitos proposto nesse trabalho apresentar-se bastante limitado, pode-se considerar como aspecto positivo o fato de o autor considerar características pedagógicas em sua proposta. Ressalta-se, no entanto, que tais requisitos não possuem a abrangência necessária, em termos pedagógicos e organizacionais, para decidir se determinado ambiente é melhor (ou mais adequado) que outro, pois não consideram aspectos relevantes para este domínio, como o controle/liberdade de navegação por parte dos alunos.

Além disso, os requisitos apresentados para avaliação e comparação de ambientes educacionais estão restritos ao gerenciamento de usuários, cursos e recursos oferecidos. Os aspectos relacionados aos requisitos genéricos que um ambiente de autoria hipermídia deve fornecer, como o suporte à geração de material (por exemplo, reutilização de aplicações, recursos que facilitem o desenvolvimento de novas aplicações) e à manutenibilidade de aplicaçōes, dentre outros, não foram considerados.

\subsection{Trabalho realizado no âmbito do projeto WebCT (Comparison of Online Course Delivery Software Products, 2000)}

O objetivo desse trabalho é permitir a comparação de diversos ambientes educacionais considerando-se uma extensa lista de requisitos relevantes para esses sistemas. São apresentados diversos requisitos para a cornparação de ambientes educacionais, categorizadas em: Características de Desenvolvimento, Ferramentas do Professor, Características Instrucionais, Ferramentas do Aluno, Suporte Técnico, Características Administrativas, Ferramentas Administrativas, Custos de Software e Custos de Hardware.

Como aspectos positivos desse trabalho pode-se citar o fato de estar em constante atualização, pois os autores sugerem que novos requisitos sejam incluídos, caso algum leitor de seu 
trabalho perceba essa necessidade. Além disso, novos ambientes educacionais podem igualmente ser acrescentados à lista daqueles avaliados.

No entanto, esse trabalho não considera os recursos que devem ser fomecidos para permitir a modelagem de uma aplicação. Além disso, não são registrados comentários a respeito da qualidade (completude, abrangência) do conjunto de requisitos proposto.

\subsection{Trabalho desenvolvido por Papatheodorou et al. (Papatheodorou et al., 1998)}

Esse trabalho propõe e avalia um framework para avaliação de sistemas de gerenciamento e desenvolvimento de aplicações hipermídia. As necessidades específicas dos usuários envolvidos no ciclo de vida de uma aplicação hipermídia e a experiência prática dos autores desse trabalho em desenvolver aplicaçōes hipermídia foram determinantes para a seleção dos requisitos de avaliação pertencentes ao framework proposto.

Os requisitos propostos são agrupados em três categorias: requisitos para avaliação da metodologia de desenvolvimento de aplicações hipermídia, requisitos para avaliação do ambiente e propriedades do sistema.

De forma a demonstrar a utilização do framework proposto, os autores realizaram um estudo comparativo envolvendo três sistemas existentes.

Apesar de essa proposta parecer bastante abrangente, os autores não registraram informaçōes relativas à qualidade dos requisitos propostos, fornecendo somente dados sobre os sistemas envolvidós no estudo de caso realizado.

\subsection{Outros Trabalhos}

Outros autores, entre eles, Balagopalan e Macknight (Balagopalan \& Macknight, 1989), Nanard e Nanard (Nanard \& Nanard, 1995) e Díaz e Isakowitz (Díaz \& Isakowitz, 1995), estabelecem requisitos cujas implementações são desejáveis em sistemas de autoria hipermídia genéricos e que podem, portanto, ser considerados em avaliaçōes de sistemas de 
autoria hipermídia educaçionais. Naturalmente esses trabalhos não consideram os requisitos relativos ao domínio de ensino.

\subsection{Considerações Finais}

Com a realização dessa fevisão bibliográfica, pôde-se observar que diferentes perspectivas foram consideradas nas propostas apresentadas. Por exemplo, algumas abordagens privilegiam aspectos gerais para sistemas de autoria hipermídia, enquanto outras tentam destacar os aspectos inerentes ao domínio de ensino.

Além disso, algumas restrições foram observadas nestes trabalhos, conforme mencionado nas seções anteriores. Dessa forma, foi realizado um trabalho de compilação de requisitos propostos em publicações da literatura visando à obtenção de um conjunto único de requisitos, que possa auxiliar satisfatoriamente a etapa de engenharia de requisitos de um novo sistema e a etapa de avaliação de sistemas existentes. O capítulo seguinte apresenta essa proposta. 


\section{Capítulo 5}

\section{Proposta de um Conjunto de Requisitos para Sistemas de Autoria Hipermídia Educacional}

\subsection{Considerações Iniciais}

O processo de desenvolvimento de um novo software é iniciado, de forma geral, pela atividade de definição é especificação dos requisitos segundo os quais o sistema será projetado e implementado. De acordo com Kotonya e Sommerville (Kotonya \& Sommerville, 1997), a engenharia de requisitos é o processo de estabelecimento de serviços que o sistema deverá fornecer e as restrições segundo as quais ele deverá operar. Portanto, a importância desta etapa no processo de desenvolvimento do software está relacionada à explicitação das características que definem o sistema.

Este capítulo tem por objetivo apresentar o conjunto de requisitos proposto neste trabalho, obtido a partir da pesquisa bibliográfica.

\subsection{Proposta de um Conjunto de Requisitos para Sistemas de Autoria} Hipermídia Educacional: Visão Geral

Os requisitos propostos neste trabalho foram classificados em (1) requisitos gerais para sistemas de autoria hipermídia e (2) requisitos para sistemas de autoria hipermídia educacional, conforme mostra a Figura 5.1. A primeira classe refere-se aos recursos que devem ser oferecidos por um sistema de autoria para possibilitar a construção de aplicações 
hipermídia sobre qualquer domínio, podendo ser utilizados, portanto, na etapa de engenharia de requisitos ou de avaliação de sistemas destinados a esta finalidade. A segunda classe refere-se aos recursos que devem ser oferecidos por um sistema de autoria para possibilitar a construção de uma aplicação do domínio específico de ensino. Analogamente, estes requisitos podem ser utilizados na etapa de engenharia de requisitos ou de avaliação de sistemas de autoria de aplicações parạ ensino.

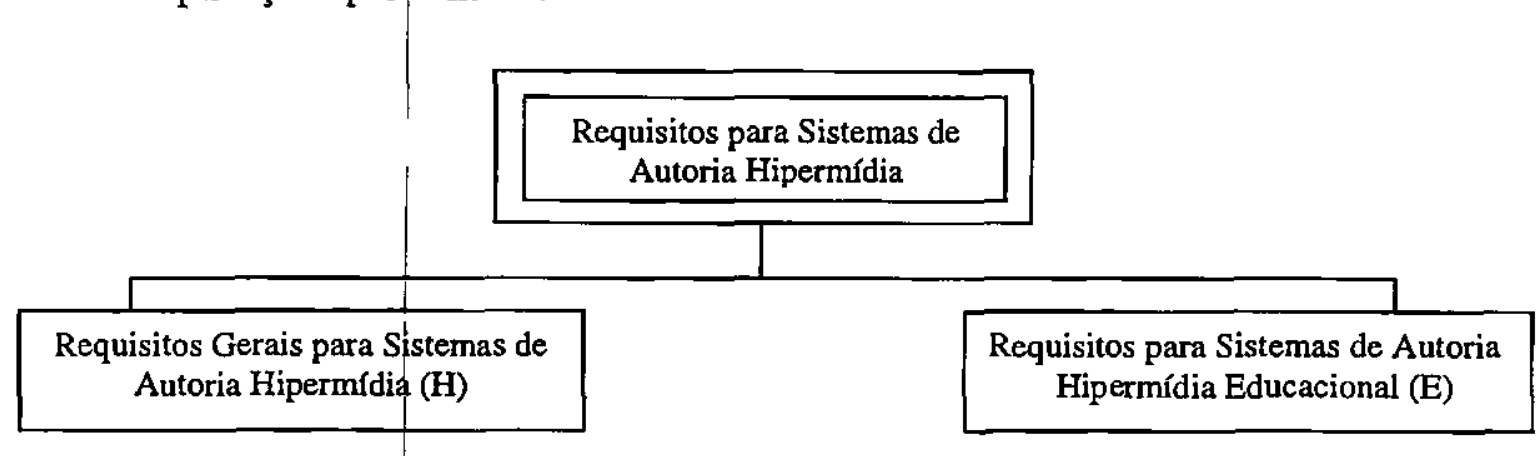

Figura 5.1 - Classificação para o conjunto de requisitos proposto

Adotou-se como critério a seleção de requisitos que haviam passado por algum processo de validação ou que forarn apresentados mais freqüentemente nas publicações, tendo sido priorizado o primeiro caso. Os requisitos foram definidos e especificados de forma a fornecer uma descrição abstrata em alto nível (definição) e uma descrição detalhada sobre o que o sistema deve possuir (especificação), conforme sugere Sommerville (Sommerville, 1996). Além disso, foram definidas questões que facilitam a avaliação desses requisitos em situações de teste. Estas questões consideram (1) a importância da implementação dos requisitos, segundo a opinião dos ạvaliadores; (2) a existência ou não dos recursos que satisfazem os requisitos; (3) a satisfaçằo do usuário no que se refere à qualidade da implementação e (4) a flexibilidade da implementação do recurso (possíveis extensões ou adaptações à implementação). Ressalta-se que outras métricas, por exemplo, a atribuição de notas à implementação dos requísitos, podem ser elaboradas e utilizadas.

\subsection{Requisitos Gerais para Sistemas de Autoria Hipermídia (H)}

Os requisitos apresentados nesta seção e na seção seguinte foram subdivididos em categorias. Esta subdivisão foi realjzada para simplificar o entendimento das duas classes mostradas na Figura 5.1, de forma a agrupar requisitos que apresentavam alguma semelhança entre si. É importante ressaltar que alguns requisitos são direcionados a sistemas que permitem a modelagem da aplicação. 
A Figura 5.2 mostrada a,seguir refere-se à síntese dos requisitos referentes à categoria $\mathrm{H}$.A, que trata do suporte à geração de material.

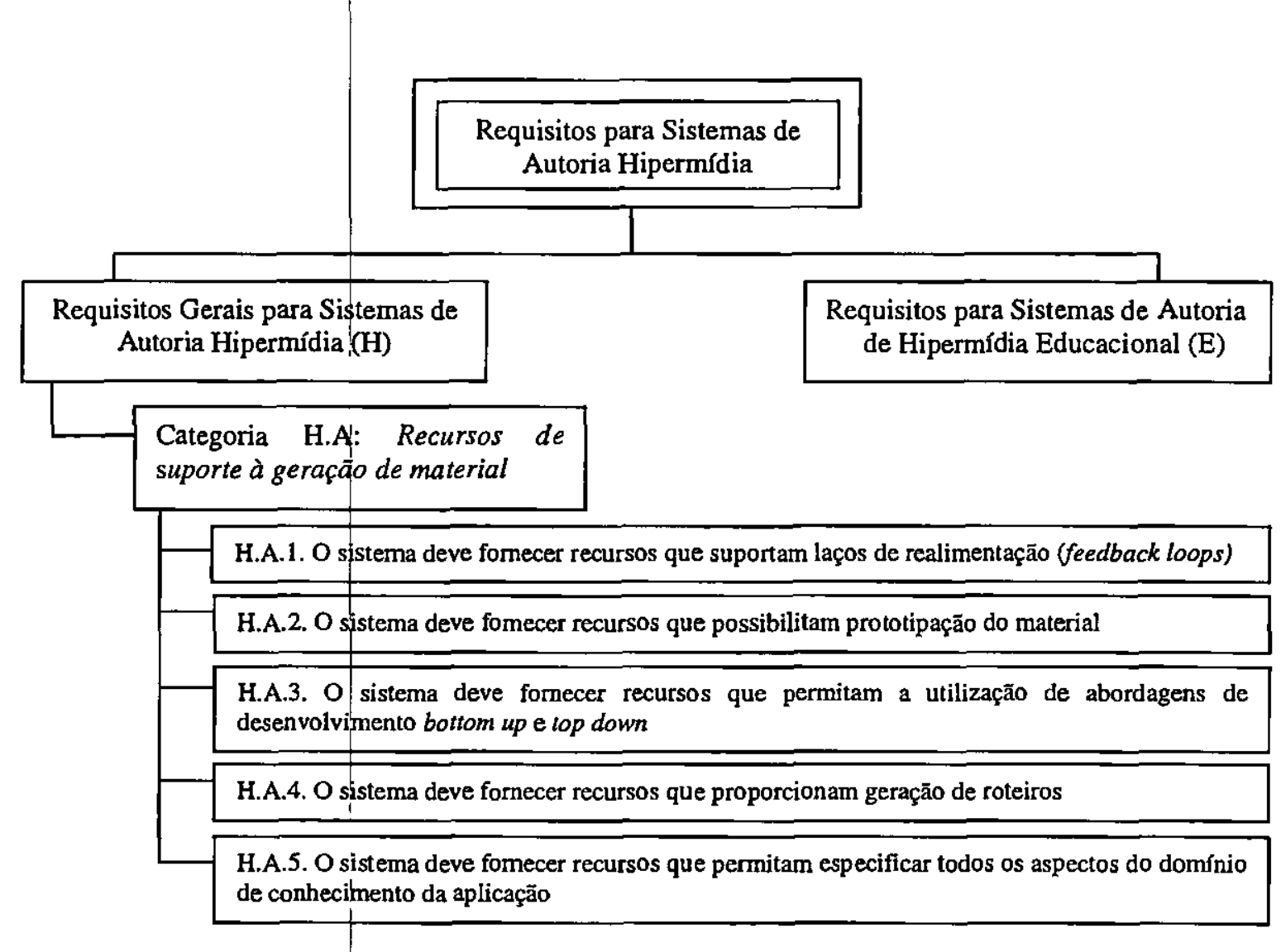

Figura 5.2 - Requisitos referentes à categoria H.A

Categoria H.A: Recursos de Suporte à geração de material: o sistema de autoria deve possibilitar que a geração de material seja uma atividade simples e que os recursos oferecidos para realização desta atividade sejam adequados e suficientes. Os recursos relacionados a esta categoria que devem ser oferecidos por um sistema de autoria são apresentados a seguir.

\section{H.A.1. O sistema deve fornecer recursos que suportam laços de realimentação (feedback} loops): o sistema de autoria deve permitir que o autor possa alternar entre as fases de projeto da aplicação (por exemplo, alternar entre as fases de modelagem do domínio de conhecimento e modelagem da navegação) e que os resultados obtidos em cada fase sirvam para apoiar a execução das demais faşes. Esses recursos facilitam as atividades de desenvolvimento e avaliação de uma aplicação (Nanard \& Nanard, 1995).

O sistema de autoria suporta laços de realimentação entre as fases de projeto da aplicação? Os recursos oferecidos auxiliam o desenvolvimento e a avaliação das aplicações? 
H.A.2. O sistema deve fornecer recursos que possibilitam prototipação do material: a possibilidade de gerar vărios protótipos de aplicação para um modelo criado facilita a geração da aplicação final. Este recurso é útil para que os autores possam testar algumas estruturas antes de decidir pela melhor, pois, a modelagem criada poderá ser avaliada objetivamente (em nível de instâncias) e as estruturas poderão ser reprojetadas e reconstruídas (em nível de abstração). Portanto, a ç̧iação de protótipos da aplicação permite a avaliação da modelagem desenvolvida (Nanard \& Nanard, 1995; Díaz \& Isakowitz, 1995).

O sistema de autoria fornece o recurso de prototipação? A implementação destes recursos é importante para o autor? Os mecanismos de prototipação dispońveis no sistema são satisfatóriфs? É fácil para o usuário gerar vários protótipos antes de decidir pelo melhor?

H.A.3. O sistema deve fornecer recursos que permitam a utilização de abordagens de desenvolvimento bottom up e top down: utilizar a abordagem de desenvolvimento bottom up significa abstrair modelos genéricos a partir de exemplos (instâncias) de um material. Por outro lado, a abordagem de desenvolvimento top down refere-se à instanciação de aplicações a partir de modelos previamente criados. Dessa forma, os sistemas de autoria devem permitir a abstração de modelos e a instanciação de aplicações a fim de estimular as atividades de estruturação e geração de aplicaçōes (Nanard \& Nanard, 1995).

O sistema de autoria fornece recursos para utilização de abordagens de desenvolvimento bottom up e top down? Os recursos fornecidos pelo sistema para utilização destas abordagens são satisfatórios?

H.A.4. O sistema deve fornecer recursos que proporcionam geração de roteiros: a partir de uma aplicação criada, 0 autor deve poder estabelecer uma seqüência de nós que oriente o usuário-leitor durante a exploração do material, de forma que os objetivos dos autores e leitores possam ser de fato alcançados. Além disso, o autor deve poder definir diferentes roteiros de navegação, vişando grupos diferentes de usuários, ou seja, diferentes "visões" do mesmo material devem poder ser criadas de acordo com os objetivos do autor (Kearsley, 1982; Papatheodorou et al., 1998; Zellwegger, 1989).

O sistema de autoria implementação destes

permite a geração de diversos roteiros de forma fácil? A recursos é importante para o autor? Alguma dificuldade foi 
encontrada na atividade de criação de roteiro? A flexibilidade oferecida para a geração desses roteiros atende às necessidades do usuário-autor?

\section{H.A.5. O sistema deve fornecer recursos que permitam especificar todos os aspectos do} domínio de conhecimento da aplicação: sistemas de autoria que permitem a especificação do domínio de conhecimento devem possuir um conjunto de primitivas para especificação das aplicações que sejam suficientes para modelar todos os aspectos do domínio de conhecimento (Hall \& Mendes, 1999).

As primitivas oferecidas pelo sistema de autoria são suficientes, no que se refere à quantidade/qualidade, para a realização da modelagem de uma aplicação hipermídia para o domínio do ensino? Quais seriam possíveis extensões ou adaptações para o conjunto de primitivas disponivel? A modelagem do domínio de conhecimento pode ser estruturada hierarquicamente? A implementação desse recurso atende às necessidades do usuário-autor?

A Figura 5.3 mostrada a seguir refere-se à síntese dos requisitos referentes à categoria H.B, que trata dos recursos de edição e alteração da aplicação.

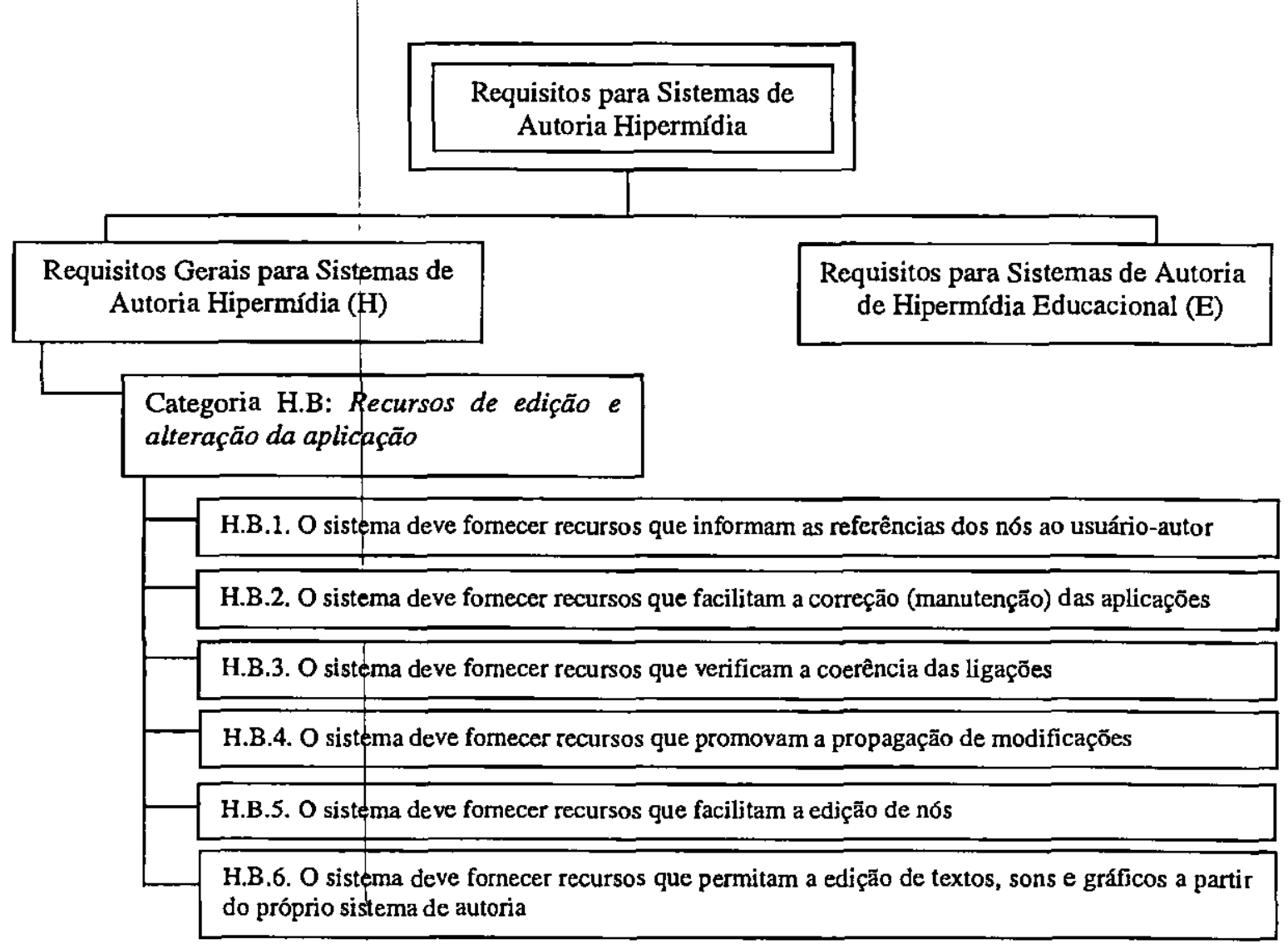

Figura 5.3 - Requisitos referentes à categoria H.B 
Categoria H.B: Recursos de edição e alteração da aplicação: o sistema de autoria deve promover fácil edição e alteração das aplicações, de forma a incentivar seu uso. Os recursos relacionados a esta categoria que devem ser oferecidos por um sistema de autoria são apresentados a seguir.

\section{H.B.1. O sistema deve fornecer recursos que informam as referências dos nós ao usuário-autor: o sistema de autoria deve fornecer uma lista de ligaçōes do nó corrente, para} que os autores possam visualizar facilmente quais os nós que referenciam e são referenciados por determinado nó. Estes recursos são particularmente importantes durante a manutenção (alteração, exclusão de nós) dos modelos da aplicação (Campos, 1994).

O sistema de autoria fornece a lista de ligações do nó que está sendo cditado? A implementação destes recursos é importante para o autor? As informações fornecidas são satisfatórias para mantê-lo informado sobre as referências dos nós durante o processo de autoria?

H.B.2. O sistema deve fornecer recursos que facilitam a correção (manutenção) das aplicações: o sistema de autoria deve permitir a correção das aplicações, possibilitando que atividades como modificação dos dados referentes aos seus componentes (nome do componente, arquivo a que está vinculado), inserção, alteração ou remoção de nós e ligações possam ser facilmente executadas (Hall \& Mendes, 1999).

A manutenção das aplicações ocorre de forma simples? Alguma dificuldade foi encontrada na realização desta atividade?

H.B.3. O sistema deve fornecer recursos que verificam a coerência das ligaçōes: o sistema de autoria não deve permitir que as referências (ligações) se tornem incoerentes quando um nó é modificado ou excluído (Campos, 1994; Papatheodorou et al., 1998).

Quando um nó é modificado, as referências a este nó são atualizadas automaticamente? Quando um nó é excluído, o sistema remove automaticamente todas as referências a ele? A implementação desses recursos é importante para o autor?

H.B.4. O sistema deve fornecer recursos que promovam a propagação de modificações: o sistema de autoria deve executar a propagação de modificações feitas a propriedades ou 
conteúdos de nós que são idênticos e que aparecem em níveis diferentes na estruturação hierárquica da aplicação. Estes recursos favorecem a consistência da modelagem (Campos, 1994).

As modificação realizadas em um nó são automaticamente atualizadas em todos os níveis em que ele aparece? A implementação desses recursos é importante para o autor?

H.B.5. O sistema deve fornecer recursos que facilitam a edição de nós: o sistema de autoria deve permitir que as informações relativas aos nós ou contextos de uma aplicação (por exemplo, nome do nó, tip o de mídia relacionada à apresentação do nó, escolha do arquivo que estará associado ao nó) sejjam facilmente editadas (Campos, 1994).

As informações relativas aos nós e contextos da aplicação são fáceis de editar? Alguma dificuldade foi encontrada na realização dessa atividade?

H.B.6. O sistema deve fọrnecer recursos que permitam a edição de textos, sons e gráficos a partir do próprio sistema de autoria: o sistema de autoria deve permitir o acesso (a partir do próprio sistema) a um editor de textos, de sons e de gráficos externos ou possuir recursos de edição equivalentes (Campos, 1994; Santos Jr., 1998; Papatheodorou et al., 1998).

O sistema de autoria permite a edição de texto, som e gráficos externa ou internamente ao sistema? A implementação desses recursos é satisfatória às necessidades do usuárioautor?

A Figura 5.4 mostrada a seguir refere-se à síntese dos requisitos referentes à categoria H.C, que trata dos recursos que possibilitam a evolução da aplicação. 




Figura 5.4 - Requisitos referentes à categoria H.C

Categoria H.C: Recursos que facilitam a evolução da aplicação: o sistema de autoria deve ser capaz de gerenciar versões da aplicação e apoiar o trabalho cooperativo, de forma a facilitar a construção das aplicações. Os recursos relacionados a esta categoria que devem ser oferectdos por um sistema de autoria são apresentados a seguir.

H.C.1. O sistema deye fornecer recursos que suportam o gerenciamento e armazenamento de versōes das aplicações hipermídia: o sistema de autoria deve facilitar evoluções da aplicação permitindo acrescentar novos nós, ligações e contextos e, consequentemente, gerar novas versões da aplicação (Campos, 1994; Papatheodorou et al., 1998).

O sistema de autoria registra as diversas versões da aplicação? A implementação desses recursos é satisfatória às necessidades do usuário-autor? É importante para o autor o suporte ao gerenciamento de versões? Quais seriam possíveis extensões ou adaptações para os recursos fornecidos?

H.C.2. O sistema deve fornecer recursos que apóiam o trabalho cooperativo: o sistema de autoria deve estabelecer uma área para que os autores colaborem na autoria de um mesmo nó e áreas específicas individuais para cada autor (Campos, 1994; Hall \& Mendes, 1999; Papatheodorou et al., 1998). 
O sistema de autoria prevê o trabalho cooperativo dos autores? A implementação destes recursos é importante para o autor? Os recursos disponíveis para a realização desta atividade são satisfatórios? Quais seriam possíveis extensões ou adaptações para os recursos fornecidos?

A Figura 5.5 mostrada a seguir refere-se à síntese dos requisitos referentes à categoria H.D, que trata dos recursos que tornam amena a utilização do sistema de autoria.

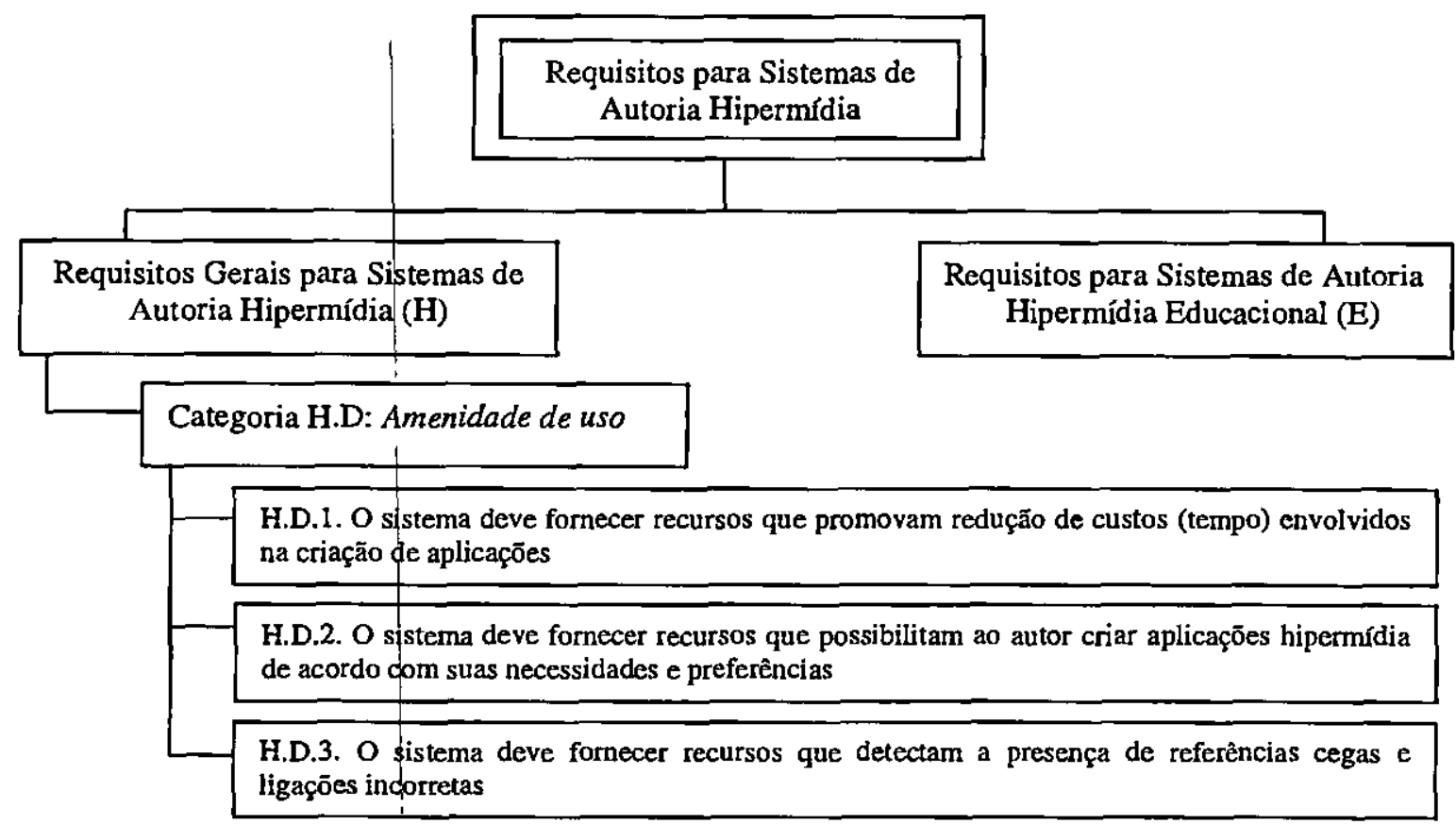

Figura 5.5 - Requisitos referentes à categoria H.D

Categoria H.D: Amenidade de uso: os recursos oferecidos pelo sistema de autoria devem gerar satisfação e confiança ao usuário durante todo o processo de autoria. Os recursos relacionados a esta categoria que devem ser oferecidos por um sistema de autoria são apresentados a seguir.

H.D.1. O sistema deve fornecer recursos que promovam redução de custos (tempo) envolvidos na criação de aplicações: o processo de modelagem de uma aplicação deve proporcionar ganhos em relação à abordagem de construção direta (de forma ad hoc) (Balagopalan \& Macknight, 1989; Kearsley, 1982).

Comparando-se o processo de modelagem da aplicação à construção direta da aplicação, o usuário-autor pode perceber algum ganho ao utilizar a primeira abordagem? 
H.D.2. O sistema deve fornecer recursos que possibilitam ao autor criar aplicações hipermídia de acordo com suas necessidades e preferências: a aplicação criada não deve ser influenciada pelas características e condições do sistema de autoria utilizado para construção, ou seja, o sistema de autoria deve permitir a criação de aplicações que implementem todos os requisitos estabelecidos para seu desenvolvimento (Hall \& Mendes, 1999).

A implementação e a interface da aplicação foram influenciadas pelas características do sistema de autoria? Há necessidade de se fazer alguma extensão ou adaptação no módulo de autoria de forma que este permita ao usuário-autor criar aplicações de acordo com suas necessidades e preferências?

\section{H.D.3. O sistema deve fornecer recursos que detectam a presença de referências cegas e} ligações incorretas: o sistema de autoria não deve permitir a presença de referências cegas (ligações cujos nós destinos não foram criados) e de ligações incorretas (Campos, 1994).

O sistema de autoria detecta referências cegas e ligações incorretas? O usuário é notificado, de forma objetiva, quando esse tipo de problema ocorre? A implementação desses recursos é importante para o autor? Quais seriam possíveis extensões ou adaptações para os recursos fornecidos?

A Figura 5.6 mostrada a seguir refere-se à síntese dos requisitos referentes à categoria H.E, que trata dos recursos de help oferecidos pelo sistema de autoria.

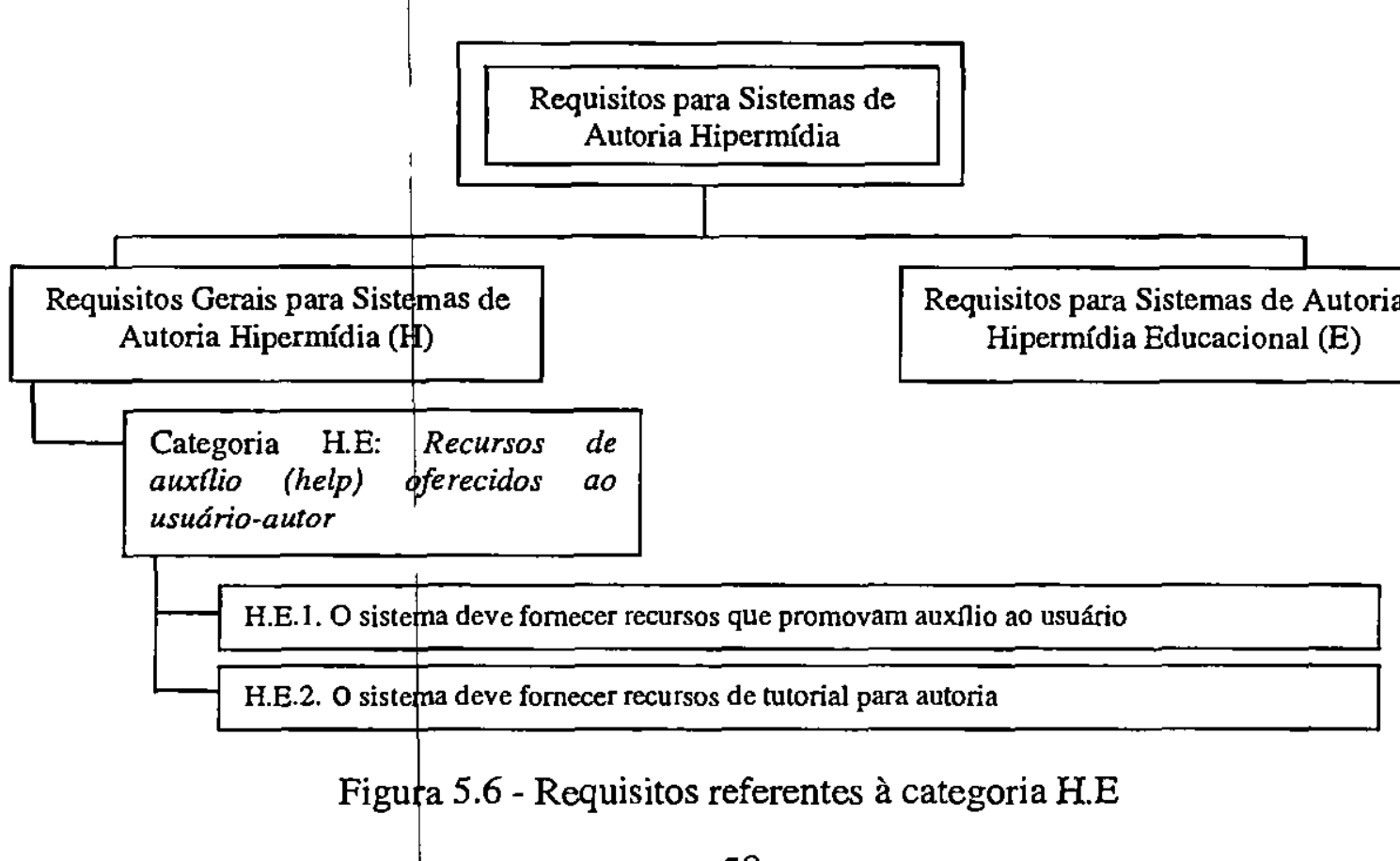


Categoria H.E: Recursos de auxílio (help) oferecidos ao usuário-autor: o sistema de autoria deve fornecer recursos que esclareçam e orientem o usuário quando o módulo de ajuda é requisitado, de forma a estimular seu uso. Os recursos relacionados a esta categoria que devem ser oferecidos por um sistema de autoria são apresentados a seguir.

H.E.1. O sistema deve fornecer recursos que promovam auxílio ao usuário: o sistema de autoria deve dispor, em tempo hábil, de instruções que norteiem a continuação do processo de autoria, de forma a auxiliar usuários novatos a aprenderem a usar o sistema e esclarecer usuários experientes durante o processo de autoria (Campos, 1994; Papatheodorou et al., 1998).

O sistema possui informações explicativas sobre o processo de autoria no instante em que o usuário desejar? Os recursos oferecidos são satisfatórios às necessidades do usuário-autor? Quais seriam possíveis extensōes ou adaptações dos recursos disponíveis?

H.E.2. O sistema deve fornecer recursos de tutorial para autoria: o sistema de autoria deve possuir um tutorial que mostre, de forma simples, como é o processo de autoria da aplicação, fornecendo ao usuário uma visão geral das etapas a serem executadas e das principais características do processo de autoria (Campos, 1994).

O sistema de autoria fornece um tutorial para o processo de autoria? A implementaçăo desses recursos é importante para o autor? Esse tutorial é satisfatório às necessidades do usuário-autor? Quais seriam possíveis extensōes ou adaptações para os recursos fornecidos?

A Figura 5.7 mostrada a seguir refere-se à síntese dos requisitos referentes à categoria H.F, que trata dos recursos de documentação fornecidos pelo sistema. 


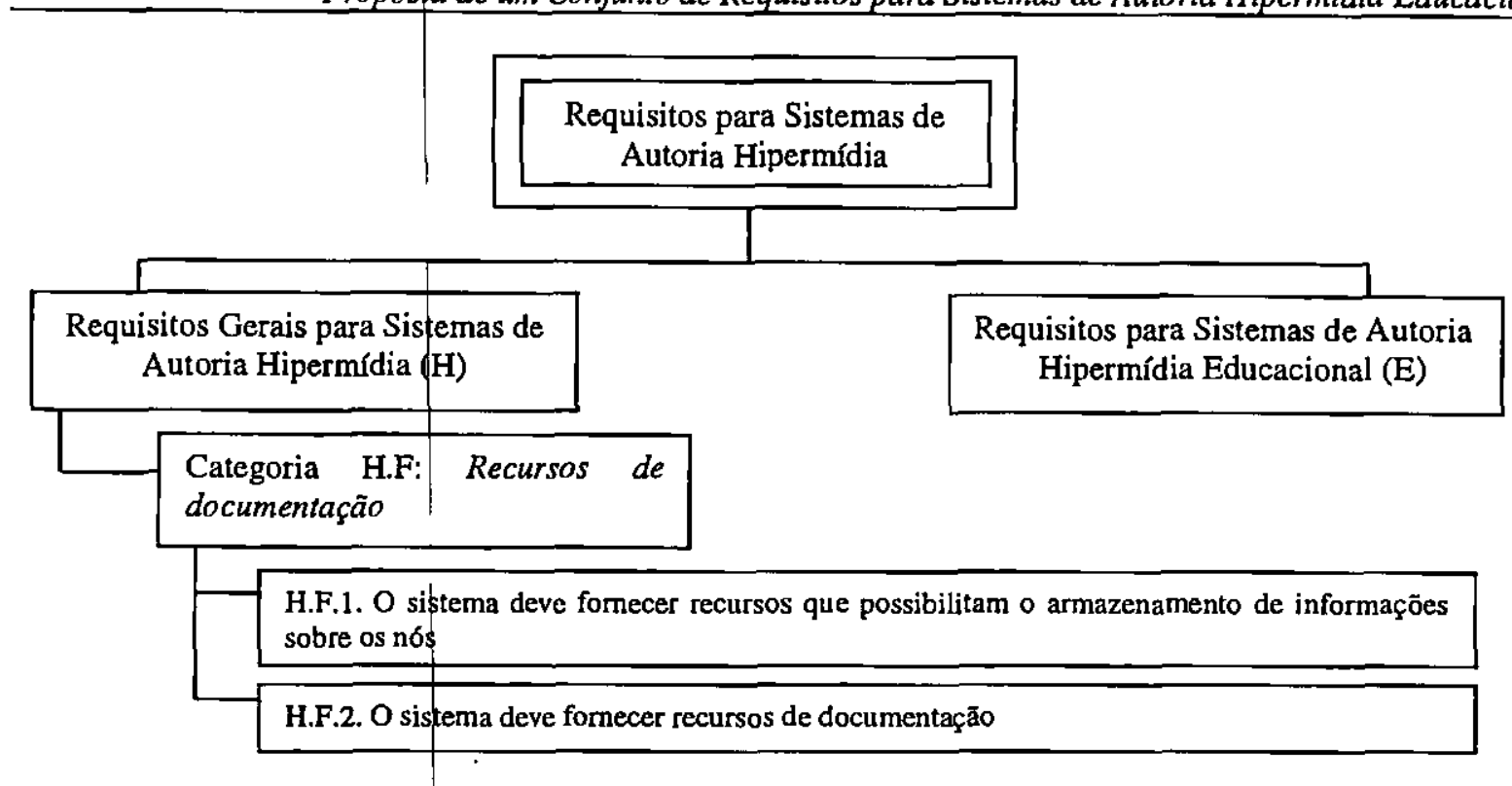

Figura 5.7 - Requisitos referentes à categoria H.F

Categoria H.F: Recursos de documentação: o sistema de autoria deve fornecer recursos para documentação das aplicações hipermídia desenvolvidas pelos usuários-autores e também documentação do próprio sistema de autoria. Os recursos relacionados a esta categoria que devem ser oferecidos por um sistema de autoria são apresentados a seguir.

\section{H.F.1. O sistema deve fornecer recursos que possibilitam o armazenamento de} informações sobre os nós: o sistema de autoria deve armazenar informações como a data de criação e modificação de um nó, os dados do usuário e as observações ou comentários relativos ao nó, de forma a permitir uma documentação rápida de dados relacionados ao processo de autoria (Campos, 1994; Kearsley, 1982).

O sistema de autoria armazena informações sobre os nós? Este recurso é importante para o autor? As informações que o sistema permite armazenar são suficientes para permitir ao autor registrar tudo o que for importante para determinado no? Quais seriam possíveis extensões ou adaptações para o conjunto de informações que o sistema aceita?

H.F.2. O sistema deve fornecer recursos de documentação: o sistema de autoria deve possuir manual de detalhamento de funções, de forma a suportar a etapa de manutenção do sistema (Campos, 1994).

O sistema de autoria possui documentação? Ela é satisfatória às necessidades de usuários novatos e experientes? Quais seriam possíveis extensões ou adaptações para os recursos fornecidos? 


\subsection{Requisitos para Sistemas de Autoria Hipermídia Educacional (E)}

Os requisitos apresentados a seguir consideram as características inerentes ao domínio de ensino, podendo ser utilizados, portanto, nas etapas de engenharia de requisitos ou avaliação de sistemas pertencentes a este domínio.

A Figura 5.8 mostrada a seguir refere-se à síntese dos requisitos referentes à categoria E.A, que trata dos recursos disponíveis à fase de projeto de aplicações hipermídia para ensino.

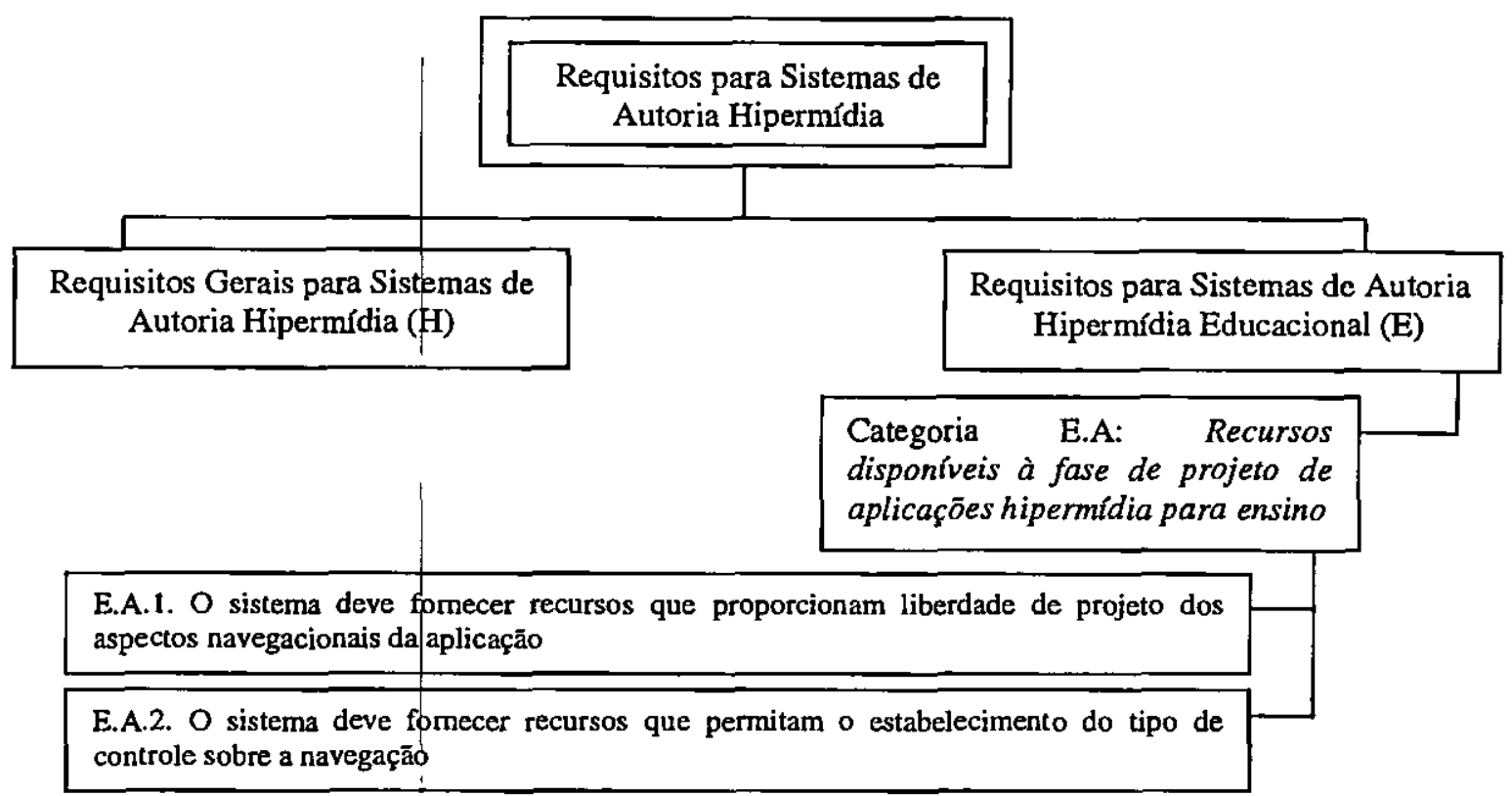

Figura 5.8 - Requisitos referentes à categoria E.A

Categoria E.A: Recursos disponíveis à fase de projeto de aplicações hipermúdia para ensino: alguns recursos relacionados ao projeto da navegação de aplicações do domínio de ensino devem ser implementados em sistemas de autoria, de forma a assegurar que os objetivos pedagógicos dd professor possam ser satisfeitos durante a construção de uma aplicação. Os recursos relacionados a esta categoria que devem ser oferecidos por um sistema de autoria são apresentados a seguir.

E.A.1. O sistema deve fornecer recursos que proporcionam liberdade de projeto dos aspectos navegacionais da aplicação: além da possibilidade de mapeamento direto do modelo conceitual para o projeto da navegação (caso o sistema forneça recursos para a construção destes modelos), o professor deve poder utilizar o rnodelo conceitual como uma orientação para projetar a aplicação, ou seja, os aspectos navegacionais da aplicação devem 
poder ser modelados de acordo com as preferências do professor, não estando vinculados somente à fase de modelagem do domínio de conhecimento. A implementação desses recursos é particularmente importante no domínio de ensino devido à necessidade de se estruturar e apresentar informações de acordo com objetivos pedagógicos. Por exemplo, um determinado elemento conceitual deve poder ser mapeado em diferentes nós do projeto navegacional: o primeiro correspondendo a uma apresentação da teoria, o segundo a um exemplo e o terceiro a um exercício (Pansanato, 1999).

O professor possui liberdade para projetar os aspectos navegacionais da aplicação em relação à modelagem do domínio de conhecimento? Alguma dificuldade foi encontrada na realização dessa atividade?

\section{E.A.2. O sistema deve fornecer recursos que permitam o estabelecimento do tipo de} controle sobre a navegação: o professor deve poder determinar "quanto" de controle sob a navegação da aplicação deve ser atribuído ao aprendiz, no sentido de perseguir um objetivo em relação a uma proposta didática subjacente. Ele deve poder estabelecer se o aprendiz terá acesso a todos os nós da aplicação ou somente a alguns deles. Isso pode ser feito, por exemplo, definindo-se o grau de liberdade (total, parcial ou nenhum) associado a cada nó (Nunes \& Pansanato, 1999a).

O professor pode estabelecer o tipo de controle sobre a navegação? A implementação destes recursos é importante para o professor? A forma segundo a qual o usuário-autor estabelece o tipo de controle sobre a navegação no SASHE é satisfatória?

A Figura 5.9 mostrada a seguir refere-se à síntese dos requisitos referentes à categoria E.B, que trata dos recursos que possibilitam a distinção de material. 


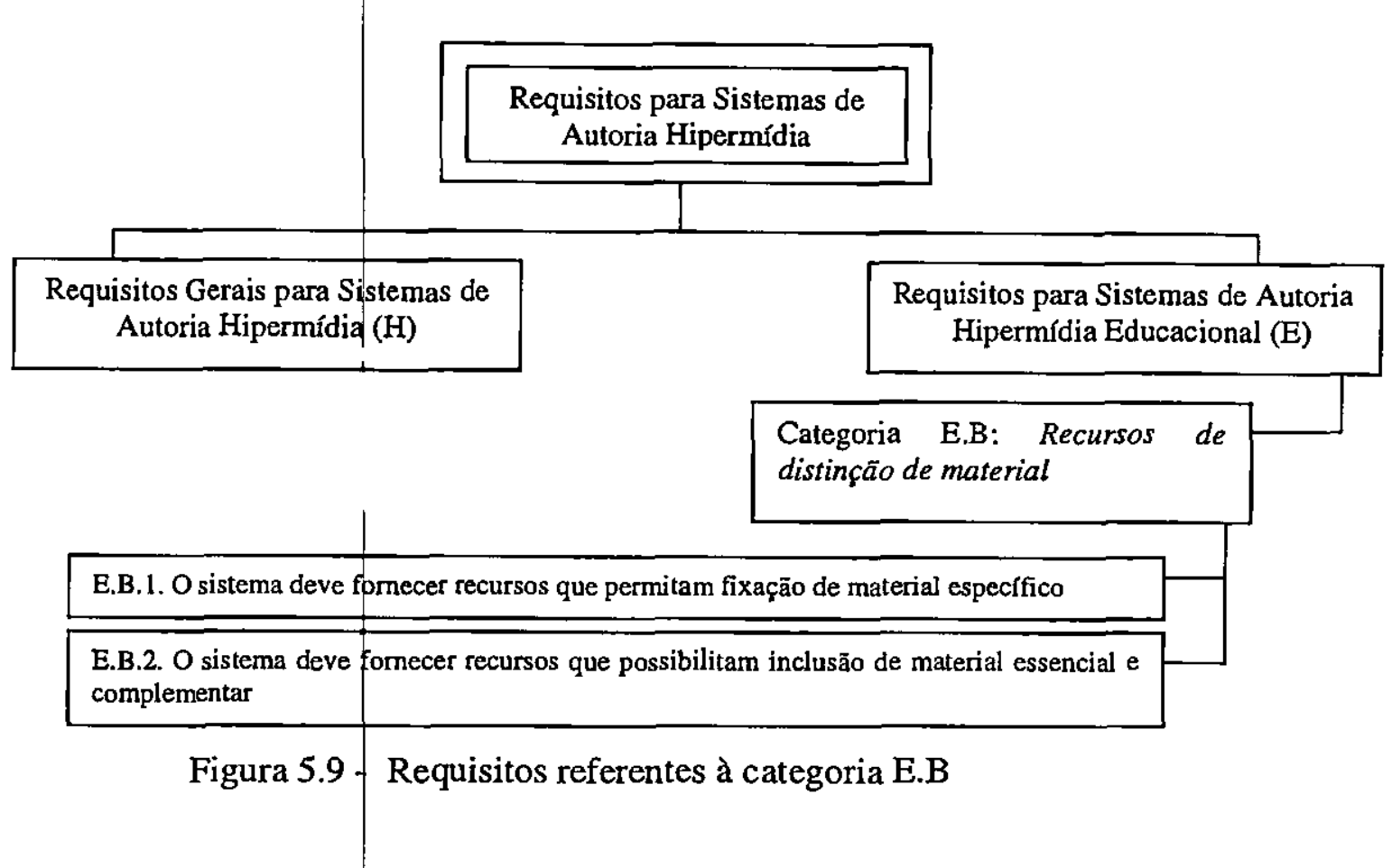

Categoria E.B: Recursos de distinção de material: no domínio de ensino, torna-se às vezes necessário diferenciar entre o material que será necessariamente apresentado do material que será apresentado somente se o aprendiz requisitá-lo. Os recursos relacionados a esta categoria que devem ser oferecidos por um sistema de autoria são apresentados a seguir.

E.B.1. O sistema deve fornecer recursos que permitam fixação de material específico: $O$ autor da aplicação deve poder designar material específico para estudantes ou grupos de estudantes. Esses recursos possibilitam que questões relacionadas à prática pedagógica (por exemplo, divisão de temas de trabalho por grupos de alunos) possam ser conservadas ao utilizar-se um sistema de autoria (Comparison of Online Course Delivery Software Products, 2000).

O sistema de autoria permite ao professor especificar material para estudantes ou grupos de estudantes? A implementação desses recursos é importante para o professor? A flexibilidade oferecida pelo sistema de autoria para realização dessa tarefa é satisfatória?

E.B.2. O sistema deve fornecer recursos que possibilitam inclusão de material essencial e complementar: no caso de aplicações hipermídia para ensino, é desejável uma estrutura que inclua o material essencial ou relevante, sem eliminar o secundário, desde que este não seja conflitante com o anterior e que possa contribuir para os objetivos do aprendiz. A implementação desses recursos é interessante em aplicações para ensino, porque possibilita 
que a flexibilidade das informações contidas na aplicação seja projetada para fornecer material adicional, que será apresentado somente se o aprendiz requisitá-lo (Pansanato, 1999).

O sistema de autoria permite a inclusão de material essencial e complementar? A implementação desses fecursos é importante para o professor? É fácil fazer a inclusão de material essencial e complementar? Alguma dificuldade foi encontrada na realização dessa atividade?

A Figura 5.10 mostrada a seguir refere-se à síntese dos requisitos referentes à categoria E.C, que trata dos recursos de suporte à construção de aplicações para ensino.

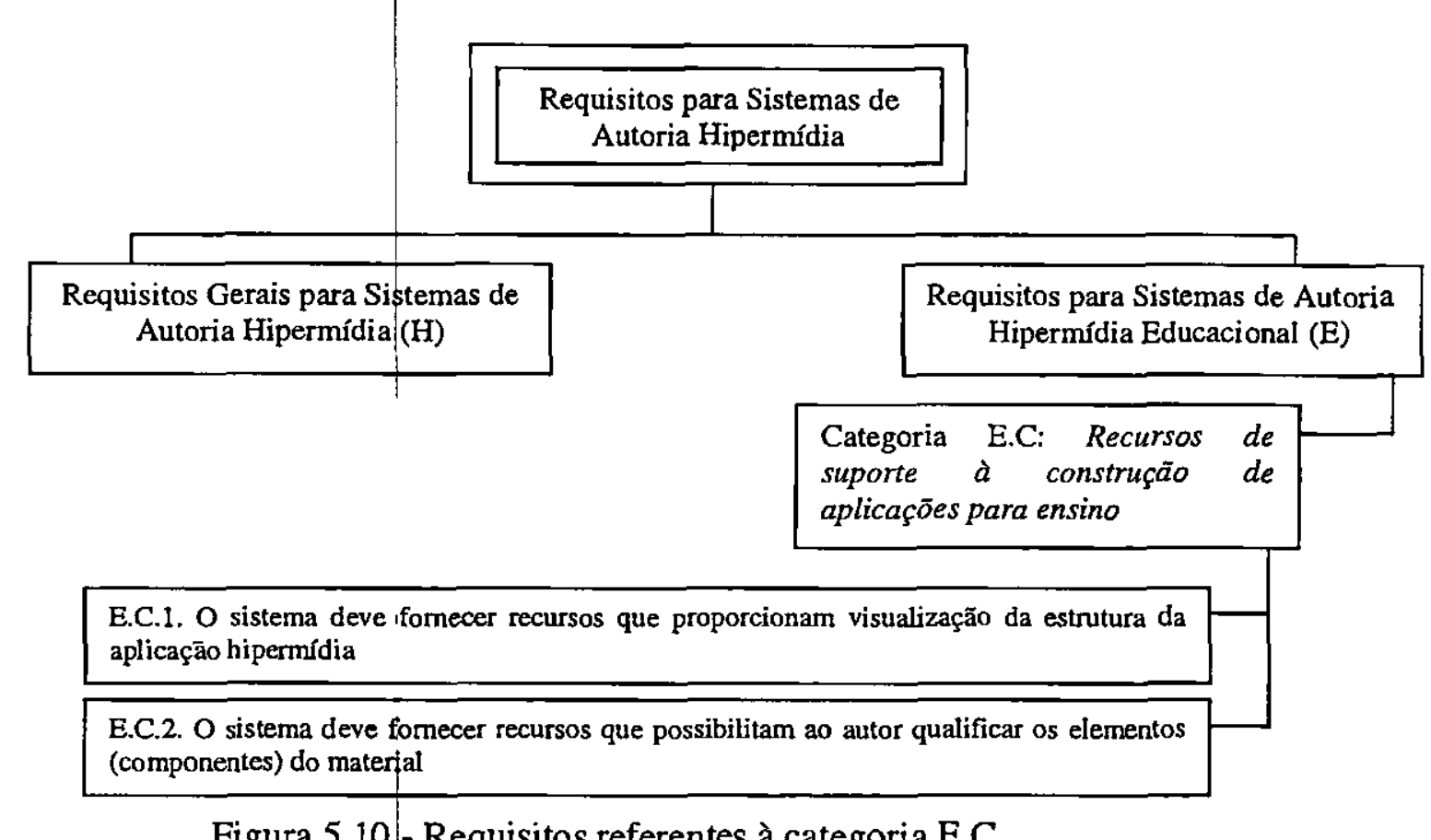

Categoria E.C: Recursos de suporte à construção de aplicações para ensino: é importante que alguns recursos de auxílio ao desenvolvimento de aplicações para ensino estejam disponíveis em sistemas de autoria destinados a este fim, de forma a facilitar esta atividade. Os recursos relacionados a esta categoria que devem ser oferecidos por um sistema de autoria são apresentados a seguir.

\section{E.C.1. O sistema deve fołnecer recursos que proporcionam visualização da estrutura da} aplicação hipermídia: é desejável que, durante o desenvolvimento de uma aplicação hipermídia para ensino, o professor consiga visualizar com clareza a estrutura da mesma para que ele possa organizar as informações conforme as estratégias pedagógicas adotadas, de forma a atingir os seus objetivos (e também os do aprendiz). A utilização de sistemas de 
autoria hipermídia que fiorneçam esses mecanismos pode trazer ganhos de produtividade e redução dos custos de dẹsenvolvimento das aplicações (Campos, 1994; Nunes \& Pansanato, 1999a).

O sistema de autoria fornece recursos para visualização da estrutura da aplicação? A implementação desses recursos é satisfatória?

E.C.2. O sistema deve fornecer recursos que possibilitam ao autor qualificar os elementos (componentes) do material: a atividade de qualificação dos elementos de uma aplicação para ensino aț̣avés de atributos pré-definidos do sistema de autoria dá suporte à implementação de recursos importantes no domínio de ensino, como a criação de roteiros (pois o professor terá informações sobre os nós que ele está inserindo no roteiro). Estes atributos podem estar relacionados, por exemplo, a função didática (resumo, introdução, definição, conclusão, etc) ou a dificuldade (fácil, regular, difícil) (Nunes et al., 1997).

Foram definidos atributos para qualificação dos elementos do material? Em relação à qualidade/quantidade, esses atributos são satisfatórios? Quais seriam as possíveis extensões ou adaptações para o conjunto de atributos disponível?

\subsection{Utilização do Conjunto de Requisitos Proposto em um Experimento de Verificação com Usuários-Autores}

Foi realizado um estudo de caso que teve por objetivo verificar a abrangência e completude do conjunto de requisitos proposto em situaçōes de avaliação. Para isso, foi realizada a avaliação do SASHE, conforme já mencionado. Este sistema foi escolhido devido aos benefícios que as informaçōes obtidas trariam à continuação do desenvolvimento do projeto. As informações relativas à preparação da avvaliação estão registradas no capítulo seguinte.

Os requisitos específicos do SASHE foram considerados nessa avaliação devido à necessidade de se obter informações sobre a qualidade da implementação de todos os requisitos do sistema, de forma que a àvaliação realizada pudesse contribuir tanto com a verificação das propriedades de abrangência e completude do conjunto de requisitos proposto quanto com a obtenção de informações que auxiliassem de fato a continuação do processo de desenvolvimento do SASHE. 
Os requisitos apresentados na Tabela 5.1 foram considerados durante a implementação do SASHE. Eles coincidem com alguns daqueles apresentados nas seções anteriores.

Tabela 5.1 - Requisitos considerados durante a implementação do SASHE

\begin{tabular}{|l|}
\hline \multicolumn{1}{|c|}{ Requisitos } \\
\hline $\begin{array}{l}\text { O sistema deve fornecer recursos que suportam laços de realimentação } \\
\text { (feedback loops) }\end{array}$ \\
\hline $\begin{array}{l}\text { O sistema deve fornecer recursos que possibilitam prototipação do } \\
\text { material }\end{array}$ \\
\hline $\begin{array}{l}\text { O sistema deve fornecer recursos que permitam a utilização de } \\
\text { abordagens de desenvolvimento bottom up e top down }\end{array}$ \\
\hline O sistema deve fornecer recursos que proporcionam geração de roteiros \\
\hline O sistema deve fornecer recursos que permitam especificar todos os \\
aspectos do domínio de conhecimento da aplicação \\
\hline $\begin{array}{l}\text { O sistema deve fornecer recursos que proporcionam liberdade de projeto } \\
\text { dos aspectos navegacionais da aplicaçäo }\end{array}$ \\
\hline $\begin{array}{l}\text { O sistema deve fornecer recursos que permitam o estabelecimento do tipo } \\
\text { de controle sobre a navegação }\end{array}$ \\
\hline $\begin{array}{l}\text { O sistema deve fornecer recursos que possibilitam inclusão de material } \\
\text { essencial e comolementar }\end{array}$ \\
\hline $\begin{array}{l}\text { O sistema deve fornecer recursos que possibilitam ao autor qualificar os } \\
\text { elementos (componentes) do material }\end{array}$ \\
\hline
\end{tabular}

São apresentados a seguir outros requisitos do SASHE. De forma análoga aos requisitos apresentados anteriormente, foram definidas questões que permitissem suas avaliações.

\section{Requisitos Especificos do Projeto SASHE (S)}

\section{S.1. O sistema deve fornecer recursos que possibilitam a contextualização de} informações e o aninhamento de contextos: um dos principais requisitos do módulo de autoria do SASHE é a utilização da característica mais importante do Modelo de Contextos Aninhados (MCA): o aninhhamento de nós de contexto. Dessa forma, através de um determinado nó de contexto escolhido pelo usuário-autor, este é capaz de limitar o acesso do estudante a um assunto, determinando-lhe um grau de liberdade. Além disso, o agrupamento lógico de nós que tratam de um tema comum possibilita melhor organização do material e requer melhor elaboração por parte do autor (Nunes et al., 1997).

Os recursos para contextualização de informações e aninhamento de contextos foram implementados no SASHE? A implementação desses recursos é importante para o autor? A implementaçāo desses recursos atende às necessidades dos usuários?

S.2. O sistema deve fornecer recursos que possibilitem ao usuário-autor gerar diferentes modelos de navegação baseados no mesmo modelo conceitual: na fase de projeto 
navegacional de contextos do EHDT, diferentes modelos navegacionais de contexto devem poder ser construídos, baseados no mesmo modelo conceitual hierárquico criado na fase anterior (modelagem conceitual hierárquica), e de acordo com propósitos educacionais diferentes (Nunes \& Pansanato, 1999a).

Utilizando-se o modelo gerado na fase de modelagem conceitual (modelagem do domínio de conhecimento), o usuário-autor pode construir diferentes modelos navegacionais? A implementação desses recursos é importante para o autor? Os modelos gerados são satisfatórios às necessidades dos usuários? Quais seriam possíveis extensões ou adaptações para os recursos de geração dos modelos navegacionais oferecidos?

\section{S.3. O sistema deve fornecer recursos que proporcionam replicação (cloning) ao nível de} instância: o SASHE permite que estruturas sejam replicadas ao permitir (1) que diferentes modelos navegacionais sejam gerados a partir do mesmo modelo conceitual, (2) que hiperdocumentos da web possam ser importados, estruturados, aninhados em contextos e apresentados aos usuários e (3) que diferentes aplicações sejam geradas, modificando-se apenas o roteiro de navegação (Pansanato, 1999).

Os recursos oferecidos pelo sistema para replicação são suficientes? Quais seriam possíveis extensões ou adaptações para os recursos disponíveis?

\section{S.4. $O$ sistema deve fornecer recursos que possibilitam que aplicações sobre quaisquer assuntos possam ser geradas: aplicações de domínios diferentes do domínio de ensino devem poder ser geradas no SASHE. Dessa forma, o módulo de autoria deve fornecer recursos genéricos ou adaptações para outros domínios (Nunes et al., 1997).}

O SASHE fornece recursos para construção de aplicações de outros domínios? Quais foram as principais limitações encontradas quando essas aplicações foram modeladas? 


\subsection{Considerações Finais}

Este capítulo apresentou os resultados obtidos a partir de um trabalho de compilação de requisitos para sistemas ide autoria hipermídia educacional propostos em publicações da literatura. Tendo em vista as restrições encontradas em diversos trabalhos revisados, foi proposto um conjunto único de requisitos, que pretende ser abrangente e suficientemente completo para auxiliar $a_{1}$ etapa de engenharia de requisitos de um novo sistema, ou para permitir a avaliação de sịstemas já existentes. Além disso, essa proposta privilegia tanto as necessidades do contexto|educacional quanto as necessidades relacionadas aos ambientes de autoria hipermídia.

A eficácia desta proposta, no que se refere à etapa de avaliação, pôde ser verificada através da execução de experimentos supervisionados com uma classe de usuários finais de um sistema de autoria. O planejamento e os resultados obtidos a partir da execução da avaliação estão registrados nos capítulos seguintes. 


\section{Capítulo 6}

\section{Estudo de Caso: Avaliação de um Sistema de Autoria Hipermídia Educacional Segundo os Requisitos Propostos}

\subsection{Considerações Iniciais}

Conforme mencionado anteriormente, o sistema SASHE foi submetido a um processo de avaliação considerando-se os requisitos descritos no capítulo anterior. De forma a definir os critérios adotados durante a realização de tal atividade, foram realizadas as etapas de especificação e planejamento da avaliação. Além disso, a realização dessas etapas é importante devido ao fato de se estabelecer o cenário e as principais características segundo as quais a avaliação foi realizada.

Para a execução dessas etapas, foram observadas as recomendações da norma ISO/IEC 14598-5 (ISO/IEC 14598-5, 1996), que orientam o planejamento e a execução de um processo de avaliação de um produto ou protótipo de software, definindo as atividades que devem ser executadas. Procurou-se observar também os aspectos descritos na seção 2.4.1, de forma a assegurar a validade dos experimentos realizados. As seções seguintes apresentam as informações relativas à execução destas etapas.

\subsection{Especificação da Avaliação}

Segundo a Norma ISO/[EC 14598-5 (ISO/IEC 14598-5), o propósito de especificar a avaliação é definir seu éscopo e as medições a serem executadas no produto que será 

avaliado. Dessa forma, os itens relacionados à etapa de especificação da avaliação são discutidos a seguir.

\subsubsection{Escopo da avaliação}

Sistema a ser avaliado: Sistema de Autoria e Suporte Hipermídia para Ensino (SASHE).

O sistema SASHE foi desenvolvido com o objetivo de permitir a criação de aplicações hipermídia por parte de usuários-autores e, conseqüentemente, permitir a navegação dessas aplicações previamente criadas no módulo de autoria por parte de usuários-leitores. Portanto, o sistema consiste basicamente dos módulos de autoria e navegação.

Foi avaliado o módulo de autoria de aplicações hipermídia do SASHE (em particular, a ferramenta EHDT), considerando-se o conjunto de requisitos proposto neste trabalho.

Ressalta-se que não fez parte do escopo avaliar o módulo de navegação do SASHE que, por possuir características próprias, exige uma avaliação particular de sua implementação. Dessa forma, todas as etapas de um processo de avaliação deverão ser executadas posteriormente para o módulo de navegação do sistema.

\subsubsection{Objetivos da avaliação}

Esta avaliação teve como principal objetivo indicar a eficácia do conjunto de requisitos proposto em relação a sua abrangência e completude. A finalidade secundária da execução dessa avaliação foi a obtenção de dados que retratassem as condições atuais da funcionalidade do módulo de autoria do SASHE, que apontassem os problemas da implementação e que indicassem sugestões para o sistema.

\subsubsection{Funções atribuídas aos participantes}

Este projeto envolveu a participação de cinco avaliadores (os usuários-autores, ou seja, os usuários finais do módulo de autoria) e de um supervisor. Os usuários-autores construíram aplicações hipermídia utilizando a ferramenta EHDT e os demais recursos a eles oferecidos (seção 6.3.5). Dessa fołma, eles puderam avaliar o sistema respondendo as questões elaboradas para os requisitos. O supervisor teve como funçōes (1) estabelecer as tarefas a 
serem cumpridas pelos avaliadores; (2) direcionar a execução da avaliação, esclarecendo dúvidas e auxiliando os avaliadores, e (3) analisar e divulgar os resultados obtidos.

Decidiu-se por realizar essa avaliação de forma supervisionada devido principalmente ao fato de o sistema ser um protótipo e, por isso, não contar com recursos de help e documentação que facilitassem o trabalho experimental. Através da supervisão, tentou-se evitar a sobrecarga cognitiva dos avaliadores, que não precisaram compreender sozinhos o processo de desenvolvimento de uma aplicação hipermídia utilizando uma ferramenta desconhecida por eles. Outro fator importante foi a necessidade de obtenção do máximo de informações sobre o sistema, e não somente de respostas que revelassem a presença ou ausência da implementação de determinado recurso ou apenas a atribuição de notas a sua implementação. Foram registradas, portanto, as opiniðes e as sugestões dos usuários-autores durante todo o processo de avaliação.

\subsubsection{Descrição do produto submetido à avaliação}

Para a realização de uma avaliação, o avaliador deve poder identificar os componentes do produto, para compreender e avaliar suas estruturas (ISO/IEC 14598-5). Dessa forma, foi elaborado um material que foi entregue aos usuários-autores anteriormente à execução da avaliação descrevendo as principais características e funcionalidades do módulo avaliado do SASHE. O material fomecido é apresentado no Apêndice A.

\subsection{Planejamento da Avaliação}

Segundo a Norma ISO/IEC 14598-5 (ISO/IEC 14598-5), o propósito do planejamento da avaliação é documentar os procedimentos a serem usados pelo avaliador para executar as medições. Devem ser descritos os recursos necessários para executar a avaliação especificada bem como a distribuição desses recursos nas várias ações a serem executadas.

\subsubsection{Treinamento oferecido aos avaliadores}

Para aprender a usar o SASHE, em particular o módulo de autoria de aplicações, o usuárioautor recebeu material explicativo sobre as principais características do EHDM e do EHDT, 
como foi citado na seção 6.2.4. Este material descreveu as etapas de modelagem e as primitivas gráficas disponíveis, e forneceu um exemplo de modelagem.

Além disso, foi oferecida ao usuário-autor uma demonstração de modelagem e construção de uma aplicação hipermídia. Após explicar as etapas mais importantes do processo de desenvolvimento, o supervisor construiu uma aplicação sobre um tema específico (Evolução dos Computadores) com os objetivos de (1) facilitar o aprendizado dos avaliadores em relação ao sistema e, dessa forma, aumentar a possibilidade de se obter dados que retratassem as reais condições do sistema e (2) diminuir a influência nos resultados da inexperiência dos usuários com o sistema.

\subsubsection{Método de avaliação}

Os requisitos descritos no capítulo anterior foram avaliados no SASHE através da execução de experimentos supervisionados realizados com usuários não experientes na utilização do sistema e que possuem a característica comum de serem professores de computação. Após a etapa de treinamento, os avaliadores puderam começar a desenvolver suas próprias aplicações sobre um tópico específico da área de Ciências de Computação (Recursão), cumprindo tarefas pré-estabelecidas pelo supervisor em um plano de avaliação (Apêndice B). As respostas às perguntas formuladas para avaliação dos requisitos e as opiniões dos avaliadores sobre a implementação das funções do sistema foram sendo registradas à medida que a aplicação foi evoluindo. Os experimentos foram gravados (apenas o áudio) para agilizar o processo de avaliação e assegurar que as informações obtidas seriam integralmente consideradas na etapa de análise dos resultados. Os experimentos foram realizados em um laboratório de Computação.

Foi utilizada a abordagem de avaliação proposta por Nielsen (seção 2.3), sendo que somente a primeira etapa de testes experimentais foi realizada, conforme é explicado na seção 7.2. Após o reprojeto do sistema (considerando-se os resultados obtidos neste trabalho), outra etapa de avaliação deverá ser realizada, seguida por novo reprojeto do sistema e nova etapa de avaliação. 


\subsubsection{Avaliação piloto}

O primeiro usuário do sistema executou todas as etapas propostas para a realização dos experimentos, porém, şa importância no contexto da avaliação esteve vinculada à identificação de possíveis problemas do processo de avaliação utilizado. A importância desta avaliação está relacionaḍa à possibilidade de descobrir os problemas do planejamento da avaliação antes de executar todos os experimentos (Preece et al., 1994). Neste trabalho, em particular, os seguintes critérios foram analisados durante a avaliação piloto:

1)- Qualidade (clareza, objetividade) das perguntas elaboradas para avaliação dos requisitos bem como a adequação da quantidade de perguntas a serem respondidas;

2)- Suficiência e qualidade do treinamento oferecido;

3)- Abrangência das tarefas estabelecidas, no sentido de se conseguir ou não avaliar todos os requisitos propostos na etapa de análise de requisitos;

4)- Adequação da hiperbase (contendo arquivos de texto, de imagem e de áudio) oferecida aos avaliadores.

Os resultados obtidos a partir da avaliação piloto são registrados na seção 7.3.

\subsubsection{Classe de usuários}

Foram convocados professores da área de Ciências de Computação, sendo que os experimentos foram executados individualmente.

\subsubsection{Recursos oferecidos aos usuários-autores}

Os usuários tiveram acesso aos seguintes recursos:

1)- Material explicativo sobre o sistema;

2)- Sistema SASHE em funcionamento;

3)- Hiperbase composta por documentos (arquivos) referentes ao assunto (tema) da aplicação a ser construída. Esses arquivos foram organizados de forma a possibilitar boa exploração do tema, oferecendo várias possibilidades aos avaliadores;

4)- Endereços de sites sobre o tema escolhido, que permitiram a utilização de outras informaçōes sobre o tema! da avaliação disponíveis na web. 


\subsection{Perfil dos usuários-autores que realizaram os experimentos}

Algumas características dos usuários que participaram dos experimentos são apresentadas a seguir. Conforme mencionado anteriormente, todos os participantes possuem a característica de serem professores da área de Ciências de Computação. A importância em coletar e divulgar estes dados está relacionada ao fato de que os resultados apresentados na seção 7.3 devem ser direcionados a esta classe de usuários.

\section{- Experiência dos usuários-autores em relação à docência}

Quais os recursos ele utiliza/utilizava para ministrar aulas (quadro/giz, livro, transparências, etc)? Alguma vez utilizou uma aplicação hipermídia?

Tabela 6.1 - Recursos didáticos utilizados pelos participantes dos experimentos

\begin{tabular}{|l|c|c|c|c|c|c|c|}
\hline & $\begin{array}{c}\text { Quadro/ } \\
\text { Giz }\end{array}$ & Livro & Transparências & $\begin{array}{c}\text { Power } \\
\text { Point }\end{array}$ & Vídeo & Internet & $\begin{array}{c}\text { Aplicação } \\
\text { Hipermídia }\end{array}$ \\
\hline Usuário 1 & $\mathrm{X}$ & $\mathrm{X}$ & $\mathrm{X}$ & & & & \\
\hline Usuário 2 & $\mathrm{X}$ & $\mathrm{X}$ & $\mathrm{X}$ & $\mathrm{X}$ & & & \\
\hline Usuário 3 & $\mathrm{X}$ & $\mathrm{X}$ & $\mathrm{X}$ & $\mathrm{X}$ & $\mathrm{X}$ & & $\mathrm{X}$ \\
\hline Usuário 4 & $\mathrm{X}$ & $\mathrm{X}$ & $\mathrm{X}$ & $\mathrm{X}$ & & & \\
\hline Usuário 5 & $\mathrm{X}$ & $\mathrm{X}$ & $\mathrm{X}$ & $\mathrm{X}$ & & $\mathrm{X}$ & \\
\hline
\end{tabular}

Qual o tempo de experiênciia em docência? Para qual nível (ensino médio, técnico, graduação) ele leciona/lecionava?

Tabela 6.2 - Experiência em docência dos participantes dos experimentos

\begin{tabular}{|c|c|c|c|}
\hline & Tempo Docência & Nível & Área de Atuação \\
\hline Usuário 1 & 2 anos e 6 meses & Graduação & Matemática/Engenharia/Química \\
\hline Usuário 2 & 9 meses & Técnico & Ciências de Computação \\
\hline Usuário 3 & 6 anos & Técnico & Ciências de Computação ${ }^{2}$ \\
\hline Usuário 4 & 6 meses & Graduação & Ciências de Computação \\
\hline Usuário 5 & 3 anos & Graduação/Técnico & Ciências de Computação \\
\hline
\end{tabular}

\section{- Experiência do autor em relação à utilização de sistemas hipermídia}

Alguma vez ele modelou uma aplicação hipermídia? Para qual área? Alguma vez ele utilizou um sistema de autoria?

Somente um dos autores (Usuário 4) havia modelado uma aplicação hipermídia anteriormente, para a área de doçumentação de software, utilizando o método OOHDM. Nenhum dos usuários havia utilizado um sistema de autoria anteriormente.

\footnotetext{
1 O usuário também ministrou aulas práticas sobre softwares matemáticos

${ }^{2} \mathrm{O}$ usuário também ministrou cursos de treinamento para professores na área de Informática na Educaçāo.
} 


\section{- Formação dos autores}

Qual é a formação (gradụação, pós graduação) do avaliador?

Todos os usuários são alunos de pós-graduação da USP, aos níveis de mestrado e doutorado, conforme pode ser observado na Tabela 6.3.

Tabela 6.3 - Grau de instrução e área de pesquisa dos participantes dos experimentos

\begin{tabular}{|l|c|c|}
\hline & Nível & Área de Pesquisa \\
\hline Usuário 1 & Mestrado & Sistemas Distribuídos \\
\hline Usuário 2 & Mestrado & Engenharia de Software \\
\hline Usuário 3 & Mestrado & Sistemas Distribuídos \\
\hline Usuário 4 & Doutorado & Inteligência Artificial (mestrado em Engenharia de Software) \\
\hline Usuário 5 & Mestrado & Engenharia de Software \\
\hline
\end{tabular}

Em síntese, as principais características referentes à classe de usuários que executou os experimentos são:

1)- Utilizam (utilizavam) os recursos didáticos: quadro/giz, livro, transparências e power point;

2)- Lecionam (lecionavam) em nível técnico ou graduação na área de Ciências de Computação (com exceção de um usuário);

3)- Não haviam modelado aplicações hipermídia anteriormente (com exceção de um usuário) e nunca haviam utilizado 'um sistema de autoria;

4)- São ou foram alunos de pós-graduação da USP em nível de mestrado, nas áreas de Engenharia de Software ou Sistemas Distribuídos.

\subsection{Considerações Finais}

As etapas preparatórias à execução efetiva da avaliação foram apresentadas neste capítulo. De acordo com a norma ISO/IEC 14598-5, a execução destas etapas é fundamental para a obtenção de resultados válidos.

De forma geral, a etapa de especificação teve por objetivo definir o escopo e o objetivo da avaliação. A etapa de planejamento da avaliação teve o propósito de definir e documentar os procedimentos utilizados para executar as medições.

O capítulo seguinte registra os resultados obtidos neste estudo de caso. 


\section{Capítulo 7}

\section{Resultados Obtidos a partir do Estudo de Caso}

\subsection{Considerações Iniciais}

Este capítulo tem por objetivo apresentar os resultados obtidos (em relação ao conjunto de requisitos proposto e às condições da implementação do SASHE) a partir da avaliação do módulo de autoria do sistema com usuários finais. São apresentados também os resultados obtidos em relação à utilização da abordagem de Nielsen (Nielsen, 2000) para avaliação de funcionalidade e os resultados obtidos a partir da avaliação piloto.

Alguns dos requisitos propostos neste trabalho não foram implementados no SASHE, o que inviabilizou suas avaliaçōes. No entanto, pôde-se questionar os usuários-autores em relação à relevância da implementạ̧̧ão destes recursos. Isto se refere aos requisitos H.B.1 (O sistema deve fornecer recursos que informam as referências dos nós ao usuário-autor); H.B.3 (O sistema deve fornecer recursos que verificam a coerência das ligações); H.B.4 (O sistema deve fornecer recursos que promovam a propagação de modificações); H.C.l (O sistema deve fornecer recursos que suportam o gerenciamento e armazenamento de versões das aplicações hipermídia); H.C.2 (O sistema deve fornecer recursos que apóiam o trabalho cooperativo); H.D.3 (O sistema deve fornecer recursos que detectam a presença de referências cegas e ligações incorretas); H.E.1 (O sistema deve fornecer recursos que promovam auxílio ao usuário); H.E.2 (O sistema deve fornecer recursos de tutorial para autoria), H.F.2 (O sistema deve fornecer recursos de documentação) e E.B.1 (O sistema deve fornecer recursos que permitam fixação de material específico). 
Alguns requisitos não foram avaliados devido à forma segundo a qual os experimentos foram planejados. Isto se refere aos requisitos: H.D.1 e S.4. Justificou-se este comportamento na seção 7.5

\subsection{Utilização da Abordagem de Nielsen para Avaliação de Funcionalidade}

Apesar de a abordagem de Landauer e Nielsen (Landauer \& Nielsen, 1993) ter sido elaborada especificamente para avaliação de usabilidade, conforme mostrado na seção 2.3 , pôde-se observar neste trabalho que esta abordagem foi aplicável à avaliação de funcionalidade.

O número de usuários que deveria executar os experimentos não foi estabelecido durante a etapa de planejamento da avaliação. Decidiu-se executar tantos experimentos quantos fossem necessários, até que o ganho obtido em um experimento em relação aos experimentos anteriores se tornasse muito pequeno.

Dessa forma, a avaliação piloto gerou a maior parte de todas as informações novas obtidas, o que não significa que ela tenha sido mais importante que as outras. Na verdade, pelo fato de ter sido a primeira avaliação, todas as informações obtidas eram novas e as demais avaliações geraram algumas das meșmas informações e acrescentaram alguns dados novos.

O gráfico a seguir (Figura 7.1) indica o ganho de informação a partir dos experimentos de cada usuário. Considerando-se os $100 \%$ de informações obtidos nos 5 experimentos realizados, observa-se que o primeiro usuário forneceu aproximadamente $45 \%$ de informações novas e o segundo usuário forneceu aproximadamente $25 \%$. De fato, conforme indicado por Nielsen, o segundo usuáfio repetiu algumas informações obtidas no primeiro experirnento. Pode-se observar também que o primeiro e o segundo experimentos juntos forneceram aproximadamente $70 \%$ de toda a informação obtida (grande parte destas informações foi repetida nos experimentos seguintes). De forma semelhante, o terceiro usuário forneceu $15 \%$ de informações novas, è repetiu muito do que havia sido dito no primeiro e segundo experimentos. O quarto e o quinto usuários forneceram $10 \%$ e $5 \%$ de informações novas, respectivamente. 
Observou-se, portanto, que $95 \%$ das informações obtidas no quinto experimento já haviam sido obtidas nos experimentos anteriores. Considerando-se este resultado e consultando os dados obtidos por Nielsłn em relação ao número de usuários que devem ser envolvidos em um processo de avaliação, decidiu-se por finalizar a etapa de execução de experimentos.

\subsection{Resultados obtidos a partir da Avaliação Piloto}

Conforme mencionado anteriormente, a primeira tarefa realizada na etapa de execução dos experimentos foi a avaliação piloto. Dessa forma, ela foi executada neste trabalho com o objetivo de verificar a adequação do planejamento e implementar as modificações necessárias antes de executar os demais experimentos.

Nesta avaliação piloto foram considerados todos os requisitos obtidos através da pesquisa bibliográfica. Foram avaliados 28 (dois requisitos não puderam ser avaliados pelos usuáriosautores), perfazendo o total de 54 perguntas respondidas por eles (de um total de 85 perguntas). Igualmente aos demais experimentos, houve uma etapa de treinamento, conforme especificado no planejamento, antes da interação do usuário com a ferramenta.

Os resultados obtidos a partir dessa avaliação foram bastante significativos. Pôde-se fazer alterações que tornaram os experimentos mais concisos. Os itens 1,2 e 3 citados a seguir referem-se a modificaçŏes realizadas no processo de avaliação. O item 4 refere-se às 
características identificadas na ferramenta que foram relevantes para a execução dos experimentos seguintes.

1)- $O$ experimento foi abpreviado. Observou-se que havia muitas perguntas que os usuários deveriam responder, o que tornou o experimento muito longo e cansativo. Dessa forma, diminuiu-se o número de perguntas de 54 para $48^{1}$.

2)- O material fornecido aos usuários (como parte do treinamento) foi modificado. Algumas explicações adicionais foram incluídas de forma a facilitar a compreensão do sistema. Modificou-se também a ordem de apresentação de alguns conceitos, de forma a relacioná-los melhor.

3)- A hiperbase contendolos arquivos sobre recursão foi modificada. Alguns arquivos de texto que estavam muito extensos foram alterados de forma a facilitarem a obtenção da aplicação final. Isto facilitou, por exemplo, a criação de âncoras na etapa de criação de protótipos, pois o autor não precisou rolarj a tela para criá-las no final do texto, e permitiu também que o autor entendesse rapidamente o conteúdo dos arquivos. Esta modificaçăo favoreceu a praticidade da criação das demais aplicações. Pôde-se observar, portanto, a necessidade de tornar simples os aspectos que estavam relacionados aos experimentos, mas que não eram primordiais a estes.

4)- Através da execução da avaliação piloto, obteve-se alguns guidelines para execução do sistema, que foram impontantes para facilitar o desenvolvimento das outras aplicaçōes. Estes guidelines são citados a seguir:

Ao começar o desenvolvimpento de uma nova aplicação, o usuário deve:

a)- Identificar primeiramente os conceitos, resultados e exemplos a serem abordados;

b)- Identificar, em seguida, os contextos;

c)- Relacionar as categoriás (de preferência fazendo inicialmente um esboço em papel);

d)- Relacionar todo o diagrama (não deixar categoria (s) "solta (s)");

Durante o desenvolvimento da aplicação, o usuário deve:

\footnotetext{
${ }^{1}$ Para os requisitos que não foram implementados no SASHE, perguntou-se na avaliação piloto quais seriam possíveis formas de se implementar os recursos (como alternativa às perguntas do tipo: "quais seriam possíveis extensões ou adaptações para os recursos fornecidos?"). Isso não ocorreu nos demais experimentos.
} 
e)- Tentar relacionar os nós à medida que são inseridos (isto evita que o sistema ignore alguns relacionamentos que são inseridos, conforme citado posteriormente);

f)- Não inserir muitos nós em um mesmo nível (optar pela hierarquia), para que o grafo não se torne muito complexo e $\phi$ autor possa fazer modificações facilmente;

g)- Não criar muitos níveis (aproximadamente três ou quatro) para que o autor consiga ter um modelo mental claro da aplicação que está sendo criada e possa gerenciá-la facilmente;

h)- Fechar o sistema de tempos em tempos, para forçar que os dados referentes à modelagem sejam salvos em disco.

Como os problemas identificados na avaliação piloto não comprometeram a qualidade dos resultados obtidos, considerou-se as informações obtidas nesta avaliação como válidas. Caso fossem necessárias modifịcações mais complexas no planejamento da avaliação, os resultados obtidos na avaliaçāo piloto seriam desconsiderados.

De forma geral, os problemas identificados no planejamento da avaliação (citados em 1, 2 e 3 desta seção) foram solucionados e os guidelines (citados em 4) foram considerados na execução dos experimentos seguintes. Isto colaborou para que os experimentos se tornassem menos demorados e incentivassem a participação dos usuários.

\subsection{Resultados obtidos a partir dos experimentos em relação ao SASHE}

Esta seção tem por objetivo apresentar os resultados da avaliação em relação à implementação do SASHE.

\subsubsection{Requisitos Gerais de Autoria Hipermídia (H)}

H.A.1. O sistema deve fornecer recursos que suportam laços de realimentação (feedback loops)

O sistema de autoria supdrta laços de realimentação entre as fases de projeto da aplicação?

O EHDT suporta laços, de realimentação ao permitir que (I) o autor possa mover-se facilmente pelas três fases do processo de modelagem da aplicação, (2) os diagramas gerados na modelagem estejam interconectados através do mapeamento dos elementos conceituais em elementos navegacionais, (3) protótipos sejam gerados a partir da tradução da especificação do diagrama navegacional para uma aplicação automaticamente. 


\section{Os recursos oferecidos auxiliam o desenvolvimento e a avaliação das aplicações?}

Segundo os usuários-autơres, estes recursos permitem aos autores avançar rapidamente pelas três fases, desde que èstejam funcionalmente satisfatórios. Em relação ao EHDT, a implementação dos recursos (1) e (3) precisa ser aprimorada, pois a etapa de criação da aplicação (geração e avaliação dos protótipos até a obtenção da aplicação final) apresenta algumas limitações (desçitas na resposta do requisito seguinte) que prejudicam o suporte a laços de realimentação. $O$ item (2) foi citado por quatro usuários-autores como sendo importante para permitir mudar rapidamente entre as fases. Três usuários comentaram também a importância de b sistema mostrar exatamente o mesmo nível de modelagem quando o usuário troca entre modelagem conceitual e navegacional, conforme foi implementado no EHDT. Segundo eles, issó evita ter que procurar pelo diagrama requerido.

\section{H.A.2. O sistema deve fornecer recursos que possibilitam prototipação do material O SASHE fornece o recurşo de prototipação?}

Sim.

A implementação desses recursos é importante para o autor?

Quatro usuários-autores acharam importante esta funcionalidade, pois pode-se observar (em nível de instância) como à navegação foi projetada antes que a aplicação esteja pronta. Além disso, o usuário pode obsẹrvar se a lógica que ele utilizou na modelagem confere com o que ele gostaria de apresentar ào usuário.

Um dos usuários-autores não soube opinar sobre a importância dessa funcionalidade.

Os mecanismos de prototipação disponiveis no sistema são satisfatórios?

Foram citadas algumas reștrições da ferramenta em relação à prototipação:

1)- Se o usuário possui um protótipo da aplicação cujos arquivos referentes aos nós (arquivos de texto, imagem, áudio, vídeo) foram editados, e se ele necessita modificar a modelagem e gerar novo protótipo, todọ o conteúdo dos arquivos é perdido. Dessa forma, o autor precisa concluir toda a modelagem para poder começar a editar os arquivos, o que prejudica a praticidade da ferramenta.

2)- Somente uma âncora é gerada em cada nó pertencente ao protótipo. Se determinado nó é modelado no EHDT possuindo mais de uma âncora, somente uma delas será gerada no protótipo.

3)- Os elos não são geradớ quando os protótipos são criados. Isso dificulta muito o processo de desenvolvimento das aplicações porque os usuários têm que retornar ao módulo de 
modelagem para relembrarem os elos que foram criados e então criá-los novamente, o que acarreta executar a mesma função (criação de elos) mais de uma vez.

É fácil para o usuário gerar vários protótipos antes de decidir pelo melhor?

Tendo em vista as dificuldades citadas anteriormente, os usuários-autores não acharam fácil a realização desta etapa. Eles se sentiram desanimados a continuar o desenvolvimento das aplicações principalmente pelo fato de terem que criar novamente os elos, conforme citado anteriormente. No entanto, eles ressaltaram a utilidade desse módulo de criação de protótipos, devido à possibilidade de gerar vários protótipos e modificá-los antes de decidir pelo melhor.

H.A.3. O sistema deve fornecer recursos que permitam a utilização de abordagens de desenvolvimento bottom up e top down

$O$ sistema de autoria formece recursos para utilização de abordagens de desenvolvimento bottom up e top down? Os recursos fornecidos pelo SASHE para utilização de abordagens de desenvolvimento bottom up e top down são satisfatórios?

Os recursos oferecidos pelo sistema para utilização dessas abordagens de desenvolvimento se referem principalmente aos módulos de modelagem e prototipação. Todos os usuários-autores acharam importante e satişfatório ${ }^{2}$ o processo de criação de modelos (abstração da aplicação) e posterior geração da aplicação (instanciação). Segundo eles, é importante ter a possibilidade de pensar na aplicação em alto nível de abstração e acrescentar detalhes posteriormente (abordagem top down). Os usuários-autores confirmaram também que a prototipação de hiperdocumentos facilita os movimentos entre as camadas abstrata e concreta da aplicação, permitindo ao autor alternar entre as abordagens bottom up e top down, de acordo com o que foi proposto para o desenyolvimento da ferramenta.

Quanto à utilização da abordagem bottom up, dois usuários-autores solicitaram que o sistema atualizasse automaticamente os modelos criados na fase de modelagem quando o autor modificasse o protótipo da aplicação, de forma a manter protótipo e modelagem consistentes.

\section{H.A.4. O sistema deve fornecer recursos que proporcionam geração de roteiros O SASHE permite a geraçăo de diversos roteiros de forma fácil?}

Atualmente o sistema permite a geração de apenas um roteiro por aplicação. Este foi um aspecto negativo do sistema mencionado por três usuários-autores.

${ }^{2} \mathrm{O}$ termo satisfatório refere-se qo processo genérico de modelar e, em seguida, criar a aplicação. 


\section{A implementação desses łecursos é importante para o autor?}

Quatro usuários-autores acharam importante a funcionalidade dos roteiros, porque permite sugerir uma ordem de navegação que facilite o aprendizado e que auxilie usuários autores e leitores a alcançarem seu's objetivos. Foi citado que a construção de roteiros é válida desde que o leitor possa seguir também o caminho dos links e que ele tenha acesso a todo o conteúdo.

Um dos usuários-autores 'entende que a navegação através de elos seria suficiente, mas acha importante a restrição do. acesso ao material. Por exemplo, o autor deve poder planejar um exercício mas deixá-lo disponível somente quando desejar.

Alguma dificuldade foi encontrada na atividade de criação de roteiro?

As dificuldades encontrad'as foram:

1)- O EHDT permite a criação automática de roteiros para os nós pertencentes ao modelo conceitual hierárquico, mas essa funcionalidade está incompleta (por exemplo, o usuário não é capaz de trocar a ordem de apresentação de um nó). Além disso, esse roteiro gerado no EHDT não é transportado para o SASHE (no qual a aplicação de fato é criada). Observou-se, dessa forma, a má integração do EHDT ao SASHE em relação à criação de roteiros.

Os itens relacionados a seguir referem-se à criação de roteiros utilizando-se o SASHE.

2)- Interface não é intuitiva. Sugeriu-se que a interface fosse semelhante à utilizada pelo Windows Explorer, que mostra a lista de arquivos pertencentes a determinado diretorio. No caso da criação de roteiros, seria mostrada a lista sequencial de nós pertencentes ao roteiro, e o usuário poderia inserir, apagar e mover nós;

3)- Informações importantes para o autor, por exemplo, nome dos nós inseridos no roteiro, aparecem apenas como hints, o que dificulta o trabalho de criação e alteração de roteiros. Dessa forma, a visualização dos nós pertencentes ao roteiro torna-se bastante problemática.

4)- O sistema não mostra as âncoras pertencentes aos nós na janela de criação de roteiros. As tarefas de criação de roteiro e estabelecimento do grau de liberdade seriam mais facilmente realizadas se os usuários pudessem visualizar as âncoras.

A flexibilidade oferecida para a geração desses roteiros atende às necessidades do usuárioautor?

Não. Devido às dificuldades mencionadas acima, e à geração de apenas um roteiro, os usuários-autores sentiram-se desconfortáveis na realização dessa etapa. 
Citou-se que seria muito interessante que a navegação pelos roteiros fosse implementada fornecendo-se aos usuários comentários (em um rodapé, por exemplo) sobre os objetivos do nó seguinte ao nó que está sendo visualizado. O usuário poderia escolher, então, por continuar seguindo o roteiro ou por fazer um desvio (navegar pelos links). Caso ele optasse pela segunda opção, seria interessante que o sistema marcasse com um flag o último nó do roteiro visitado, e então, quando o usuário necessitasse ou desejasse, poderia solicitar ao sistema que retornasse àquele nó, e iele continuaria seguindo o roteiro sugerido. Obviamente, ler as mensagens sobre os objetivos dos nós poderia gerar sobrecarga cognitiva, mas ficaria como uma opção ao usuário.

\section{H.A.5. O sistema deve fornecer recursos que permitam especificar todos os aspectos do domínio de conhecimento da aplicação}

As primitivas oferecidas pelo EHDT são suficientes, no que se refere à quantidade/qualidade, para a realização da modelagem de uma aplicação hipermídia para o domínio do ensino?

Os usuários-autores observaram que a categoria conceito foi a mais importante para a modelagem. Para a aplicação desenvolvida apenas um usuário utilizou a categoria resultado e três utilizaram a categoria exemplo. Dois usuários-autores citaram que a categoria resultado seria útil somente em alguns domínios, por exemplo, o domínio da Física. A categoria exemplo foi citada como sendo importante para o domínio de Ensino.

Quais seriam possiveis exłensões ou adaptaçōes para esse conjunto de primitivas?

Os usuários-autores nã citaram extensões para as categorias de conhecimento e relacionamentos. Um deles comentou o fato de que criar categorias de conhecimento é um trabalho muito complexo e envolve muito estudo, por isso, é difícil sugerir categorias.

Em relação às adaptações:

1)- Tomar a categoria exemplo hierarquizável, pois o usuário pode desejar colocar diversos exemplos em um mesmo contexto ou detalhar um exemplo e assim necessitar criar um novo nível;

2)- Possibilitar maior liberdade de escolha dos relacionamentos, de forma que a ligação entre categorias não fique restrita a alguns relacionamentos. Um exemplo seria permitir ligar duas instâncias da categoria conceito com o relacionamento de dedução ${ }^{3}$.

\footnotetext{
${ }^{3}$ Os autores entendem, no entanto, que toda dedução implica um resultado e não outro conceito.
} 
A modelagem do domínio de conhecimento pode ser estruturada hierarquicamente?

O EHDT permite a estruturação hierárquica da modelagem. Quatro usuários-autores acharam válida e fundamental a idéia de hierarquizar um modelo, o que o torna mais simples. Além disso, foi citado que hierarquizar facilita o entendimento de um modelo, o que é especialmente importante quando um usuário-autor precisa compreender um modelo criado por outro usuário para estendê-lo ou adaptá-lo, pois, possuindo-se maior nível de detalhes, a pessoa poderá compreender melhor o que terá que fazer. Entre esses quatro usuários-autores que acharam importante a estruturação hierárquica, um deles citou que gostaria que o sistema permitisse que vários níveis fossem mostrados simultaneamente na tela.

No entanto, um dos usuários-autores não sentiu necessidade de criar diferentes níveis hierárquicos (utilizou somente o primeiro nível - genérico - e criou o segundo nível, com toda a modelagem), mas percebeu também certa deficiência do sistema em relação à visibilidade de níveis. O usuário-autor citou, ainda, que se o sistema mostrasse os níveis de forma top down, como se fosse uma árvore, em uma única tela, ficaria mais fácil fazer a estruturação. Segundo ele, uma ferramenta que oferece um editor que possui essa funcionalidade é o ConcurTaskTrees (Paternò et al., 1997). Foi sugerido que o EHDT adotasse um editor semelhante.

A implementação desse recurso atende às necessidades do usuário-autor?

Em relação à modelagem do domínio de conhecimento, dois usuários-autores citaram como restrição a rigidez envolvida nesta etapa, pois o usuário precisa selecionar categorias e relacionamentos e, quando o sistema gera o modelo navegacional de contextos, todos os relacionamentos se tornarăo elos e todas as categorias se tornarão nós.

\section{H.B.1. O sistema deve fornecer recursos que informam as referências dos nós ao usuário-autor}

O sistema de autoria fornece a lista de ligações ou mapa local do nó que está sendo editado? O SASHE não oferece este recurso.

\section{A implementação desses recursos é importante para o autor?}

Três usuários-autores acham a implementação deste requisito importante porque facilita a manutenção das aplicações. Caso ele queira modificar uma categoria (por exemplo, mudar uma categoria conceito para a categoria resultado), essas informações são relevantes porque 
permitiriam ao autor visualizar quais são os tipós de relacionamentos existentes com a categoria atual, e se esses relacionamentos deverão ser modificados (porque existem relacionamentos específicos para cada tipo de categoria). Caso o autor queira apagar uma categoria, essas informações permitiriam que ele visualizasse quais as consequências dessa decisão em relação às outras categorias, antes de apagar efetivamente.

Dois usuários-autores citaram que, apesar de importante, este não é um requisito primordial.

\section{H.B.2. O sistema deve fornecer recursos que facilitam a correção (manutenção) das aplicações}

A manutenção das apliçações (modificação dos dados referentes aos componentes das aplicações - nome, arquịo a que está vinculado; inserção, alteração ou remoção de nós $e$ ligações) ocorre de forma simples? Alguma dificuldade foi encontrada na realização desta atividade?

Segundo quatro usuáriosłautores, a manutenção das aplicações não ocorre de forma simples. Algumas dificuldades foram destacadas:

1)- Na etapa de modelagẹm, o sistema não permite que uma categoria ou relacionamento seja modificado diretamente. $O$ usuário precisa apagar o item atual e inserir um novo item. Além disso, quando o usuário seleciona a opção Alterar, mas não seleciona uma categoria, o sistema mostra a janela de alteração mas não permite a interação do usuário. Sugeriu-se que o sistema alertasse o usuário (através do envio de uma mensagem) sobre a necessidade de selecionar a categoria; ou que a janela de alteração não fosse mostrada;

2)- Na etapa de criação de roteiros, pelo fato de a janela Roteiros não apresentar uma interface intuitiva, torna-se difícil executar atividades, como excluir um nó do roteiro, mudar o grau de liberdade de um nó, alterar a ordem de apresentação entre dois ou mais nós, etc;

3)- Citou-se novamente o fato de o sistema apagar o conteúdo dos arquivos quando o usuário precisa alterar algum aspecto da modelagem. Segundo o usuário, dificilmente alguém faria alguma manutenção nos modelos criados, pois isso implicaria em editar novamente o conteúdo dos nós.

Um dos usuários-autores hão teve dificuldades em relação à manutenção da aplicação.

\section{H.B.3. O sistema deve fornecer recursos que verificam a coerência das ligações}

Quando um nó é modificado, as referências a este nó são atualizadas automaticamente?

Este item não foi avaliado devido ao sistema não permitir a alteração direta de uma categoria.

Quando o usuário precisa fazer uma alteração, ele tem que apagar a categoria existente e 
inserir uma nova, conforme citado anteriormente. Ao apagá-la, seus relacionamentos são automaticamente apagados.

Quando um nó é excluído, o sistema remove automaticamente todas as referências a ele? Sim.

\section{A implementação desses recursos é importante para o autor?}

Três usuários-autores opinaram que, caso um sistema permita a atualização de categorias, esse é um requisito importante somente se as aplicações que estão sendo construídas forem grandes ou complexas. Dopis usuários-autores não souberam opinar.

\section{H.B.4. O sistema deve fornecer recursos que promovam a propagação de modificações}

As modificações realizadas em um nó são automaticamente atualizadas em todos os níveis em que ele aparece?

Este requisito não foi avaliado devido ao fato de o sistema não implementar estes recursos. Quando o usuário escolhe o mesmo nome para dois nós (categorias) diferentes, o sistema trata-os distintamente. Lфgo, as modificações realizadas em um não podem ser propagadas para o outro.

A implementação desses hecursos é importante para o autor?

Três usuários-autores citaram a importância de o sistema suportar a utilização do mesmo nó mais de uma vez e não fazer distinção entre eles. Sugeriu-se a utilização de um flag, que indicaria que determinado nó está sendo utilizado mais de uma vez, e tudo o que fosse editado/modificado em um, por default, seria atualizado no outro.

\section{H.B.5. O sistema deve fornecer recursos que facilitam a edição de nós}

As informações relativas aos nós e contextos da aplicação (nome do nó, tipo de mídia relacionada à apresentação do nó, escolha do arquivo que estará associado ao nó) são fáceis de editar? Alguma dificuldade foi encontrada na realização desta atividade?

No geral, os usuários acharam fácil a edição das informações relativas aos nós e não tiveram dificuldades em relação a esta tarefa. Sugeriu-se, no entanto, que seja modificada a forma de seleção de origem e destino de relacionamentos porque, à medida que aumenta o número de categorias, torna-se cansativo selecioná-las. 


\section{H.B.6. O sistema deve fornecer recursos que permitam a edição de textos, sons e} gráficos a partir do próprio sistema de autoria

O sistema de autoria permite a edição de textos, sons e gráficos externa ou internamente ao sistema?

O SASHE possui um editor de textos próprio. O sistema não permite a utilização direta (a partir do próprio sistema) de editores de sons e gráficos, porém, os autores concordam que deve ser possível utilizá-los partir do sistema. Alegou-se que, devido à complexidade de desenvolvimento de um editor e tendo em vista a existência de diversos editores, seria suficiente que o SASHE permitisse o acesso a editores externos.

A implementação desses recursos é satisfatória às necessidades do usuário-autor?

Foram citadas algumas suggestões em relação ao editor de textos:

1)- Adotar o critério WYSIWYG (what you see is what you get) pois, durante a edição, o autor não visualiza o docłmento da mesma forma que ele será apresentado aos usuários. Ele tem disponível apenas tags de formatação e textos;

2)- Habilitar os hints dos botões;

3)- Permitir aumentar e diminuir o tamanho das letras do texto que é editado.

H.C.1. O sistema deve fornecer recursos que suportam o gerenciamento e armazenamento de versốes das aplicações hipermídia

O sistema de autoria registra as diversas versões da aplicação?

O SASHE não suporta o gerenciamento e armazenamento das versões das aplicações.

E importante para o autor o suporte ao gerenciamento de versões?

Todos os usuários-autores acham importante a implementação desse requisito. Segundo eles, essa é uma funcionalidade importante para qualquer sistema, mas a implementação não requer rigidez.

H.C.2. O sistema deve fornecer recursos que apóiam o trabalho cooperativo

O sistema de autoria prevê o trabalho cooperativo dos autores?

O SASHE não suporta o trabalho cooperativo. 
A implementação desses récursos é importante para o autor?

Para os usuários-autores, ạ implementação desses requisitos é importante, tendo-se em vista os benefícios que podem ser obtidos a partir do desenvolvimento cooperativo de aplicaçōes.

H.D.2. O sistema deve fornecer recursos que possibilitam ao autor criar aplicações hipermídia de acordo com suas necessidades e preferências

A implementação e a intérface da aplicação foram influenciadas pelas características do sistema de autoria?

As aplicações geradas por quatro usuários-autores não foram influenciadas pelas características do sistema. Somente alguns ajustes precisaram ser feitos no sentido de adequar as necessidades do autor à funcionalidade da ferramenta. Estes ajustes estavam relacionados a não permissão do sistema à expansão da categoria de exemplos e à quantidade excessiva de categorias que precisariam ser inseridas quando o usuário necessitou colocar vários exemplos para motivar um conceito, 0 que tornaria o diagrama sobrecarregado (optou-se por inserir os nós utilizando-se a janela de inserção de nós essenciais e complementares). Foi citado que, em determinados momentos, teve-se que mudar a forma de pensar para continuar o desenvolvimento da aplicação (o que o usuário achou normal), mas conseguiu-se alcançar o objetivo.

Há necessidade de se fazer alguma extensão ou adaptação no módulo de autoria de forma que este permita ao usuário-autor criar aplicações de acordo com suas necessidades $e$ preferências?

Um dos usuários citou que gostaria de poder utilizar applets Java, porque as aplicaçōes hipermídia não podem ser totalmente passivas, ou seja, devem ser interativas, como acontece em www.cut-the-knot.com, que oferece diversos problemas e curiosidades matemáticas e permite ao usuário interagịir diretamente com figuras até que ele obtenha uma solução. $O$ usuário gostaria, portanto, de poder utilizar recursos semelhantes.

H.D.3. O sistema deve fornecer recursos que detectam a presença de referências cegas e ligações incorretas

O sistema de autoria detecta referências cegas e ligações incorretas?

No caso do EHDT este requisito não foi avaliado porque a ferramenta somente permite que um relacionamento seja inșerido quando o usuário seleciona uma origem e um destino (não permite referências cegas). $:$ m relação às ligações incorretas, o sistema permite selecionar o 
relacionamento somente depois que forem escolhidas a origem e o destino, ou seja, o próprio sistema filtra os relacionamentos que podem ser escolhidos e apresenta-os ao autor. Naturalmente, ligaçס̃es incorretas não são inseridas. No entanto, percebeu-se que, quando o

usuário escolhe origem e destino iguais, o sistema habilita o botão $O k$, o que não é um procedimento correto. Se este botão é pressionado, o usuário recebe a mensagem que o diagrama não pode ser mostrado, mas os dados são salvos em arquivos (o que é um bug do sistema).

A implementação desses recursos é importante para o autor?

Segundo os usuários-autores, caso o sistema permita referências cegas ou ligações incorretas, é importante que o sistema detecte esses problemas e comunique-os ao autor.

\section{H.E.1. O sistema deve fornecer recursos que promovam auxílio ao usuário}

O sistema de autoria possui informações explicativas sobre o processo de autoria no instante em que o usuário desejar?

O sistema não fornece informações explicativas sobre o processo de autoria. Esses recursos foram solicitados diverșas vezes durante os experimentos. Os usuários acham muito importante a disponibilização dos mesmos. Sugeriu-se o help do windows 2000 como modelo, pois este oferece alguns recursos simples e interessantes, como a utilização de janelas flutuantes para definições breves, glossário e tópicos relacionados por assunto.

Os experimentos não foram prejudicados pela falta de um help porque foram realizados de forma supervisionada, conforme citado anteriormente.

\section{H.E.2. O sistema deve fornecer recursos de tutorial para autoria \\ O sistema de autoria fornece um tutorial para o processo de autoria? \\ O SASHE não oferece um tutorial.}

\section{A implementação desses recursos é importante para o usuário-autor?}

Todos os usuários-autores acharam importante a implementação desse recurso. Mencionou-se que, especialmente para usuários novatos, é importante que o sistema possua um tutorial que explique em detalhes cómo o sistema funciona, quais são seus objetivos, quais são os benefícios obtidos a partir de sua utilização e o que ele gera, explicando também como construir uma aplicação, pois os usuários têm diferentes níveis de habilidade e um tutorial auxiliaria a suprir as dificuldades de usuários menos experientes ou usuários que não sejam da 
área de Ciências de Computação. Citou-se como exemplo de ferramentas que oferecem bons tutoriais (e que poderian ser utilizados como modelo) o Autocad (Autocad, 2000) e o CorelDraw (CorelDraw, 2000).

\section{H.F.1. O sistema deve fornecer recursos que possibilitam 0 armazenamento de informações sobre os nós}

O sistema de autoria armazena informações sobre os nós?

O sistema permite armazẹnar informações a respeito da função didática e dificuldade do nó. No entanto, não permite armazenar informações como data de criação, atualização, etc. Uma sugestão para implementação dessa funcionalidade no EHDT é a utilização de um arquivo de $\log$ que registre todas as modificações que forem realizadas, como foi implementado em http://www.nondot.org/sabre/os/ e em http://www.extremeprogramming.org/, que oferecem a possibilidade de autores eq leitores verem o que foi modificado em todas as atualizações e nas mais recentes atualizações da página, respectivamente.

\section{Este recurso é importante para o autor?}

Quatro usuários-autores acham importante o armazenamento de informações, principalmente se muitos usuários estiverem trabalhando na mesma modelagem. Outra justificativa se referiu à importância de armazenar dados relativos a quem alterou ou teve a responsabilidade de alterar uma entidade, porque houve necessidade de alterar e como foram afetadas as demais entidades após a alteração! como forma de facilitar o trabalho em grupo e torná-lo organizado. Foi citado como sendo mais importante o armazenamento da data de criação do nó e da data de última alteração.

Um dos usuários não acha interessante o armazenamento de dados devido ao fato de aumentar o trabalho de usuários-autores. Segundo ele, isso aumentaria o número de campos a serem preenchidos.

\section{H.F.2. O sistema deve fornecer recursos de documentação}

O sistema de autoria possui documentação?

O SASHE possui documentação para a versão 1.0 (Feltrim \& Fortes, 1999). Essa documentação não engloba o EHDT.

Ela é satisfatória às necessidades de usuários novatos e experientes? Quais seriam possíveis melhorias da documentaçấo existente? 
Estes itens não foram avaliados porque o EHDT não possui documentação. Pôde-se observar que todos os usuários-autores requisitaram este recurso e expressaram a sua relevância no contexto de qualquer sistema, ou seja, ela serve principalmente como auxílio para novos usuários e como referência técnica sobre a implementação do sistema para futuras manutenções.

\subsubsection{Requisitos para Sistemas de Autoria Hipermídia Educacional (E)}

E.A.1. O sistema deve fornecer recursos que proporcionam liberdade de projeto dos aspectos navegacionais da aplicação

O professor possui liberdade para projetar os aspectos navegacionais da aplicação em relação à modelagem do domínio de conhecimento?

Os usuários-autores preferiram gerar automaticamente o modelo navegacional de contextos. Todos eles acharam a inserção de dados necessários para a geração automática fácil e simples. Algumas dúvidas estavałn relacionadas à nomenclatura utilizada pelo sistema e às etapas a serem seguidas, devido à inexperiência dos usuários com o mesmo.

Ao tentar modificar o modelo navegacional gerado, sentiu-se a necessidade de o sistema indicar de forma mais clara que, ao inserir um novo elemento (contexto navegacional ou nó), o autor pode fazer um rhapeamento desse novo elemento com algum elemento do modelo conceitual.

Alguma dificuldade foi encontrada na realização dessa atividade?

As dificuldades estavam kelacionadas principalmente à interface. Foi sugerido que o sistema indique que o usuário jeve clicar o botão de Opções, para setar as categorias e os relacionamentos para os quais ele deseja criar o modelo de navegação, o que seria bastante útil para usuários novatos. Além disso, foi sugerido que ficassem setadas todas as categorias e relacionamentos na janela $O p c ̧ o ̄ e s$, de forma a diminuir o trabalho do usuário.

E.A.2. O sistema deve fornecer recursos que permitam o estabelecimento do tipo de controle sobre a navegação

O professor pode estabelecer o tipo de controle sobre a navegação?

Sim. Durante a criação de roteiros, o usuário-autor estabelece o grau de liberdade de cada nó que é inserido. 
A implementação destes recursos é importante para o professor?

Para dois usuários-autoress a navegação não deve ser controlada, ou seja, para eles, em um ambiente de aprendizado o aprendiz tem direito de explorar o assunto pelo qual surgiu interesse. Deve-se estabelecer um roteiro para evitar que o usuário navegue em ordem não desejada, mas que serviria apenas como um esquema de navegação preferencial. Esse roteiro permitiria ao aprendiz investigar o material de acordo com seu interesse, como acontece em http://www.extremeprogramming.org/, que oferece botões $(x p)$ que compõem o roteiro de navegação sugerido e links através dos quais o usuário pode navegar. Em contrapartida, um desses usuários citou que pode ser importante em algum momento determinar um caminho para que o aprendiz veja|um determinado assunto de uma forma, e então, o controle sobre a navegação torna-se importante. Ambos alegaram também que essa questão é mais complexa que apenas responder sim ou não, porque deve envolver estudo e conhecimento pedag6gico. Dois usuários-autores foram favoráveis ao controle sobre a navegação porque, para eles, é uma tarefa difícil fazer com que o aprendiz concentre-se em algo delimitado. Isso se tornaria mais difícil se o aprendiz tivesse a chance de visualizar tudo.

Um usuário não soube respponder à questão devido à falta de conhecimento de pesquisas nessa área.

A forma segundo a qual o usuário-autor estabelece o tipo de controle sobre a navegação no SASHE é satisfatória?

Foram citadas as seguintels restrições em relação à implementação dessa funcionalidade:

1)- Na janela Liberdade de Navegação, o autor tem a idéia de que a liberdade da navegação estará restrita a nós precedentes ao nó atual (que será inserido no roteiro) mas, na realidade, estabelece-se a liberdade de navegação em relação a todo o contexto, a toda a aplicação ou ao nó atual somente.

2)- A mesma janela não oferece as opções de Cancelar ou Fechar, ou seja, o usuário não tem a chance de desistir de inserir um nó no roteiro enquanto utiliza esta janela. Para isso ele deverá inserir o nó e depois apagá-lo. Apesar de o usuário perceber que essa janela foi projetada dessa forma devido à obrigatoriedade de escolha da liberdade de navegação, citouse que esse não é o padrão das janelas do ambiente windows.

\section{E.B.1. O sistema deve fơrnecer recursos que permitam fixação de material específico}

O sistema de autoria permite ao usuário-autor especificar material para estudantes ou grupos de estudantes?

O sistema não oferece esta funcionalidade. 
A implementação desses recursos é importante para o professor?

Os usuários-autores não consideram a implementação desse requisito importante.

E.B.2. O sistema deve fornecer recursos que possibilitam inclusão de material essencial e complementar

O sistema de autoria permite a inclusão de material essencial e complementar? Sim.

A implementação desses recursos é importante para o professor?

Os usuários-autores consideram essa funcionalidade importante, porque permite ao autor fazer comentários adicionais sobre o assunto que está sendo ensinado, colocar material relacionado ao tema mas que não seja primordial, mostrar o mesmo assunto sob outra perspectiva, sugerir outràs referências bibliográficas, enfim, enriquecer o material básico.

É fácil fazer a inclusão de material essencial e complementar? Alguma dificuldade foi encontrada na realização dessa atividade?

O sistema permite facilmente fazer a distinção de material essencial e complementar porque o autor precisa somente selecionar (clicar) os nós que serão complementares. No entanto, algumas restrições relacionadas a essa funcionalidade foram citadas:

1)- A distinção de material não é intuitiva e a ferramenta não indica como o usuário deve proceder para realizar a tarefa;

2)- O EHDT permite a distinção de material mas, ao gerar a aplicação para o domínio do SASHE, todos os nós (essenciais e complementares) são tratados igualmente, ou seja, a distinção de material é feita somente em nível de modelagem. $O$ usuário gostaria que o SASHE indicasse se determinado nó foi modelado como essencial ou complementar;

3)- Ao inserir um nó complementar, utilizando-se a janela de inserção de nós essenciais e complementares, o usuário gostaria que o EHDT explicitasse-o no diagrama.

\section{E.C.1. O sistema deve fọrnecer recursos que proporcionam visualização da estrutura da} aplicação hipermídia

O SASHE fornece recurs s para visualização da estrutura da aplicação?

Sim. O usuário pode modelar primeiramente a aplicação utilizando o EHDT e criar a aplicação no SASHE, que permitirá a visualização da estrutura da aplicação. 
A implementaçâo desses recursos é satisfatória?

Todos os usuários-autores acharam muito bons os recursos disponíveis para visualização da estrutura do SASHE. A interface, por ser bastante familiar (semelhante à interface do Windows Explorer), é totalmente satisfatória.

E.C.2. O sistema deve fornecer recursos que possibilitam ao autor qualificar os elementos (componentes) do material

Foram definidos atributos para qualificação dos elementos do material?

O SASHE permite que o professor qualifique os elementos da aplicação de acordo com a função didática (motivação, introdução, definição, exemplo, exercício, resumo) e com a dificuldade (baixa, regular, alta).

Em relação a qualidadelquantidade, esses atributos são satisfatórios? Quais seriam as possiveis extensōes ou adaptaçōes para esse conjunto de atributos?

Em relação aos atributos de função didática:

Três usuários-autores acharam as opções de atributos oferecidas pelo sistema satisfatórias e não sugeriram novos atriputos.

Os demais usuários-autores citaram a falta de um atributo que indicasse um experimento ou uma prática, que seriam especialmente importantes para disciplinas como Química e Física. Outra extensão sugerida seria a inclusão de um atributo que indicasse uma aplicação prática de um assunto.

Em relação aos atributos de dificuldade:

Três usuários-autores acharam satisfatórios e pertinentes os atributos relacionados à dificuldade. No entanto, dois usuários-autores citaram a questão da subjetividade na escolha de um dos atributos. Um assunto pode ser fácil para um leitor, mas difícil para outro; ou pode ser fácil para o autor da aplicação (que já estudou sobre o tema) e difícil para aqueles que estarão estudando o assunto pela primeira vez. Além disso, a transição de um assunto considerado difícil para um assunto considerado fácil pode acontecer muito rapidamente, ou seja, a medida que um autor ou leitor se interessa por um assunto e começa a pesquisar sobre ele, os conceitos vão se tornando mais fáceis. 


\subsubsection{Requisitos Específicos do Projeto SASHE (S)}

\section{S.1. O sistema deve fornecer recursos que possibilitam a contextualização de informações e o aninhamento de contextos}

Os recursos de contexłualização de informações $e$ aninhamento de contextos foram implementados no SASHE?

Sim.

A implementação desses recursos é importante para o autor?

Todos os usuários-autores acharam importante a contextualização e o aninhamento das informações, pois, segundo eles, o material pode ser facilmente organizado e estruturado. Dois usuários-autores citaram também que a importância em contextualizar e aninhar informações está diretamente relacionada ao controle sobre a navegação, porque o autor pode decidir facilmente como será o acesso do leitor ao material, baseando-se no conteúdo dos nós pertencentes aos contextos.

A implementaçāo desses recursos atende às necessidades dos usuários?

A implementação dessa fụncionalidade foi considerada satisfatória pelos usuários-autores.

\section{S.2. O sistema deve fornkcer recursos que possibilitem ao usuário-autor gerar diferentes} modelos de navegação báaseados no mesmo modelo conceitual

Utilizando-se o modelo gerado na fase de modelagem conceitual hierárquica, o usuário pode construir diferentes modelos navegacionais?

Sim.

A implementação desses recursos é importante para o autor?

Dois usuários-autores acharam que esta é uma questão difícil de responder, alegando que não conhecem suficientemente $o$ assunto. Um deles mencionou que a geração de diferentes modelos navegacionais e a criação de roteiros apresenta a mesma funcionalidade, o que dispensaria esta etapa de geração de vários modelos navegacionais, pois podem ser gerados vários roteiros.

Dois usuários-autores acharam essa funcionalidade útil. Eles concordam que a possibilidade de criar diferentes aplicaçōes de acordo com diferentes classes de usuários e de acordo com as necessidades destas classes é bastante interessante. 
Um dos usuários foi indiferente à geração de mais de um modelo navegacional para um modelo conceitual. Ele acha difícil que alguém queira gerar um modelo navegacional apenas para uma parte do modelo conceitual, se ele pode gerar para todo o modelo. No entanto, ele também não eliminaria essa funcionalidade.

Os modelos gerados são satisfatórios às necessidades dos usuários?

Sim.

Quais seriam possiveis extensões ou adaptações para os recursos de geração de modelos navegacionais oferecidos?

Os usuários-autores observaram que, apesar de o sistema permitir a geração de diferentes modelos navegacionais, do tentarem criar a aplicação (no contexto do SASHE) apenas para o modelo navegacional atual (o que está selecionado), o sistema gera a aplicação para todos os modelos, ou seja, o EHDT permite criar o modelo navegacional de apenas uma parte do modelo conceitual, mas o SASHE não cria a aplicação somente dessa parte. Segundo os usuários, essa seria uma importante adaptação a ser feita no sistema.

\section{S.3. O sistema deve fornecer recursos que proporcionam replicação (cloning) ao nível de} instância

Os recursos oferecidos pelo sistema para realização dessa tarefa sāo suficientes? Quais seriam possíveis extensões ou adaptações para os recursos disponíveis?

O EHDT permite que diyersos modelos navegacionais sejam criados a partir de um mesmo modelo conceitual hierárquico. O módulo de importação de hiperdocumentos web não está disponível na versão 2.0 e o sistema não permite que sejam criadas diferentes aplicações modificando-se apenas o roteiro de navegação.

Segundo os usuários-autorres, os recursos oferecidos atualmente não são satisfatórios. Foi sugerido que sejam disponibilizadas as funcionalidades citadas acima e que o sistema possibilite a geração de un modelo navegacional a partir de outro modelo navegacional. 


\subsection{Requisitos que não Foram Avallados por Usuários-Autores}

Conforme mencionado na seção 6.1, os requisitos H.D.1 e S.4 não foram avaliados durante a execução dos experimentos com usuários-autores. Essa seção apresenta informações referentes a estes requisitos.

\section{H.D.1. O sistema deve fornecer recursos que promovam redução de custos (tempo) envolvidos na criação de aplicações}

Comparando-se o processo de modelagem da aplicação à estruturação direta da aplicação, o usuário-autor pode perceber algum ganho ao utilizar a primeira abordagem?

Este requisito não pôde ser avaliado porque os usuários não desenvolveram aplicações adotando a abordagem da estruturação direta (sem utilizar a ferramenta de modelagem). No entanto, pode-se fornecer o tempo gasto no desenvolvimento das aplicações utilizando-se a ferramenta de modelagẹm para posterior geração da aplicação. É importante observar, contudo, que os dados se referem ao tempo total gasto em cada experimento, ou seja, considerou-se o tempo envolvido no treinamento ${ }^{4}$ oferecido e na discussão a respeito da implementação dos requisitos. Logo, esses dados devem ser cuidadosamente analisados caso sejam utilizados em futuras comparações relacionadas ao custo de desenvolvimento.

Usuário 1 - 14h 05m divididas em quatro sessões (Avaliação Piloto)

Usuário 2 - 5h 10m divididas em duas sessões

Usuário 3 - $5 \mathrm{~h} 30 \mathrm{~m}$ divididas em duas sessões

Usuário 4 - 4h 45m divididas em duas sessões

Usuário 5 - 4h 30m divịdidas em duas sessões

S.4. O sistema deve forpecer recursos que possibilitam que aplicações sobre quaisquer assuntos possam ser geradas

O SASHE fornece recursos para construção de aplicações de outros domínios?

Foram desenvolvidos alguns trabalhos relacionados à extensão dos recursos oferecidos pelo SASHE, de forma a tornar possível a construção de aplicações pertencentes ao domínio de Engenharia de Software:

1)- Adequação do SASHE ao domínio da documentação de engenharia reversa de software (Feltrim, 1999). Neste trabalho a autora propõe mudanças nas funções de navegação, nos atributos de qualificação de nós terminais e na nomenclatura utilizada na interface. Além 
disso, percebeu-se que recursos como criação de roteiros e controle sobre a navegação não são relevantes para o novo domínio.

2)- Adaptação do SASHE à tarefa de documentação de software (Silva, 2000). Este trabalho resultou no desenvolvimento do SASHDoc - Sistema de Autoria e Suporte Hipermídia para Documentação de Software, em que foram reutilizados diversos componentes do SASHE e definidas novas funções para atenderem ao domínio de documentação de software.

Quais foram as principais limitações encontradas quando aplicações de outros domínios foram modeladas?

Este item não pôde ser avaliado porque, para o desenvolvimento deste trabalho de avaliação do SASHE, foram consideradas apenas aplicações relacionadas ao domínio de ensino.

Algumas informações adicionais obtidas durante a realização dos experimentos foram registradas em Paiva e Nunes (Paiva \& Nunes, 200I). Essas informações referem-se a aspectos relativos à usabillidade do SASHE e do EHDT, sugestões de melhoria para o sistema, problemas relacionados à sua execução e aos seus aspectos positivos.

\subsection{Resultados Obtidos a partir dos Experimentos em Relação ao Conjunto de Requisitos Proposto}

De forma geral, as questães elaboradas para a avaliação se mostraram satisfatórias à obtenção de resultados relativos às condições atuais da implementação do módulo de autoria do SASHE. Durante a avalíação de alguns requisitos, os usuários-autores foram questionados quanto à relevância da implementação dos recursos, sendo que o único considerado como não relevante foi o requisito E.B.1, que trata da designação de material para grupos específicos de aprendizes. Segundo os usuários, os benefícios advindos da implementação deste requisito não compensa o custo da implementação. Além disso, eles não consideram problema a disponibilização de atividades para grupos específicos de trabalho a todos os grupos. Bastaria que o professor indicasse explicitamente os grupos a que cada atividade se refere.

Os requisitos H.B.1 (O sistema deve fornecer recursos que informam as referências dos nós ao usuário-autor) e H.B.3 (O sistema deve fornecer recursos que verificam a coerência das

${ }^{4} \mathrm{O}$ tempo médio de duração dos experimentos foi de quarenta minutos. 
ligações), apesar de terem sido considerados importantes, foram citados como sendo não primordiais, pois, apesar de facilitarem o desenvolvimento das aplicações, referem-se a atividades que podem ser executadas sem muito esforço pelos autores.

Por outro lado, foi solịcitada a implementação de recursos de suporte à reutilização de modelos, requisito que não foi considerado na avaliação. Segundo os usuários, a implementação desses rẹcursos facilitaria bastante o desenvolvimento de novas aplicações. Este requisito foi definido e especificado abaixo, de forma a complementar o conjunto de requisitos proposto.

O sistema deve fornecer recursos que proporcionam a reutilização de modelos criados na etapa de especificaçẫo de uma aplicação: o sistema de autoria deve permitir que partes de um modelo existente possam ser reutilizadas na construção de novos modelos, possibilitando ao autor cọpiar uma estrutura existente e modificá-la. Dessa forma, os recursos de reutilização de modelos promovem a propagação de uma estrutura e sua utilização na construção de uma novạ aplicação sem precisar especificá-la novamente, aprimorando e facilitando, portanto, a geração de material.

O sistema de autoria permite a reutilização de modelos? Os recursos oferecidos pelo sistema para realizaçẩp dessa tarefa são suficientes?

Pôde-se observar também que a importância de alguns requisitos foi ressaltada pelos avaliadores. Isto refere-se|aos seguintes requisitos:

a)- H.A.1. O sistema deve fornecer recursos que suportam laços de realimentação (feedback loops);

b)- H.A.2. O sistema deve fornecer recursos que possibilitam prototipação do material;

c)- H.A.4. O sistema devel fornecer recursos que proporcionam geração de roteiros;

d)- H.B.2. O sistema deve fornecer recursos que facilitam a correção (manutenção) das aplicações;

e)- H.E.1. O sistema deve|fornecer recursos que promovam auxílio ao usuário;

f)- E.B.2. O sistema deve fornecer recursos que possibilitam inclusão de material essencial e complementar.

Por fim, a avaliação sobre a importância da implementação do requisito E.A.2 (O sistema deve fornecer recursos que permitam o estabelecimento do tipo de controle sobre a 
navegạ̧̧ão) foi considerada difícil, devido ao fato de os usuários-autores considerarem relevante um embasamento em conhecimentos pedagógicos - o que dizem não possuir - para respondê-lo.

\subsection{Considerações Finais}

Este capítulo registrou os resultados obtidos a partir da avaliação realizada com o sistema SASHE, considerando-se o conjunto de requisitos proposto neste trabalho.

Em última análise, pode-se concluir que as principais restrições relacionadas ao sistema observadas pelos avaliadores estão relacionadas à rigidez da manutenção das aplicações desenvolvidas, a não criação automática de elos e à dificuldade de utilização de arquivos cujo conteúdo tenha sido previamente editado.

Os principais aspectos ppsitivos relacionados ao sistema referem-se à possibilidade de modelagem da aplicação e à criação de protótipos da aplicação. Segundo eles, estas vantagens diferenciam-no de outros sistemas.

Em relação ao conjunto de requisitos proposto, observou-se que a maioria dos requisitos foi considerada importante płlos avaliadores e que eles forneceram resultados que poderão colaborar com a evolução do projeto SASHE. 


\section{Capítulo 8}

\section{Conclusões}

\subsection{Considerações Iniciais}

Este trabalho teve por objetivo propor um conjunto de requisitos cuja implementação é considerada desejável em sistemas de autoria hipermídia educacional e verificar a abrangência e completude desta proposta através da realização de um estudo de caso.

Como revisão bibliogrâfica, foi apresentado um estudo sobre avaliação de software, destacando-se alguns aspectos relevantes para o desenvolvimento deste trabalho. Foram apresentados também alguns sistemas de autoria hipermídia, métodos genéricos para o projeto de aplicações e métodos êspecíficos para o projeto de aplicações educacionais, além de terem sido apresentadas as prindipais características do SASHE e do EHDM.

Diante dos problemas encontrados nos trabalhos revisados que indicavam requisitos para sistemas de autoria hipermídia educacional, foi proposto um conjunto de requisitos que pudesse superar tais restrições. De forma a verificar a eficácia desta proposta, foi realizado um estudo de caso com ó módulo de autoria do SASHE. Para isso, baseadas na literatura da área, foram realizadas as etapas de especificação e planejamento da avaliação, que definiram as medições a serem expcutadas no sistema e os procedimentos a serem utilizados para executar as medições. Foram realizados, em seguida, experimentos com os usuários-autores do sistema. Por fim, foram divulgados os resultados obtidos em relação ao conjunto de requisitos proposto e à quạlidade da implementação do sistema avaliado.

\subsection{Contribuições}

As principais contribuiçōes relacionadas a este trabalho podem ser resumidas como: 
1. Recuperação e análise crítica de trabalhos relacionados à proposta de requisitos para sistemas de autoria hipermídia para domínios genéricos e para o domínio de ensino.

2. Recuperação do conjunto de requisitos do SASHE.

3. Proposta de um conjunto de requisitos para sistemas de autoria hipermídia que privilegia os aspectos positivos dos trabalhos revisados e supre as restrições observadas nos mesmos. Este conjunto de requisitos páderá auxiliar a etapa de engenharia de requisitos de um novo sistema ou a etapa de avaliação de uma aplicação existente. Esta proposta considera tanto as necessidades do contexto educacional quanto as necessidades relacionadas aos ambientes de autoria hipermídia.

4. Obtenção de resultados, a partir de um estudo de caso, que indicaram a eficácia da proposta de requisitos e forneceram informações a respeito da qualidade da implementação do SASHE. No segundo caso, os resultados poderão auxiliar futuras decisões em relação à evolução do sistema.

5. Constatação, através da realização de experimentos, de que a abordagem de Nielsen (Nielsen, 2000) (elaborada para avaliação de usabilidade) pode ser satisfatoriamente utilizada em uma avaliação de funcionalidade indicando, dessa forma, uma extensão para esta abordagem.

\subsection{Trabalhos Futuros}

A continuação e complemnentação deste trabalho podem ser realizadas através da execução das seguintes atividades:

1) Em relação ao conjunto de requisitos proposto

a) Realização da etapa de validação dessa proposta: neste trabalho foi realizada apenas a atividade de verificação em relação aos atributos de abrangência e completude da proposta. Um trabalho de validação envolveria, portanto, a utilização destes requisitos na etapa de avaliação de outros sistemas de autoria hipermídia utilizando-se diversas classes de usuários. Isto permitiria uma análise estatística e, consequientemente, a generalização dos resultados obtidos em relação à proposta. Outra possibilidade seria a utilização dessa proposta como apoio ao desenvolvimento de novos sistemas de autoria hipermídia educacional. 
2) Em relação ao SASHE

a) Execução da etapa de reprojeto do sistema considerando-se os resultados obtidos na avaliação, de acordo com a abordagem de Nielsen. As demais etapas de avaliação propostas na mesma abordagem também devem ser executadas.

b) Execução da avaliaçãọ com outras classes de usuários, de forma a fomecer dados sobre a relevância do sistema parạ autores de áreas de conhecimento diferentes daquela investigada.

c)- Execução da avaliação de qualidade do sistema, reutilizando-se, possivelmente, as etapas de especificação e planejamento da avaliação descritas no Capítulo 5 e utilizadas no desenvolvimento deste trábalho. Observa-se, no entanto, que algumas adaptações poderão ser necessárias.

d)- Execução de todo o processo de avaliação com o módulo de navegação do SASHE. Para isso, será necessário estabeleccr um novo conjunto de requisitos direcionado ao módulo de navegação, bem como recuperar os requisitos estabelecidos para o desenvolvimento deste módulo no SASHE. Esta atividade também poderá reutilizar as etapas de especificação e planejamento descritas neste trabalho.

\subsection{Considerações Finais}

Diante da crescente utilização de recursos de informática no contexto educacional, observa-se o aprimoramento de recur\$os que apóiam o envolvimento dessas disciplinas.

Em particular, os sistemas de autoria hipermídia educacional disponíveis oferecem diversas particularidades, o que permite ao autor de aplicações selecioná-los de acordo com suas necessidades.

A tarefa de propor um novo conjunto de requisitos para tais sistemas demonstrou-se relevante, pois os resultados obtidos podem, certamente, colaborar com o desenvolvimento de novos projetos ou apoiar a etapa de avaliação de projetos existentes.

É importante ressaltar, no entanto, que empregar novas tecnologias não implica necessariamente o sucessó no aprendizado. É necessário haver, sobretudo, motivação das pessoas envolvidas com o hovo paradigma e um planejamento da implantação e utilização dos novos recursos. 


\section{Referências Bibliográficas}

(Abowd et al., 1999) Abowd, G.; Pimentel, M.G.C.; Kerimbaev, B.; Ishiguro, Y.; Guzdial. M. Anchoring discussions in lecture: an approach to collaboratively extending classroom digital media. In: CSCL'99, Palo Alto, 1999. Proceedings.

(Aulanet, 1997) Projeto Aulanet. [Online]. Acessado em 25/05/2000. $<$ http://guiaaulanet.eduweb.com.br/imprensa.htm>

(Autocad, 2000) Home page do AutoCAD. [Online]. Acessado em 18/12/2000. <http://www3.autodesk.com/adsk/section/0,284288-123112,00.html>

(Bache \& Bazzana, 1994) Bache, R.; Bazzana, G. Software Metrics for Product Assessment, Software Quality Assurance Series. London. McGraw-Hill Book, 1994.

(Balagopalan \& Macknight, 1989) Balagopalan, S.; Macknight, C.B. An Evaluation Tool for Measuring Authoring System Performance. Communications of the ACM, v.32, n.10, p. 1231-1236, 1989.

(Basili, 1992) Basili V. R. The Experimental Paradigm in Software Engineering. In: International Workshop of Dagstuhl, Dagstul, 1992. Anais. p.3-12.

(Basili, 1996) Basili, V.R. The role of experimentation: Past, present, future. /Apresentado no 18th International Conference on Software Engineering, Berlin, Germany, 1996./

(Bias \& Mayhew, 1994) Bias, R.G.; Mayhew, D.J. (Eds.) Cos Justifying Usability. Boston, Academic Press, 1994. 
(Britain, 1999) Britain, S. A Framework for Pedagogical Evaluation of Virtual Learning Environments. Bangor, 1999. (Relatório Técnico da Universidade de Wales, 41). Disponível na Internet <http://www.leeds.ac.uk/educol/documents/00001237.htm>

(Brusilovsky et al., 1990) Brusilovsky, P.; Sxhwarz, E.; Weber, G. A Tool for Developing Adaptative Eletronic Textbooks on WWW. In: Workshop on Architectures and Methods for Designing Cost-Effective and Reusable ITSs, Montreal, Canada, 1996. Proceedings.

(Campos, 1994) Campos, F. C. A. Hipermídia na Educação: Paradigmas e Avaliação da Qualidade. Rio de Janeiro, 1994. 136 p. Dissertação (Mestrado) - Engenharia de Sistemas e Computação, COPPE / Universidade Federal do Rio de Janeiro.

(Campos et al., 1994) Campos, F.C.A; Rocha, A.R.C; Campos, G.H.B. Hipermídia na Educação: uma Lista de Atributos para Verificação da Qualidade. In: V Simpósio Brasileiro de Informática na Educação. Porto Alegre, 1994. Anais.

(Campos et al., 1999) Campos, F.C.A; Rocha, A.R.C; Campos, G.H.B. Qualidade de Software Educacional: uma Proposta. In: Workshop de Qualidade de Software (WQS), Simpósio Brasileiro de Engenharia de Software. Florianópolis, 1999. Anais. Universidade Federal de Santa Catarina.

(Carvalho, 1998) Carvalho, M.R. HMBS/M - Um método orientado a objetos para o projeto e $o$ desenvolvimento de aplicações hipermídia. São Carlos, 1998. 133p. Dissertação (Mestrado) - Instituto de Ciências Matemáticas e de Computação, Universidade de São Paulo.

(Casanova et al., 1991) Casanova, M.A., Tucherman, L.; Lima, M.J.; Rangel, J.L.; Rodriguez, N.L.R.; Soares, L.F.G. The Nested Context Model for Hyperdocuments. In: Third ACM Conference on Hypertext, San Antonio, 1991. Proceedings. p.193-201.

(Comparison of Online Course Delivery Software Products, 2000) Comparison of Online Course Delivery Software Products, [Online]. Acessado em 12/01/2000. <http://multimedia.marshall.edu/cit/webct/compare/comparison.html> 
(CorelDraw, 2000) Home page do CorelDraw. [Online]. Acéssado em 18/12/2000. $<$ http://www3.corel.com/cgi-bin/gx.cgi/AppLogic+FTContentServer? pagename $=$ Corel/Index $>$

(Díaz \& Isakowitz, 1995) Díaz, A.; Isakowitz, T. RMCase: Computer-Aided Support for Hypermedia Design and Development. In: International Workshop on Hypermedia Design, Montpellier, France. Proceedings, 1995.

(Dix et al., 1998) Dix, A.J.; Finlay, J.E.; Abowd, G.D.; Beale, R. Human-Computer Interaction, Prentice Hall, 1998.

(Dunsmore et al., 1986) Dunsmore, H.E.; Conte, S.D.; Shen, V.Y. Software Engineering Metrics and Models, Cummings Publishing Company, 1986.

(Elmasri \& Navate, 1990) Elmasri, R.; Navate, S. Fundamental of Database Systems. 2nd ed., The Benjamim/Cummings Publishing Company, 1990.

(Faria, 1995) Faria, W. Mapas conceituais: aplicações ao ensino, currículo e avaliação. São Paulo, E.P.U., 1995.

(Feltrim, 1999) Feltrim, V.D. Apoio à Documentação de Engenharia Reversa de Software por Meio de Hipertextos. São Carlos, 1999. 116 p. Dissertação (Mestrado) - Instituto de Ciências Matemáticas e de Computação, Universidade de São Paulo.

(Feltrim \& Fortes, 1999). Feltrim, V.D.; Fortes, R.P.M. Documentação do sistema SASHE recuperada por meio de engenharia reversa. São Carlos, ICMC, 1999. (Relatório Técnico ICMC-USP, 90, 254p)

(Garzotto et al., 1993) Garzotto, F.; Paolini, P.; Schwabe, D. HDM. A Model-Based Approach to Hypertext Application Design. ACM Transactions on Information Systems, v.11, n.1, p.1-26, 1993.

(Geller \& Enricone, 1999) Geller, M.; Enricone, D. Informática na Educação: um Estudo de Opiniões de Alunos do Curso de Pedagogia. Pontifícia Universidade Católica do Rio Grande do Sul. [Online]. Acessado em 11/12/99. <http://phoenix.sce.fct.unl.pt/ribie 
/cong1996/CONGRESSO_HTML/20/ARTIGO.htm/\#INFORMATICA NA

EDUCAÇÃO: UM ESTUDO DE OPINIÕES DE ALUNOS DO CURSO DE PEDAGOGIA>

(Goldberg et al., 1996) Goldberg, M.W.; Salari, S.; Swoboda, P. Word Wide Web - Course Tool: An Environment for Building WWW-Based Courses. Computer Networks and ISDN Systems, n.28, 1996.

(Gray \& Salzman, 1998) Gray, W.D.; Salzman, M.C. Damaged Merchandise? A Review of Experiments That Compare Usability Evaluation Methods. Human-Computer Interaction, v.13, p.203-261, 1998

(Guzdial, 1999) Guzdial, M. Collaborative website supporting open authoring. Journal of the Learning Sciences, 1999.

(Haber, 1999) Habber, R.R. Uma ferramenta de importação de documentos HTML para um ambiente de ensino. São Carlos, 1999. 104p. Dissertação (Mestrado) - Instituto de Ciências Matemáticas e de Computação, Universidade de São Paulo.

(Hall \& Mendes, 1999) Hall, W.; Mendes, M.E.X. Hyper-authoring for education: a qualitative evaluation. Computers \& Education, v.32, n.1, p.51-64, 1999.

(Harel, 1987) Harel, D. Statecharts: A Visual Formalism for Complex Systems. Science of Computer Programming, n.8, p.231-274, 1987.

(Isakowitz et al., 1995) Isakowitz, T.; Stohr, EA.; Balasubramanian, P. RMM: A Methodology for Structured Hypermedia Design. Communications of the ACM, v.38, n.8, p.23-44, 1995.

(ISO/IEC 14598-5, 1996) ISO/IEC 14598-5, International Standard. Information Technology - Software product evaluation - Part 5: Process for evaluators; 1996 (DIS).

(ISO/IEC 9126, 1991) IS\$O/IEC 9126, International Standard. Information Technology Software Product Evaluation - Quality characteristics and guidelines for their use, 1991. 
(Jorgensen, 1999) Jorgensen, M. Software Quality Measurement. Advances in Engineering Software, v.30, n.12, p.907-912, 1999.

(Kawasaki \& Fernandes, 1996) Kawasaki, E.I.; Fernandes, C.T. Modelo para Projeto de Cursos Hipermídia. In: VII Simpósio Brasileiro de Informática na Educação, Belo Horizonte, 1996. Anais. p.227-240

(Kearsley, 1982) Kear\$ley, G. Authoring Systems in Computer Based Education. Communications of the ACM, v.25, n.7, p.429-437, 1982.

(Kitchenham, 1996) Kitchenham, B.A. Evaluating Software Engineering Methods and Tool. Part 1: The Evaluation Context and Evaluation Methods. ACM SIGSOFT Software Engineering Notes, v.21, n.1, p.11-15, 1996.

(Kotonya \& Sommerville, 1997) Kotonya, G.; Sommerville, I. Requirements Engineering processes and techniques. England, Wiley, 1997.

(Lange, 1994) Lange, D.B. An object-oriented design method for hypermedia information systems. In: International Conference on System Sciences. New York, 1994. Proceedings. p.366-375.

(Landauer \& Nielsen, 1993) Nielsen, J.; Laundauer, T.K. A mathematical model of the finding of usability problems. In: ACM INTERCHI'93 Conference. Amsterdam, 1993. Proceedings. p.206-213.

(LearningSapce, 2000) Home page do LearningSpace. [Online]. Acessado em 20/12/2000. <http://www.lotus.com/home.nsf/welcome/learnspace>

(Lucena et al., 1997) Lucena, C.; Fuks, H.; Milidiú, R; Macedo, L.; Santos, N.; Laufer, C.; Fontoura, M.; Neves, R.; Crespo, S.; Cardia, E.; Torres, V. "AulaNet: Um Ambiente para Desenvolvimento e Manutenção de Cursos na WWW", Monografias em Ciência da Computação, Departamento de Informática, PUC-Rio, 1997.

(Michener, 1978) Michener, E.R. Understanding understanding Mathematics. Cognitive Science, v.2, n.4, 1978. 
(Moreira \& Buchweitz, 1987) Moreira, M.A.; Buchweitz, B. Mapas Conceituais: Instrumentos Didáticos, de Avaliação e de Análise de Currículo. São Paulo. Editora Moraes Ltda, 1987.

(Nanard \& Nanard, 1995) Nanard, J.; Nanard, M Hypertext Design Environments and the Hypertext Design Process. Communications of the ACM, v.38, n.8, p.49-56, 1995.

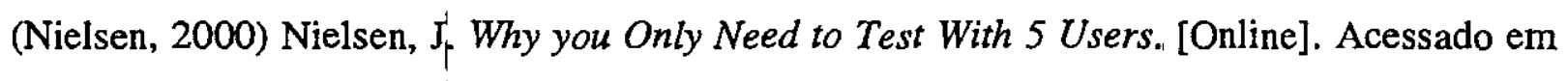
20/06/2000. <http://www.useit.com/alertbox/20000319.html>

(Nunes et al., 1996) Nunes, M.G.V.; Hasegawa R.; Vieira, F.M.C. HIP/Windows: um ambiente de autoria de hiperbases multimídia. São Carlos, ICMSC, 1996. (Relatório Técnico ICMC-USP, 38, 34p).

(Nunes et al., 1997) Nunęs, M.G.V.; Hasegawa, R.; Vieira, F.M.C.; Santos, G.H.R.; Fortes, R.P.M. SASHE: Sistema de Autoria e Suporte Hipermídia para Ensino. São Carlos, Instituto de Ciências Matemáticas e de Computaçāo, Universidaḍe de Sāo Paulo, 1997. (Notas ICMSC-USP, n.33, 22p.).

(Nunes \& Fortes, 1997) Nunes, M.G.V.; Fortes, R.P.M. Roteiros em Áplicações no Ensino: A Questão do Controle do Leitor. In: III Workshop em Sistemas Multimídia e Hipermídia. São Carlos, 1997. Anais. p.15-28.

(Nunes \& Pansanato, 1999a) Nunes, M.G.V.; Pansanato, L.E. EHDM: Método para Projeto de Hiperdocumentos para Ensino. In: V Simpósio Brasileiro de Multimídia e Hipermídia SBMIDIA'99. Goiânia, 1999. Anais. p.29-42.

(Nunes \& Pansanato, 1999b) Nunes, M.G.V.; Pansanato, L.E. EHDM: Método para Projeto de Hiperdocumentos para Ensino. São Carlos, Instituto de Ciências Matemáticas e de Computação, Universidade de São Paulo, 1999. (Notas ICMSC-USP, n.43, 42p.)

(Nunes \& Pansanato, 1999c) Nunes, M.G.V.; Pansanato, L.E. Autoria de Aplicações Hipermídia para Ensino. Revista Brasileira de Informática na Educação, n.5, p.103-124, 1999. 
(Paiva \& Nunes, 2001) Paiva, D.M.B; Nunes, M.G.V. Resultados Experimentais da Avaliação do SASHE. São Carlos, ICMC, 2001. (Relatório Técnico ICMC-USP, 38p)

(Pansanato, 1999) Pansanato, L.T.E. EHDM: Um Método para o Projeto de Aplicações Hipermídia para Ensino. São Carlos, 1999. 104p. Dissertação (Mestrado) - Instituto de Ciências Matemáticas e de Computação, Universidade de São Paulo.

(Papaspyrou et al., 1999) Papaspyrou, N.; Retalis, S.; Efremidis, G.; Skordalakis, E. Webbased teaching in software engineering. Advances in Engineering Software, v.30, n.12, p.901-906, 1999.

(Papatheodorou et al., 1998) Papatheodorou, T. S.; Styliaras, G. D.; Christodoulou, S. P. Evaluation of Hypermedia Application Development and Management Systems. In: The Ninth ACM Conference on Hypertext and Hypermedia. Pittsburgh, 1998. Proceedings. p. $1-10$.

(Paternò et al., 1997) Paternò, F.; Mancini, C.; Meniconi, S. ConcurTaskTrees: A Diagrammatic Notation for Specifying Task Models. In: Interact'97. Sydney, 1997. Proceedings. p.362-369.

Disponível na Internet: <http://giove.cnuce.cnr.it/ctte.html >

(Pfleeger et al., 1994) Pfleeger, S.L.; Fenton, N.; Glass, R.L. Science and substance: a challenge to software engineers. IEEE Software, p.86-95, 1994.

(Pimentel, 1997) Pimentel, M.G. MAPHE: Metodologia de Apoio a Projetos de Hipertextos Educacionais. In: VIII Simpósio Brasileiro de Informática na Educação. São José dos Campos, 1997. Anais. p.351-368.

(Pimentel et al., 1998) Pimentel, M.G.C.; Santos, J.B.; Fortes, R.P.M. Modelagem, autoria e apresentação de documentos didáticos estruturados. In: Simpósio Brasileiro de Sistemas Multimídia e Hipermídia. Rio de Janeiro, 1998. Anais. p.211-222.

(Pimentel et al., 2000) Pimentel, M.G.C.; Abowd, G.; Ishiguro, Y.; Kerimbaev, B.; Guzdial, M. Supporting long-term educational activities through dynamic web interfaces. Interacting with Computers Journal, 2000. 
(Premkumar et al., 1998) Premkumar, K.; Hunter, W.; Davidson J.; Jennett P. Development and validation of an evaluation tool for multimedia resources in health education. International Journal of Medical Informatics, v.50, n.1-3, p.243-250, 1998.

(Pressman, 1997) Pressmah, R.S. Software Engineering. 4th ed. United States, McGraw-Hill Companies, 1997.

(Preece et al., 1994) Preepe, J.; Rogers, Y.; Sharp, H.; Benyon, D.; Holland, S.; Carey, T. Human-Computer Interaction, Addison-Wesley, 1994.

(Rumbaugh et al., 1991) Rumbaugh, J. et al. Object Oriented Modeling e Design. Prentice Hall, 1991.

(Ransdell, 1993) Ransdell, S. Educational software evaluation research: Balancing internal, external and ecological validity. Behavior Research Methods, Instruments \& Computers, v.25, n.2, p.228-232, 1993.

(Rossi, 1996) Rossi, G. Um Método Orientado a Objetos para o Projeto de Aplicações Hipermídia. Rio de Janeiro, 1996. 205p. Tese (doutorado) - Departamento de Informática, Pontifícia Universidade Católica do Rio de Janeiro.

(Santos et al., 1997) Santos, G.H.R.; Vieira, F.M.C.; Hasegawa, R.; Nunes, M.G.V. SASHE: Autoria de Aplicações Hipermídia para o Ensino. In: VIII SIMPÓSIO BRASILEIRO DE INFORMÁTICA NA EDUCAÇÃO. São José dos Campos, 1997. Anais. ITA, p.425-440.

(Santos Jr., 1998) Santos Jr, J.B. Documentos Estruturados para o Domínio de Aplicaçāo Ensino: Modelagem, Autoria e Apresentação na WWW. São Carlos, 1998. 107p. Dissertação (Mestrado) - Instituto de Ciências Matemáticas e de Computação, Universidade de São Paụlo.

(Shwabe \& Rossi, 1995) Shwabe, D.; Rossi, G. The Object-Oriented Hypermedia Design Model. Communications of the ACM, v.38, n.8, p.45-46, 1995.

(Silva, 2000) Silva, W.F. Sistema Hipermídia de Apoio à Documentação de Software: Uma Investigação sobre a "Mudança de Domínio de Software". São Carlos, 2000. 114p . 
Dissertação (Mestrado) - Instituto de Ciências Matemáticas e de Computação, Universidade de São Paulo.

(Sommerville, 1996) Sommerville, I. Software Engineering. 5th ed. England, AddisonWesley, 1996.

(Tichy et al., 1995) Tichy, W.F.; Prechelt, L.; Heinz, E.A.; Lukowicz, P. Experimental Evaluation in Computer Science: A Quantitative Study. Journal of Systems and Software, v.28, n.1, p.9-18, 1995 .

(TopClass, 2000) Home page do TopClass [Online]. Acessado em 15/10/2000. $<$ http://www.wbtsystems.com/index.html>

(Tsukumo et al., 1997) Tsukumo, A.N.; Salviano, C.F. et al. A Framework for Incremental Evaluation of Software Product Quality Based on ISO/IEC 9126. In: Fifth International Conference on Software Quality Management. Bath, Inglaterra, 1997. Proceedings. p.111121.

(Turine, 1998) Turine, M.A.S HMBS: Um Modelo Baseado em Statecharts para a Especificação Formal de Hiperdocumentos. São Carlos, 1998. 192p. Tese (Doutorado) Instituto de Física de Sắo Carlos, Universidade de São Paulo.

(Turine et al., 1998) Turine, M.A.S.; Oliveira M.C.F.; Masiero, P.C. HySCharts: Um Ambiente de Autoria e Navegação Baseado no Modelo HMBS. In: IV Simpósio Brasileiro de Sistemas Multimídia e Hipermídia (SBMIDIA'98), Rio de Janeiro. Anais. p.27-38, 1998.

(Valente, 1999) Valente, J.A. Diferentes usos do Computador na Educação [Online]. Acessado em 12/12/99. < http://www.proinfo.gov.br/prf_txtie2.htm>

(Wallace \& Zelkowitz, 1996) Wallace, D.R.; Zelkowitz, Marvin V. Models of Software Experimentation. /Apresentado no I SERN Annual Meeting, Sydney, Australia, 1996./

(Wallace \& Zelkowitz, 1997) Wallace, D.R.; Zelkowitz, Marvin V. Experimental validation in software engineering, Information and Software Technology, v.39, n.11, p.735-743, 1997. 
(Wallace \& Zelkowitz, 1998) Wallace, D.R.; Zelkowitz, Marvin V. Experimental Models for Validating Computer Technology. IEEE Computer, v.31, n.5, p.23-31, 1998.

(WebCT, 2000) WebCT /Home Page. [Online]. Acessado em 19/10/2000. Disponível na Internet http://www.webct.com/webct

(Welzel \& Hausen, 1997) Welzel, D.; Hausen, H.L. Pratical Concurrent Software Evaluation for Certification. The Journal of Systems and Software, v.38, n.1, p.71-85, 1997.

(Yin, 1984) Yin, R. Case Study Research: Design and Methods. Sage Publications, 1984.

(Zellwegger, 1989) Zellwegger, P. T. Scripted Documents: A Hypermedia Path Mechanism. In: Hypertext'89. Pittsburgh, Pennsylvania, 1989. Proceedings. p.1-14. 


\section{Apêndice A}

\section{Material Explicativo sobre o SASHE Entregue aos Usuários}

O Sistema de Autoria e Suporte Hipermídia para Ensino (SASHE) é um ambiente de autoria e navegação de aplicaçōes para ensino desenvolvido no Instituto de Ciências Matemáticas e de Computação (ICMC). O principal objetivo desse sistema é facilitar a construção de aplicações hipermídia bem como fornecer recursos adicionais à navegação tradicional.

O EHDT (Educational Hyperdocuments Development Tool) é uma ferramenta que foi especialmente desenvolvida para possibilitar a modelagem de aplicaçōes hipermídia no SASHE. A principal cafacterística do EHDT é a utilização de primitivas gráficas para modelar o domínio de conhecimento da aplicação.

Esse projeto tem como objetivo avaliar os recursos fornecidos aos usuários-autores que possibilitam a construção (modelagem) de aplicaçōes hipermídia, considerando-se alguns requisitos (por exemplo, suporte à geração de material, amenidade de uso do sistema, disponibilidade de documentação).

A seguir descreve-se as etapas de modelagem de aplicações bem como as principais características de cada etapa.

As fases do processo de desenvolvimento de aplicações hipermídia utilizando-se o EHDT são:

1- Modelagem Conceitual Hierárquica, que consiste em estruturar o domínio de conhecimento utilizando-se primitivas de categorias de conhecimento e relacionamentos;

2- Projeto Navegacional de Contextos, que deriva um modelo de navegação para a aplicação a partir do modelo conceitual hierárquico criado na fase anterior;

3- Construção e Teste, que consiste na criação efetiva da aplicação através de um processo de tradução do model $\phi$ navegacional de contextos em uma aplicação. Nessa fase, ocorrem também os testes, que procuram identificar os erros ocorridos na construção da aplicação. 
Para a construção do modelo conceitual hierárquico (fase 1), o autor deve classificar os principais elementos do domínio de conhecimento em três categorias: Conceito, Resultado e Exemplo.

A categoria Conceito abłange as características, propriedades, atributos, regularidades e/ou observações de um objetô, fenômeno ou evento relativo a um domínio de conhecimento. De modo geral, as descrições definições, princípios e procedimentos podem ser considerados como conceitos.

Os conceitos podem ser estruturados através de relacionamentos indicando que um conceito A deve ser representado antes de um conceito $B$, refletindo uma relação de ordem pedagógica. Essa relação pode representar uma preferência na sequência de apresentação dos conceitos ou ainda que a sequência é pedagogicamente necessária para o aprendizado (pré-requisito). As primitivas gráficas para a categoria 'Conceito' e para os relacionamentos 'Precedência preferencial' e 'Precedência necessária' são apresentados a seguir:

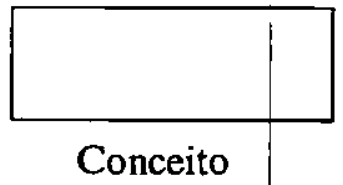



Precedência preferencial

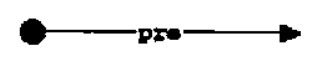

Precedência necessária

A figura a seguir mostra um exemplo de modelagem, em que o conceito ' $A$ ' deve ser necessariamente apresentado antes do conceito 'B'.



conceito 'A'

conceito 'B'

A categoria 'Resultado' abrange as consequências lógicas obtidas a partir de conceitos do domínio e de outros resultados previamente estabelecidos. Os resultados podem ser estruturados através de uma relação de dedução indicando que um resultado 'A' deduz (ou deriva/causa) um resultado 'B'. As primitivas gráficas para a categoria 'Resultado' e para o relacionamento 'Dedução' são apresentados abaixo:

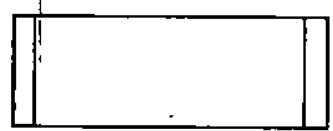

Resultado

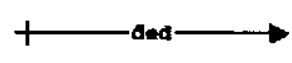

Dedução

A figura a seguir mostra um exemplo que indica que o resultado ' $\mathrm{B}$ ' pode ser deduzido a partir do resultado 'A'.

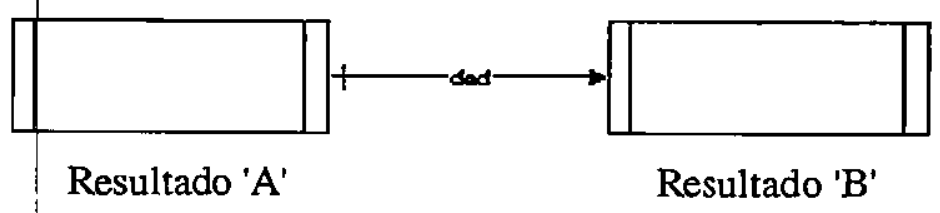

A categoria 'Exemplo' abrange as ilustrações e instanciaçōes relativas a um conceito ou resultado identificados no domínio. Os exemplos podem ser estruturados por relacionamentos que refletem uma ordem de complexidade. Essa relação indica que um exemplo é menos 
complexo (ou mais simples) que outro exemplo. As primitivas gráficas para a categoria 'Exemplo' e para o relacionamento 'Complexidade' são apresentados abaixo.
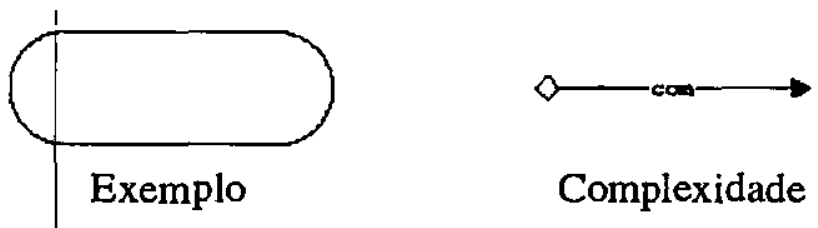

A figura a seguir mostra exemplos relacionados por ordem de complexidade. $O$ exemplo ' $A$ ' é menos complexo que o exemplo 'B' que, por sua vez, é menos complexo que o exemplo 'C'.

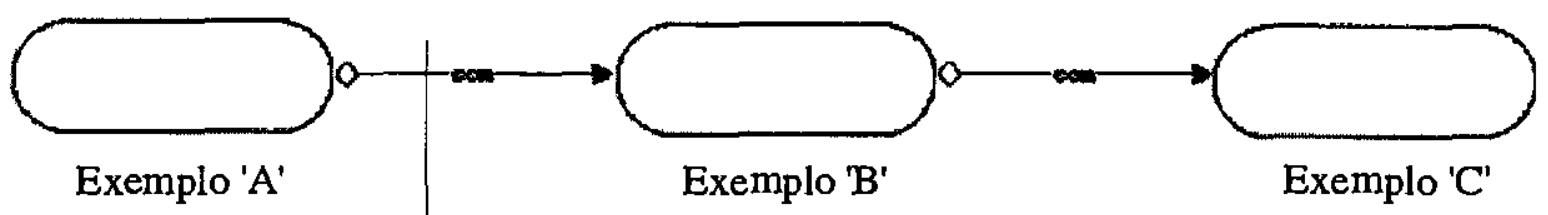

Alguns relacionamentos podem ser estabelecidos entre as categorias de conhecimento: os relacionamentos 'necessidade' e 'utilização' que relacionam as 3 categorias de conhecimento (Conceito, Resultado e Exemplo) e o relacionamento 'motivação/ilustração' que relaciona a categoria 'Exemplo' com as. outras duas categorias ('Conceito' e 'Resultado'). O relacionamento 'necessidade' indica que um determinado item de uma categoria é necessário para discutir, descrever ou apresentar outro. O relacionamento 'utilização' indica que um item de uma categoria utiliza outro como base para sua construção ou definição. O relacionamento motivação/ilustração, quando parte de um exemplo, considera que este exemplo é utilizado para motivar um conceito ou resultado. Por outro lado, quando um exemplo é destino do relacionamento, ele é utilzzado para ilustrar um conceito ou resultado. Ás primitivas para os relacionamentos 'necessidade', 'utilização' e 'motivação/ilustração' são apresentados na figura abaixo.

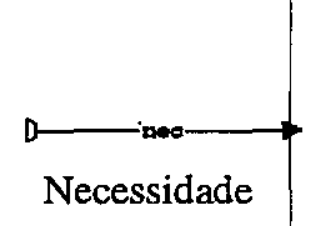

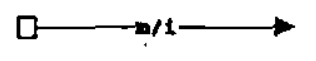

Motivação/llustração

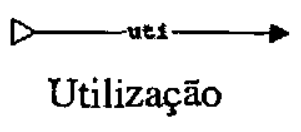

Um exemplo de Modelo Conceitual Hierárquico para o domínio da Física, construído utilizando-se o EHDT pode ser visualizado a seguir: 


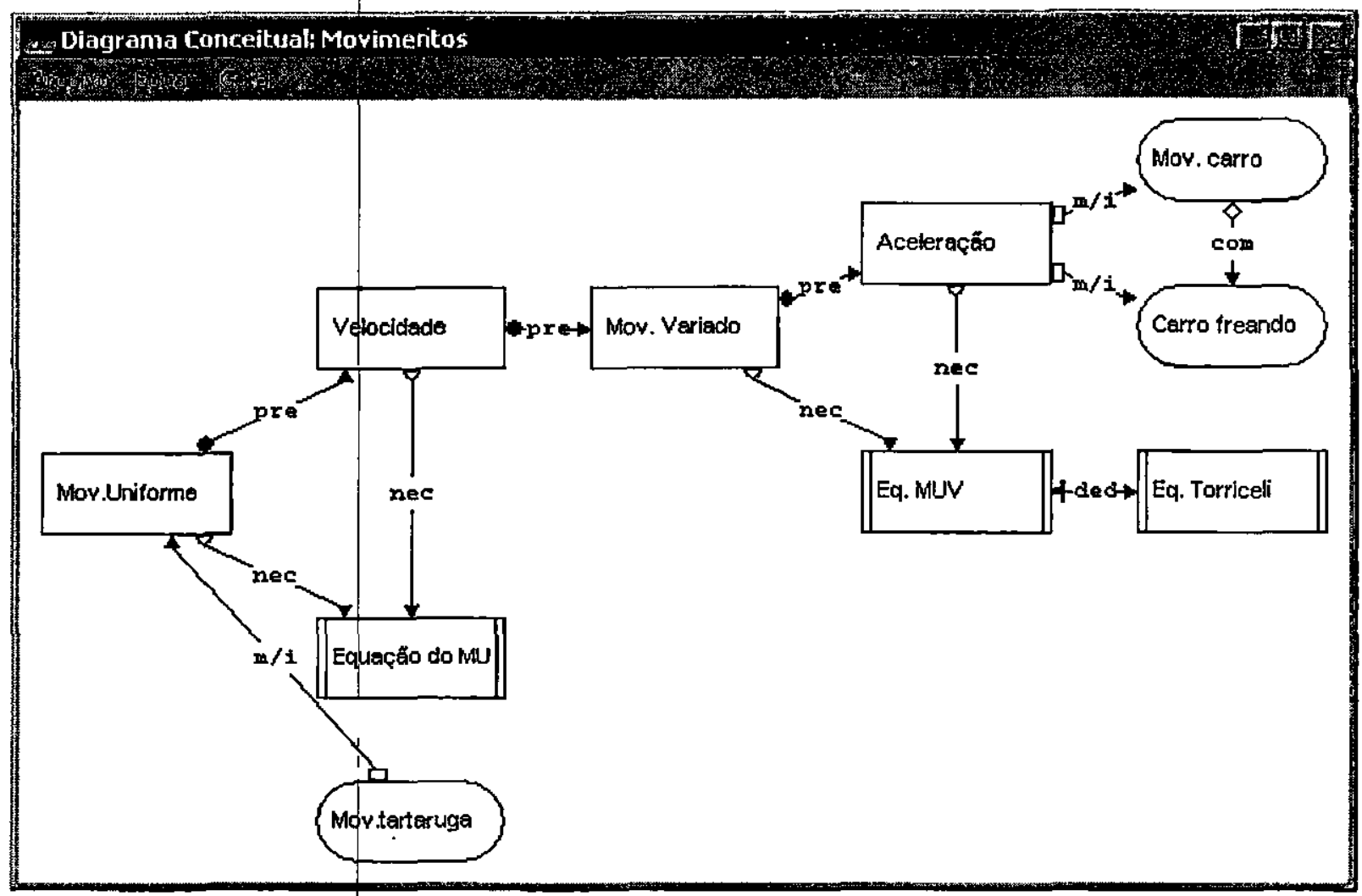

A segunda etapa do processo de modelagem da aplicação é o Projeto Navegacional de Contextos. O projeto da estrutura de navegação das aplicaçōes é a etapa crucial no empreendimento de desenvolvimento. O resultado dessa fase é um modelo navegacional de contextos que representa ưma aplicação.

$\mathrm{Na}$ fase de projeto navegacional de contextos, diferentes modelos navegacionais de contextos podem ser construídos, baseados no mesmo modelo conceitual hierárquico criado na fase anterior (modelagem conceitual hierárquica), e de acordo com propósitos educacionais diferentes. A motivação é permitir que usuários (aprendizes) diferentes vejam o mesmo conteúdo através de perspectivas diferentes. Nessa etapa são especificadas as características dos elementos (nós) da aplicação: palavras-chaves, função didática (introdução, definição, exercícios, etc.), nível de dificuldade (baixa, regular, alta), forma de apresentação (texto, imagem, áudio ou vídeo) e o arquivo a ser apresentado. São especificadas também informações que devem ser apresentadas aos usuários durante a navegação (informações essenciais) e informaçōes que serão apresentadas somente se o usuário desejar (informações complementares).

Um modelo navegacional de contextos define um conjunto de contextos e entidades navegacionais. Os contextos navegacionais determinam a estrutura (organização hierárquica) do hiperdocumento, enquanto as entidades navegacionais, nó e elo, especificam os elementos que são apresentados ao usuário. A figura a seguir mostra as primitivas gráficas de modelagem navegacional,

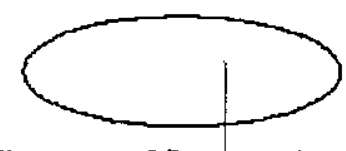

Contexto Navegacional

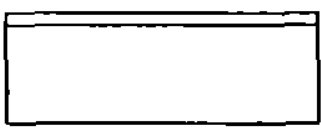

Nó

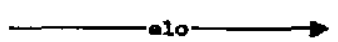

Elo 
As entidades navegacionais (nó e elo) são organizadas em contextos navegacionais. Um contexto navegacional também pode conter outros contextos (aninhados), resultando em uma organização hierárquica de contextos. Nesse sentido, o contexto navegacional é um mecanismo para definir a estrutura da aplicação.

Os conceitos navegacionais podem ser derivados diretamente do modelo conceitual hierárquico. A expansão de um elemento conceitual cria naturalmente um espaço de informação que pode ser interpretado como um contexto navegacional. Isso não é uma regra rígida, pois a organização dos contextos pode ser alterada e/ou novos contextos podem ser criados. O modelo Navegacional de Contextos gerado para o exemplo de Modelo Conceitual Hierárquico mostrado anteriormente pode ser visualizado a seguir. Outros modelos navegacionais podem ser gerados de acordo com as necessidades do usuário-autor.

A terceira etapa consiste na construção e teste da aplicação. Nessa fase, o modelo navegacional de contextos é convertido em objetos disponíveis no ambiente de implementação escolhido. O desenvolvedor pode gerar a aplicação final e testá-la segundo os requisitos iniciais da aplicação e, caso seja necessário, modificar a especificação (modelagem) e gerar nova aplicação.

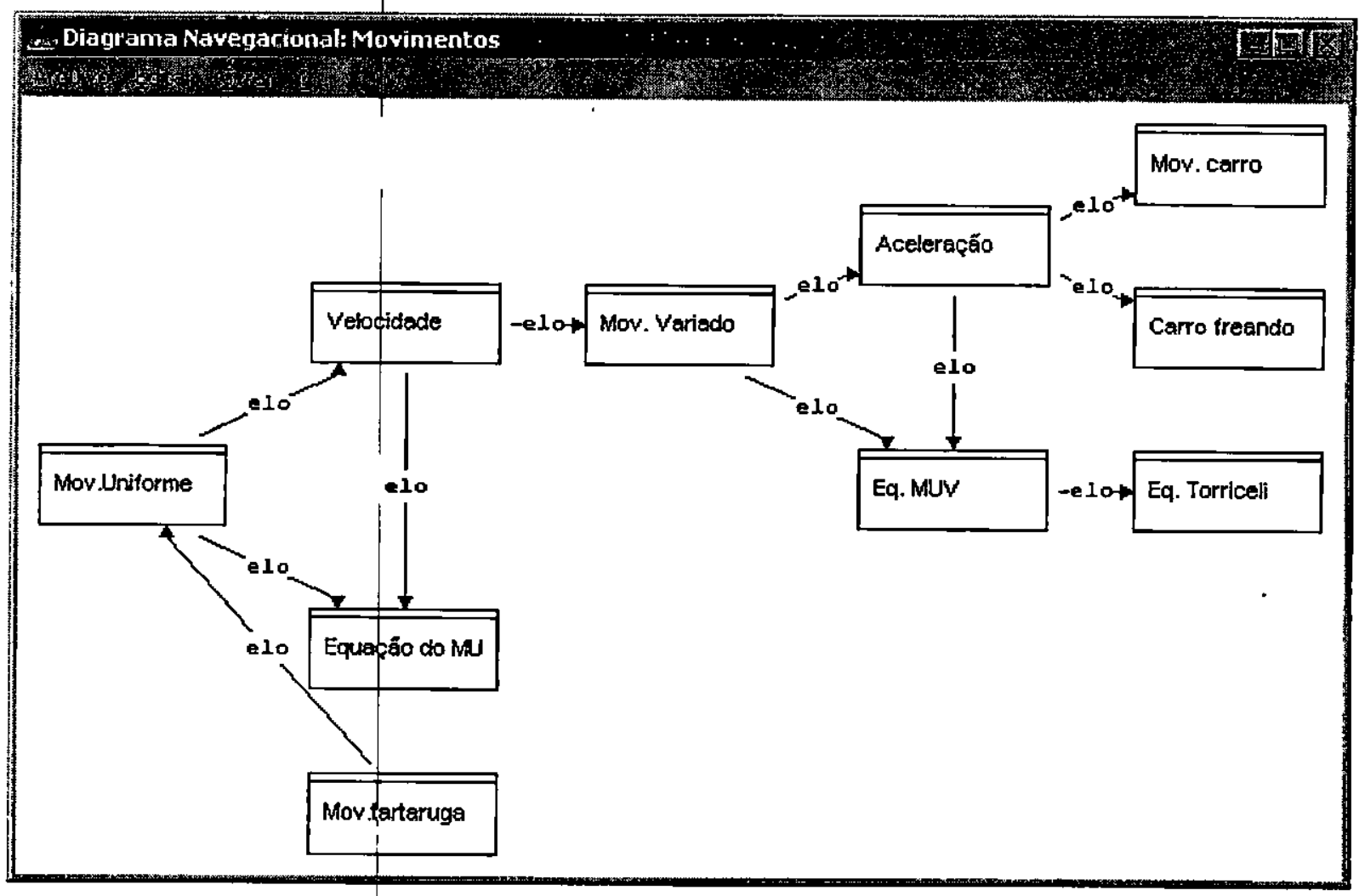

O EHDT oferece ainda o recurso de geração de roteiros, ou seja, permite ao usuário-autor criar roteiros de acordo com as necessidades de diferentes grupos de usuários. Um roteiro é um conjunto de nós e contextos navegacionais que estabelece um caminho de navegação pelo hiperdocumento. Ele é definido através da especificação da sequência dos nós e contextos selecionados para compor, o roteiro. 


\section{Apêndice B}

\section{Plano de Avaliação}

\section{1)- Esclarecimentos fołnecidos aos avaliadores}

1.1- Explicar ao avaliador as etapas mais importantes para a modelagem, observando se ele compreendeu o material que lhe foi entregue.

- Explicar as três letapas do processo de desenvolvimento (metodologia de desenvolvimento);

- Explicar que a primeira etapa consiste na modelagem do domínio de conhecimento e que existem as 3 categorias de conhecimento e os relacionamentos para essas categorias. Mostrar na ferramenta como um componente pode ser inserido, alterado, excluído e expandido (para o caso das categorias conćeito e resultado).

- Explicar que a segunda etapa consiste no projeto de nave gação da aplicação é que existem os contextos navegacionais, os nós e os elos. Explicar que o modelo pode ser gerado automaticamente e que o usuário pode modificá-lo, se necessário.

- Explicar que a última etapa consiste na criação automática da aplicação.

1.2- Explicar ao avaliador o tema da aplicação que deverá ser construída (Recursão), mostrando-lhe os arquivos da hiperbase disponíveis. Mostrar-lhe alguns sites relacionados ao tema que poderão ser utilizados para obtenção de informação extra.

1.3- Treinamento oferecido ao avaliador. A ferramenta de modelagem será utilizada para criação de um modelo exఢmplo.

\section{2)- Tarefas a serem executadas pelos avaliadores}

2.1- Fazer a distinção entre conceitos, resultados e exemplos do conteúdo dos arquivos disponíveis.

Deve-se considerar que: 
- O avaliador pode tentar fazer a distinção primeiramente em papel ou tentar usar diretamente a ferramenta

- Novos arquivos podem ser incluídos;

- Nem todos os arquivós disponíveis precisam ser utilizados;

- O avaliador deverá |relacionar as categorias durante ou após a fase de distinção do conteúdo em categorias.

\section{2- Criar o Modelo Conceitual Hierárquico.}

$O$ avaliador deve começar especificando os nós (conceitos e resultados) mais genéricos, que poderão ser expandidos ẹm nós específicos. Deve ser considerado o máximo de 3 a 4 níveis. Durante a realização desta etapa estará sendo avaliado o seguinte requisito:

- H.A.5: O sistema deve fornecer recursos que permitam especificar todos os aspectos do domínio de conhecimento da aplicação.

As primitivas oferecidas pelo sistema de autoria são suficientes, no que se refere à quantidadelqualidade, para a realizaçāo da modelagem de uma aplicação hipermídia para o domínio do ensino? Quais seriam possíveis extensões ou adaptações para o conjunto de primitivas disponível? Aj implementação do recurso de estruturação hierárquica atende às necessidades do usuário-autor?

\section{3- Criar o Modelo Nayegacional de Contextos}

O avaliador poderá gerar automaticamente o modelo navegacional de contextos ou criá-lo. Caso opte pela primeira ppção, o modelo poderá ser editado (modificado) de acordo com as necessidades. Nesse modelo, os contextos também poderão ser expandidos. As informações dos nós podem ser especificadas clicando-se duas vezes em um nó e preenchendo-se os campos da janela que é obtida. Durante a realização dessa etapa estará sendo avaliado o seguinte requisito:

- E.A.1: O sistema deve fornecer recursos que proporcionam liberdade de projeto dos aspectos navegacionais da aplicação

$O$ professor possui liberdade para projetar os aspectos navegacionais da aplicação em relação à modelagem do domínio de conhecimento? Alguma dificuldade foi encontrada na realização dessa atividade?

\section{4- Gerar Modelos}


O avaliador deverá gerar outros modelos de navegação baseados no mesmo modelo conceitual. Durante a realłzação dessa etapa estarão sendo avaliados os seguintes requisitos:

- S.2: O sistema deve fornecer recursos que possibilitem ao usuário-autor gerar diferentes modelos de navegação baseados no mesmo modelo conceitual

A implementação desses recursos é importante para o autor? Os modelos gerados sāo satisfatórios às necessidddes dos usuários? Quais seriam possíveis extensões ou adaptações para os recursos de gerağāo dos modelos navegacionais oferecidos?

- S.3: O sistema deve fornecer recursos que proporcionam replicação (cloning) ao nível de instância.

Os recursos oferecidos pelo sistema para replicação são suficientes? Quais seriam possíveis extensões ou adaptações para os recursos disponíveis?

\section{5-Editar propriedades dos nós}

$O$ avaliador deverá especificar as informaçōes relativas aos nós do modelo navegacional. Devem ser incluídas as palavras-chave e as informações relativas a "Função Didática" e "Dificuldade", além de se escolher o caminho do arquivo correspondente ao conteúdo da informação. $O$ avaliador deverá indicar também as informações essenciais e complementares. Durante a realização dessa etapa estarão sendo avaliados os seguintes requisitos:

- H.B.5: O sistema deve fornecer recursos que facilitam a edição de nós As informações relativas aos nós e contextos da aplicação são fáceis de editar? Alguma dificuldade foi encontradạ na realização dessa atividade?

- H.F.1: O sistema deve fornecer recursos que possibilitam o armazenamento de informações sobre os nos

Este recurso é importante para o autor? As informaçöes que o sistema permite armazenar são suficientes para permitir ao autor registrar tudo o que for importante para determinado nó? Quais seriam possíveis extensões ou adaptaçōes para o conjunto de informações que o sistema aceita?

- E.C.2: O sistema deve fornecer recursos que possibilitam ao autor qualificar os elementos (componentes) do material. 
Em relação à qualidadelquantidade, esses atributos são satisfatórios? Quais seriam as possiveis extensões ou adaptações para o conjunto de atributos disponivel?

- E.B.2: O sistema deve fornecer recursos que possibilitam inclusão de material essencial e complementar

A implementação desses recursos é importante para o professor? É fácil fazer a inclusão de material essencial e complementar? Alguma dificuldade foi encontrada na realização dessa atividade?

\section{6- Gerar Protótipos}

O avaliador deverá realizar várias gerações parciais de protótipos com opções idênticas ou diferentes para um mesmo diagrama navegacional, o que facilita a geração de um protótipo maior ou com estruturas ppcionais. $O$ avaliador poderá experimentar algumas estruturas antes de abstrair a melhor. Para isso, ele deverá criar os elos da aplicação, navegar pelos "esqueletos" criados, criar roteiros, editar o conteúdo dos arquivos e navegar no módulo do estudante. Durante a realização dessa etapa estarão sendo avaliados os seguintes requisitos:

- H.A.1: O sistema deye fornecer recursos que suportam laços de realimentação (feedback loops)

Os recursos oferecidos auxiliam o desenvolvimento e a avaliação das aplicações?

- H.A.2: O sistema deve fornecer recursos que possibilitam prototipação do material. A implementação destes fecursos é importante para o autor? Os mecanismos de prototipação disponiveis no sistema sấo satisfatorios? É fácil para o usuário gerar vários protótipos antes de decidir pelo melhor?

- H.A.3: O sistema deve fornecer recursos que permitam a utilização de abordagens de desenvolvimento bottom up e top down.

Os recursos fornecidos pelo sistema para utilização destas abordagens são satisfatórios?

\section{7- Gerar Roteiros}

O avaliador deverá gerar alguns roteiros, estabelecendo a liberdade de navegação. Durante a realização dessa etapa estarão sendo avaliados os seguintes requisitos:

- E.A.2: O sistema deve fornecer recursos que permitam o estabelecimento do tipo de controle sobre a navegaçăo 
A implementação destes recursos é importante para o professor? A forma segundo a qual o usuário-autor estabelece o tipo de controle sobre a navegação no SASHE é satisfatória?

- H.A.4: O sistema deve fornecer recursos que proporcionam geração de roteiros $O$ sistema de autoria permite a geração de diversos roteiros de forma fácil? A implementação destes recursos é importante para o autor? Alguma dificuldade foi encontrada na atividade de criação de roteiro? A flexibilidade oferecida para a geração desses roteiros atende às necessidades do usuário-autor?

\section{8- Manutenção da Aplicação}

O usuário deverá modificar os dados de um nó, por exemplo, modificar o nome de um componente, o arquivo a que está vinculado, modificar um conceito para resultado. Durante a realização dessa etapa estarão sendo avaliados os seguintes requisitos:

- H.B.2: O sistemal deve fornecer recursos que facilitam a correção (manutenção) das aplicações

A manutenção das aplicações ocorre de forma simples? Alguma dificuldade foi encontrada na realização desta atividade?

- H.B.3: O sistema deve fornecer recursos que verificam a coerência das ligaçōes

A implementação desses recursos é importante para o autor?

Ao final da avaliação, o usuário deverá responder as questões relacionadas aos requisitos:

- H.D.2: O sistema deve fornecer recursos que possibilitam ao autor criar aplicaçōes hipermídia de acordo com suas necessidades e preferências

A implementação e a interface da aplicação foram influenciadas pelas características do sistema de autoria? Há necessidade de se fazer alguma extensão ou adaptação no módulo de autoria de forma que este permita ao usuário-autor criar aplicações de acordo com suas necessidades e preferências?

- S.1: O sistema deve fornecer recursos que possibilitam a contextualização de informações e o aninhamento de contextos

A implementação desses recursos é importante para o autor? A implementação desses recursos atende às necessidades dos usuários? 
- E.C.1: O sistema dever fornecer recursos que proporcionam visualização da estrutura da aplicação hipermídia

A implementação desses recursos é satisfatória?

- H.B.6: O sistema deve fornecer recursos que permitam a edição de texto, som e gráficos a partir do próprio sistema de autoria

A implementação desses recursos é satisfatória às necessidades do usuário-autor?

\section{Observações}

1)- A importância de alguns requisitos que não foram implementados no SASHE serão investigadas. São eles:

- H.B.1 O sistema deve fornecer recursos que informam as referências dos nós ao usuário-autor

A implementação destes recursos é importante para o autor?

- H.B.3 O sistema deve fornecer recursos que verificam a coerência das ligações

A implementação destes recursos é importante para o autor?

- H.B.4 O sistema devé fornecer recursos que prornovam a propagação de modificações A implementação destes recursos é importante para o autor?

- H.C.1 O sisterna deve fornecer recursos que suportam o gerenciamento e armazenamento de versões das aplicações hipermídia

A implementaçāo destes recursos é importante para o autor? Quais seriam possiveis extensões ou adaptações para os recursos fornecidos?

- H.C.2 O sistema deve fornecer recursos que apóiam o trabalho cooperativo

A implementação destes recursos é importante para o autor? Quais seriam possíveis extensöes ou adaptações para os recursos fornecidos?

- H.D.3 O sistema deve fornecer recursos que detectam a presença de referências cegas e ligações incorretas

A implementação desses recursos é importante para o autor? Quais seriam possíveis extensões ou adaptaçöes para os recursos fornecidos? 
- H.E.2 O sistema deve fornecer recursos de tutorial para autoria A implementação|desses recursos é importante para o auttor? Quais seriam possiveis extensõe ou adaptações para os recursos fornecidos?

- E.B.1 O sistema deve fornecer recursos que permitam fixação de material específico A implementação desses recursos é importante para o professor?

2)- Em relação aos requisitos abaixo, os avaliadores serão questionados em relação à possíveis formas de implementação (como alternativa às perguntas do tipo: "quais seriam possíveis extensões ou adaptações para os recursos fornecidos?").

- H.E.1 O sistema deve fornecer recursos que promovam auxílio ao usuário

Quais seriam possiveis formas de se implementar esses recursos?

- H.F.2 O sistema deve fornecer recursos de documentação

Quais seriam posł̧iveis formas de se implementar esses recursos? 